A) Check for updates

Cite this: Org. Chem. Front., 2019, 6 , 2514

Received 26th April 2019,

Accepted 3rd June 2019

DOI: 10.1039/c9qo00562e

rsc.li/frontiers-organic

\title{
Synthesis of rigidified shikimic acid derivatives by ring-closing metathesis to imprint inhibitor efficacy against shikimate kinase enzyme $\uparrow$
}

\author{
Marina Pernas, (D) a Beatriz Blanco, (iD) a Emilio Lence, (iD) a Paul Thompson, (iD ${ }^{b}$ \\ Alastair R. Hawkins ${ }^{\mathrm{b}}$ and Concepción González-Bello (iD *a
}

\begin{abstract}
Diverse rigidified shikimic acids derivatives, which are stable mimetics of the high-energy conformation of shikimic acid, have been synthesized to enhance inhibitor efficacy against shikimate kinase enzyme (SK), an attractive target for antibiotic drug discovery. The synthesis of the reported conformationally restricted shikimic acid derivatives was carried out by ring-closing metathesis of allyloxy vinyl derivatives as the key step. The rigidification of the ligand conformation was used to maximize the effectiveness of the substituents introduced in the ether carbon bridge of the scaffold by pre-orienting their interaction with key residues and enzyme domains that are essential for catalysis and enzyme motion. Molecular Dynamics simulation studies on the enzyme/ligand complexes revealed marked differences in the positioning of the ligand substituent in the active site of the two enzymes studied (SK from Mycobacterium tuberculosis and Helicobacter pylori) and this explains their greater efficacy against one of the enzymes. This enhancement is due to the distinct induced-fit motion of the two homologous enzymes. A 20-fold improvement against the $\mathrm{H}$. pylori enzyme was achieved by the introduction of a $\mathrm{CH}_{2} \mathrm{OEt}$ group in the rigid ether bridge of the reported shikimic acid analogs.
\end{abstract}

\section{Introduction}

Flexible ligands upon binding to their biological target may suffer an entropic penalty due to the freezing of their rotatable bonds to achieve the active binding conformation. ${ }^{1,2}$ In some cases these ligands may also adopt high-energy active conformations in order to maximize favorable interactions with the residues involved in the protein binding pocket. ${ }^{3,4}$ Hence, preorganization of the ligand conformation or stabilization of the required high-energy active arrangements through the introduction of conformational constraints is a very attractive strategy that is used in drug design. ${ }^{5-9}$ The rigidification of the ligand conformation can also be considered as an 'atomefficient approach', since it maximizes the efficiency of the functional groups introduced into the initial scaffold during

\footnotetext{
${ }^{a}$ Centro Singular de Investigación en Química Biolóxica e Materiais Moleculares (CiQUS), Departamento de Quimica Orgánica, Universidade de Santiago de Compostela, Jenaro de la Fuente s/n, 15782 Santiago de Compostela, Spain.

E-mail: concepcion.gonzalez.bello@usc.es

${ }^{b}$ Institute of Cell and Molecular Biosciences, Medical School,

University of Newcastle upon Tyne, Newcastle upon Tyne NE2 4HH, UK

$\dagger$ Electronic supplementary information (ESI) available: Full details of the experimental procedures for the synthesis of carbonates $\mathbf{8}$, inhibition assays and extra figures. See DOI: 10.1039/c9qo00562e
}

the drug optimization process as the interactions of those groups with the binding pocket are well pre-oriented..$^{10-12}$

We became interested in using this appealing concept in the development of inhibitors of the fifth enzyme of the shikimic acid pathway, namely the shikimate kinase (SK) enzyme. SK is an attractive target for antibiotic drug discovery because (i) it has no counterpart in human cells; and (ii) it is essential in several very relevant pathogenic bacteria that nowadays show high levels of resistance to many antibiotics in clinical use. Specifically, SK is crucial for: (i) Mycobacterium tuberculosis, which is responsible for tuberculosis - a globally established Word Health Organization (WHO) priority; (ii) Helicobacter pylori, which is the causative agent of gastric and duodenal ulcers and has also been classified as a type I carcinogen; and (iii) Pseudomonas aeruginosa, which is one of the most common pathogens in healthcare-associated infections and a WHO critical pathogen for R\&D of new antibiotics. SK catalyzes the stereospecific phosphorylation of the C3 hydroxyl group of shikimic acid (1) by transferring the $\gamma$-phosphate group of ATP to the hydroxyl group to provide shikimate 3-phosphate and ADP (Fig. 1A). This enzyme is an amazing example of how the specific transformation of only one of three hydroxyl groups of the ligand is achieved by an exquisitely designed stabilization of its high-energy conformation. By forcing the axial disposition of the $\mathrm{C} 4$ and C5 hydroxyl 
A

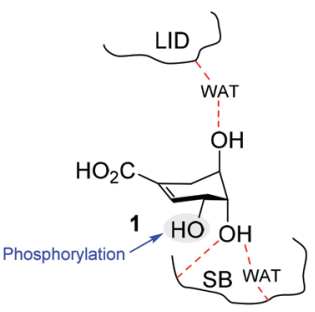

B

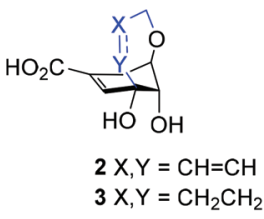

C
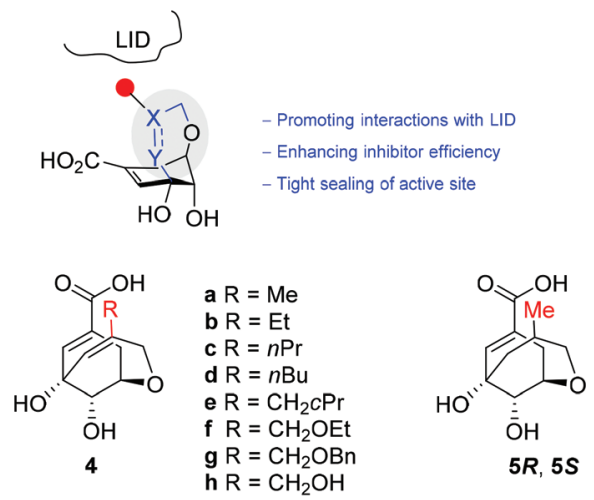

Fig. 1 A. Schematic representation of shikimic acid (1) recognition by SK. B. Previously reported reversible competitive inhibitors. C. Target compounds.

groups in 1, the enzyme achieves the equatorial arrangement of the C3 hydroxyl group for selective phosphorylation by ATP.

Based on the aforementioned recognition, we reported previously that the rigidified shikimic acid derivative 2 , in which the conformation that the enzyme recognizes for catalysis is fixed by an unsaturated ether bridge between positions C3 and C5 in 1, is a reversible competitive inhibitor of SK from M. tuberculosis (Mt-SK) (Fig. 1B) ${ }^{13}$ Compound 2 proved to have an inhibition constant $\left(K_{\mathrm{i}}\right)$ of $62 \mu \mathrm{M}$, which is lower than the enzyme $K_{\mathrm{m}}(544 \mu \mathrm{M})$. The crystal structure of $M t$-SK in complex with ADP and 2 (PDB entry 4BQS, $2.15 \AA$ ) revealed that the ligand occupies the active site with a similar arrangement and polar interactions (hydrogen bonding and electrostatic interactions) as 1. More importantly, the structure shows that the rigidification of the diaxial conformation of the $\mathrm{C} 4$ and C5 hydroxyl groups in $\mathbf{1}$ by a C3-C5 ether bridge causes a dramatic reduction in the flexibility of the lid and shikimic acid binding (SB) domains, the plasticity of which is essential for catalytic turnover. The SB domain, which involves several highly conserved lipophilic residues, isolates the substrate from the solvent environment to perform the reaction. Molecular Dynamics (MD) simulation studies also revealed that a closed form of the lid and SB domains are required for catalysis. ${ }^{13}$ Moreover, reduction of the double bond of the C3-C5 ether bridge in 2, to give compound 3, improves the ligand affinity a little more $\left(K_{\mathrm{i}}=46 \mu \mathrm{M}\right)$ by enhancing lipophilic interactions between the ether bridge and residues of the lid domain, thus sealing the active site even more.

Based on these results, we report herein the possible enhancement of the inhibitor efficiency of this scaffold, com- pound 2, by promoting favorable lipophilic interactions between the ligand and the lid (Fig. 1C). To this end, we carried out the synthesis of rigidified shikimic acid derivatives 4-5 in which the closest $\mathrm{sp}^{2}$ carbon of the unsaturated bridge to the lid was substituted with diverse apolar groups that preorient their interaction with this important part of the enzyme. In addition, the relevance of the double bond to ligand affinity was studied with compounds $\mathbf{5}$. The results of inhibition studies with the SK from M. tuberculosis and from H. pylori, along with MD simulation studies on the enzyme/ ligand complexes, allowed us to explain the higher efficacy of the reported compounds observed for the H. pylori enzyme.

\section{Results and discussion}

\section{Synthesis of compounds 4-5}

The synthesis of conformationally restricted shikimic acid derivatives 4-5 was carried out by ring-closing metathesis of the allyloxy vinyl derivatives $\mathbf{6}$ as the key step (Fig. 2).

In an effort to facilitate the formation of the seven-membered bridge ring in $\mathbf{6}$, the axial arrangement of the vinyl group in $\mathrm{C} 3$ was induced by protecting the hydroxyl groups in the $\mathrm{C} 3$ and $\mathrm{C} 4$ positions of the shikimic acid derivative as an acetal (Fig. S1†). The key compounds $\mathbf{6}$ were prepared by Trost allylation of previously reported alcohol $7^{13}$ using the appropriate allyl methyl carbonates $\mathbf{8}$.

Allyl methyl carbonates $\mathbf{8}$ were prepared from the corresponding alcohols 14-21 by treatment with methyl chloroformate and pyridine (Scheme 1). Alcohols 15-17 were synthesized by 1,2-reduction of $\alpha, \beta$-unsaturated aldehydes $\mathbf{1 1}$ (commercially available) and 12-13, with the latter compounds readily prepared from pentanal (9) and hexanal (10), respectively. Alcohol 18 was obtained in four steps from ethyl malonate (22): (i) alkylation of $\mathbf{2 2}$ with cyclopropylmethyl bromide; (ii) decarboxylative hydrolysis; (iii) aldol condensation; and (iv) 1,2-reduction of $\alpha, \beta$-unsaturated acid 23. Alcohols 20-21 were synthesized by alkylation of commercially available 2-methylene-1,3-propanodiol (19). Finally, carbonate $\mathbf{8} \mathbf{i}$ was obtained by TBS-protection of carbonate $\mathbf{8 h}$.

Palladium-catalyzed Trost allylation of 7 with allyl methyl carbonates $8 \mathbf{8}-\mathbf{g}$ and $8 \mathbf{i}$ gave the key intermediates $6 \mathbf{a}-\mathbf{g}$ and $\mathbf{6 i}$ in yields ranging from $32-88 \%$ (Scheme 2 and Table 1). Ringclosing metathesis of $\mathbf{6 a - g}$ and $\mathbf{6 i}$ was achieved by using

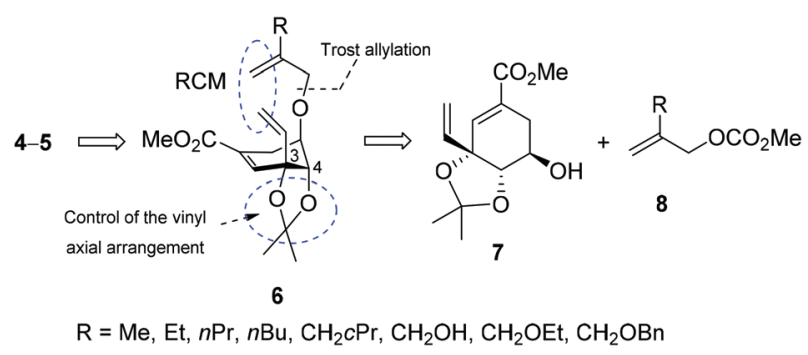

Fig. 2 Synthetic approach. 


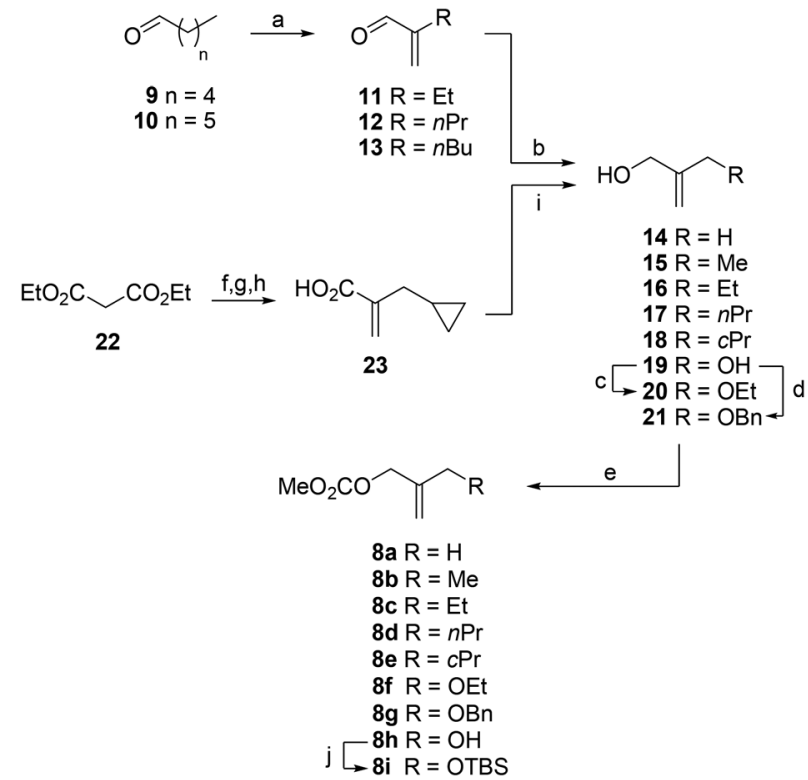

Scheme 1 Synthesis of carbonates 8. Reagents and conditions. (a) $\mathrm{HCHO}$, pyrrolidine, propionic acid, iPrOH, $45{ }^{\circ} \mathrm{C}$. (b) $\mathrm{NaBH}_{4}, \mathrm{MeOH}$, $\mathrm{Et}_{2} \mathrm{O}, 0{ }^{\circ} \mathrm{C}$ to RT. (c) $1 . \mathrm{NaH}, \mathrm{DMF}, 0{ }^{\circ} \mathrm{C} ; 2$. EtBr, RT. (d) $1 . \mathrm{NaH}, \mathrm{THF}, 0{ }^{\circ} \mathrm{C}$; 2. $\mathrm{BnBr}, \mathrm{RT}$. (e) $\mathrm{MeOCOCl}, \mathrm{Py}, \mathrm{DCM}, 0{ }^{\circ} \mathrm{C}$ to RT. (f) 1 . $\mathrm{NaH}, \mathrm{THF}, 0{ }^{\circ} \mathrm{C} ; 2$. $\mathrm{BrCH}_{2} \mathrm{CPr}, \Delta$. (g) $\mathrm{NaOH}(2 \mathrm{M}), \Delta$. (h) piperidine, $\mathrm{HCHO}, \mathrm{EtOH}, 80^{\circ} \mathrm{C}$. (i) $\mathrm{BH}_{3} \cdot \mathrm{Me}_{2} \mathrm{~S}, \mathrm{THF}, 0^{\circ} \mathrm{C}$ to RT. (j) TBSCl, DMAP, TBAl, Et ${ }_{3} \mathrm{~N}, \mathrm{DMF}, 0{ }^{\circ} \mathrm{C}$ to RT.

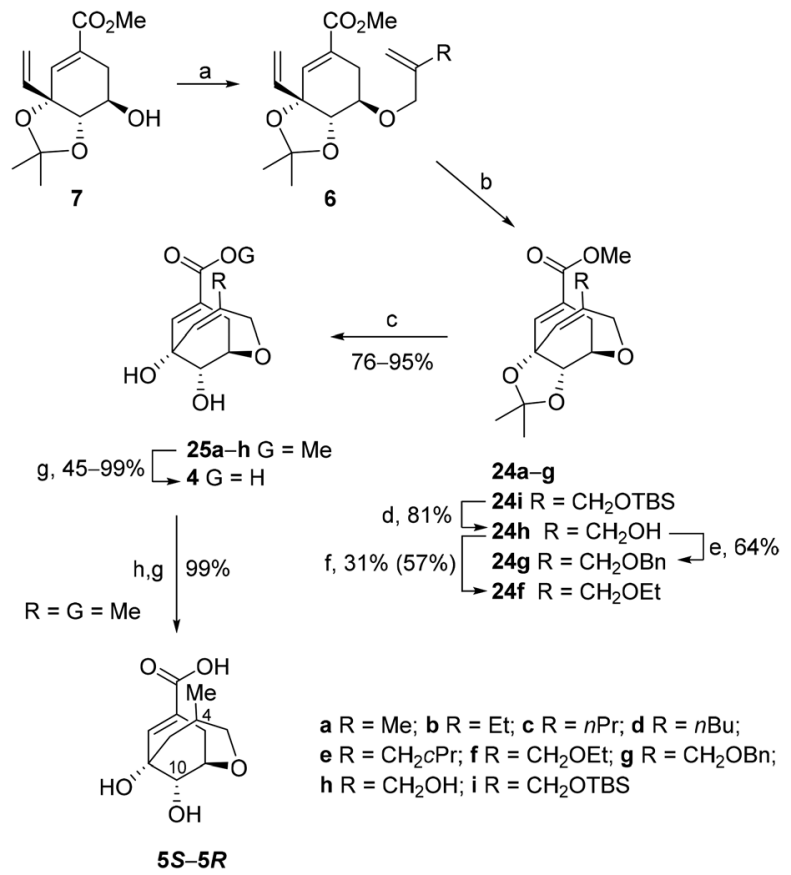

Scheme 2 Synthesis of compounds 4-5. Reagents and conditions. (a) $8 \mathrm{a}-\mathrm{g}$ and $8 \mathrm{i}, \mathrm{Pd}_{2}(\mathrm{dba})_{3}$ (cat), dppb, THF, $\Delta$. (b) $2^{\text {nd }}$ generation Grubbs' catalyst, $\mathrm{PhMe}, 90^{\circ} \mathrm{C}$. (c) $\mathrm{MeOH}, \mathrm{HCl}(6 \mathrm{M}), 60^{\circ} \mathrm{C}$. (d) $\mathrm{TBAF}, \mathrm{THF}, 0^{\circ} \mathrm{C}$. (e) 1. $\mathrm{NaH}, \mathrm{THF}, 0{ }^{\circ} \mathrm{C} ; 2 . \mathrm{BnBr}, \mathrm{RT}$. (f) $1 . \mathrm{NaH}, \mathrm{DMF}, 0{ }^{\circ} \mathrm{C} ; 2$. EtBr, RT. (g) 1. $\mathrm{LiOH}$ (aq.), THF, RT. 2. Amberlite IR-120 $\left(\mathrm{H}^{+}\right)$, RT. (h) $\mathrm{H}_{2}$, Rosenmund catalyst, $\mathrm{MeOH}, \mathrm{Py}$. RT.
Table 1 Yields for the conversion $7 \rightarrow 6$ and $6 \rightarrow 24$

\begin{tabular}{lllll}
\hline $\mathrm{R}$ & $\mathbf{6}$ & Yield $^{a}(\%)$ & $\mathbf{2 4}$ & Yield $^{a}(\%)$ \\
\hline $\mathrm{Me}$ & $\mathbf{6 a}$ & 88 & $\mathbf{2 4 a}$ & $63(77)$ \\
$\mathrm{Et}$ & $\mathbf{6 b}$ & $32(74)$ & $\mathbf{2 4 b}$ & $47(97)$ \\
$n \mathrm{Pr}$ & $\mathbf{6 c}$ & 47 & $\mathbf{2 4 c}$ & $63(89)$ \\
$n \mathrm{Bu}$ & $\mathbf{6 d}$ & 49 & $\mathbf{2 4 d}$ & 54 \\
$c \mathrm{Pr}$ & $\mathbf{6 e}$ & 34 & $\mathbf{2 4 e}$ & $45(99)$ \\
$\mathrm{CH}_{2} \mathrm{OEt}$ & $\mathbf{6 f}$ & 54 & $\mathbf{2 4 f}$ & $16(78)$ \\
$\mathrm{CH}_{2} \mathrm{OBn}$ & $\mathbf{6 g}$ & 63 & $\mathbf{2 4 g}$ & $26(94)$ \\
$\mathrm{CH}_{2} \mathrm{OTBS}$ & $\mathbf{6 i}$ & 43 & $\mathbf{2 4 i}$ & 42
\end{tabular}

${ }^{a}$ Isolated yields. Corrected yields are shown in brackets.

second-generation Grubbs' catalyst in toluene at $90{ }^{\circ} \mathrm{C}$ to afford bicyclic derivatives $\mathbf{2 4 a - 9}$ and $\mathbf{2 4 i}$ in yields ranging from $16-63 \%$, and from $42-99 \%$ considering the recovered starting material. Bicyclic derivative $\mathbf{2 4 h}$ was efficiently prepared from 24i by TBS-deprotection with TBAF. As expected, the metathesis reaction proved to be quite sensitive to the presence of substitution in the allyl moiety, since: (i) when $\mathrm{R}=\mathrm{H}$ the transformation took place at room temperature and in a higher yield $(88 \%) ; ;^{13}$ and (ii) an increase in the steric hindrance of the substituent led to lower reaction yields and required higher reaction temperatures (Table 1). Derivatives $\mathbf{2 4 g}$ and 24f, which contained a $\mathrm{CH}_{2} \mathrm{OBn}$ and a $\mathrm{CH}_{2} \mathrm{OEt}$ group, respectively, gave the lowest yields. These compounds were alternatively prepared by alkylation of alcohol $24 \mathrm{~h}$ in $64 \%$ and $31 \%$ $(57 \%)$ yield, respectively. Deprotection of the acetal group in 24, followed by basic hydrolysis of the resulting esters 25a-h and subsequent protonation with Amberlite IR-120 ( $\left.\mathrm{H}^{+}\right)$ionexchange resin efficiently afforded the target compounds 4 . Finally, compounds 5, which have a flexible substituted ether bridge, were synthesized from methyl derivative 25 a by catalytic hydrogenation using Rosenmund catalyst in the presence of pyridine, followed by hydrolysis of the methyl ester to give a $1: 1$ mixture of epimers in the $\mathrm{C} 4$ position, i.e., compounds $\mathbf{5 S}$ and $\mathbf{5 R}$, which were separated by HPLC. The configuration of the new chiral center was determined by NOE experiments. Inversion of $\mathbf{H 1 0}$ in bicycles $\mathbf{5 S}$ and $\mathbf{5 R}$ led to enhancement of the signals for $\mathrm{H} 4(3.6 \%)$ and the methyl group (5.2\%), respectively.

\section{Inhibition studies}

The inhibitory activity of the reported conformationally restricted shikimic acid derivatives $\mathbf{2 - 5}$ was assayed against SK from Helicobacter pylori ( $\mathrm{Hp}$-SK) and from M. tuberculosis (Mt-SK). All of the compounds proved to be competitive reversible inhibitors of shikimic acid for both enzymes. The inhibition data $\left(K_{\mathrm{i}}\right)$, which were obtained from Dixon plots (1/v vs. [I]), are summarized in Table 2.

In general: (i) the ligands proved to be more potent against the $H$. pylori enzyme than the $M$. tuberculosis enzyme; (ii) a rigid ether bridge between the C3 and C5 positions of shikimic acid provided more potent inhibitors (Table 2, entries 3 vs. 11); (iii) for $H p$-SK, the inhibition potency of the ligands increased with the length of the substituent chain (Table 2, entries 5 and 
Table $2 K_{\mathrm{i}}(\mu \mathrm{M})$ values of compounds $2-5$ against SK enzymes ${ }^{a}$

\begin{tabular}{lllcl}
\hline Entry & Comp & $\mathrm{R}$ & H. pylori & M. tuberculosis \\
\hline 1 & $\mathbf{2}$ & $\mathrm{H}$ & $104 \pm 4$ & $62 \pm 1$ (ref. 13) \\
2 & $\mathbf{3}$ & - & $47 \pm 6$ & $46 \pm 2$ (ref. 13) \\
3 & $\mathbf{4 a}$ & $\mathrm{Me}$ & $54.5 \pm 5.7$ & $28 \pm 1$ \\
4 & $\mathbf{4 b}$ & $\mathrm{Et}$ & $15.5 \pm 1.1$ & $41 \pm 2$ \\
5 & $\mathbf{4 c}$ & $\mathrm{nPr}$ & $9.2 \pm 1.0$ & $72 \pm 4$ \\
6 & $\mathbf{4 d}$ & $\mathrm{nBu}$ & $12 \pm 2$ & $177 \pm 3$ \\
7 & $\mathbf{4 e}$ & $c \mathrm{Pr}$ & $10.0 \pm 0.6$ & $101 \pm 2$ \\
8 & $\mathbf{4 f}$ & $\mathrm{CH}{ }_{2} \mathrm{OEt}$ & $5.0 \pm 0.3$ & $170 \pm 3$ \\
9 & $\mathbf{4 g}$ & $\mathrm{CH}_{2} \mathrm{OBn}$ & $68 \pm 3$ & $121 \pm 5$ \\
10 & $\mathbf{4 h}$ & $\mathrm{CH}_{2} \mathrm{OH}$ & $38 \pm 3$ & $333 \pm 10$ \\
11 & $\mathbf{5 S}$ & $\mathrm{Me}$ & $465 \pm 41$ & $360 \pm 7$ \\
12 & $\mathbf{5 R}$ & $\mathrm{Me}$ & $\mathrm{ND}$ & $645 \pm 16$
\end{tabular}

${ }^{a}$ Assay conditions: Tris. $\mathrm{HCl}(100 \mathrm{mM}, \mathrm{pH} 7.7)$, ATP $(2.5 \mathrm{mM}), \mathrm{NADH}$ (0.2 mM), PEP (1 mM), $\mathrm{MgCl}_{2}(5 \mathrm{mM}), \mathrm{KCl}(100 \mathrm{mM})$, lactate dehydrogenase/pyruvate kinase ( 2.8 units), $25{ }^{\circ} \mathrm{C}$. For $M t$-SK: $K_{\mathrm{m}}(\mathbf{1})=544 \pm$ $14 \mu \mathrm{M} ; k_{\mathrm{cat}}=295 \pm 8 \mathrm{~s}^{-1}$. For $H p$-SK: $K_{\mathrm{m}}(\mathbf{1})=39 \pm 8 \mu \mathrm{M} ; k_{\mathrm{cat}}=116 \pm$ $4 \mathrm{~ms}^{-1} . \mathrm{ND}=$ not determined.

8 vs. 1 and 4), while for $M t$-SK only the introduction of a methyl group in the rigid ether bridge improved the inhibitory activity (Table 2, entries 3 vs. 5); (iv) the presence of a hydroxyl or an ether group in the substituent only enhanced the inhibitory activity for $\mathrm{Hp}$-SK (Table 2, entries 8 vs. 5).

For the H. pylori enzyme, the best inhibitor in the series was compound $\mathbf{4 f}$, which has a $\mathrm{CH}_{2} \mathrm{OEt}$ substituent in the ether bridge. This enhanced the inhibitory potency by up to 20-fold. For the M. tuberculosis enzyme, a 2 -fold improvement in activity was achieved with compound $\mathbf{4 a}$, which has a methyl group. Computational studies were performed in an effort to gain a better understanding at the atomic level of the differences observed experimentally in the inhibitory potency of the reported conformationally rigid shikimic acid analogs 4-5. The results of these studies are discussed below.

\section{Computational studies}

Molecular docking using the GOLD 5.2.2 ${ }^{14}$ program and the protein coordinates found in the crystal structures of $\mathrm{Hp}$-SK in complex with shikimate-3-phosphate and ADP (PDB entry $3 \mathrm{MUF},{ }^{15} 2.3 \AA$ ) and of $M t$-SK in complex with 2 and ADP (PDB entry $4 \mathrm{BQS},{ }^{13} 2.15 \AA$ ) were carried out first. The highest score solutions obtained by docking were further analyzed by Molecular Dynamics (MD) simulation studies in order to assess the stability and therefore the reliability of the postulated binding. The monomer of the $\mathrm{Hp}$-SK/ATP/ $/ \mathrm{Mg}^{2+} /$ ligand and $M t$-SK/ATP $/ \mathrm{Mg}^{2+} /$ ligand complexes in a truncated octahedron of water molecules obtained with the molecular mechanics force field $\mathrm{AMBER}^{16}$ was employed and the system was then subjected to $100 \mathrm{~ns}$ of dynamic simulation. The latter was carried out with the most active ligands, compounds $4 \mathbf{4}-\mathbf{d}$ and 4f, as well as the analogs with a flexible ether bridge, i.e., $5 \mathbf{S}$ and $\mathbf{5 R}$ (Fig. 3).

The results of the computational studies revealed that, in all cases, the ligands would be stable in the shikimic acid active site, since significant variations were not observed during the whole simulation, both in the position of the ligand and in the protein backbone (Fig. S2 and S3†). As one would expect, the ligands would be anchored to the active site by the same electrostatic and polar interactions as the original compound 2 (Fig. S4†). More importantly, relevant differences were identified in the arrangement of the substituent of the ether bridge of the ligands for both enzymes and this would explain the experimentally obtained activity. Thus, for $\mathrm{Hp}$-SK and during most of the simulation, these substituents were mainly embedded in the active site, with both the lid and the SB domain completely surrounding the entire ligand (Fig. 3A-F). For compounds $\mathbf{4 b}-\mathbf{d}$ and $\mathbf{4 f}(\mathrm{R} \neq \mathrm{H}, \mathrm{Me})$, the percentage of conformations with the substituent 'inside' the active site increased as the chain length increased, which is in good agreement with the observed improvement in the inhibitory potency $\left(\mathrm{CH}_{2} \mathrm{OEt}>n \mathrm{Bu}>n \mathrm{Pr}>\mathrm{Et}\right)$ (Fig. $\left.3 \mathrm{I}\right)$. These values were calculated by analyzing the variation of the dihedral angle between the atoms C5 (CAF), C4 (CAE) and the first two atoms of the substituent, $\mathrm{C}$ (CAP) and $\mathrm{C}(\mathrm{CAR}) / \mathrm{O}(\mathrm{OAR})$, in $\mathbf{4 b}-$ d and 4f during the whole simulation (Fig. S5 and S6†). 'Substituent inside conformations' were considered for values of the dihedral angle between $-50^{\circ}$ and $-150^{\circ}$. As a result of this arrangement, the shikimic acid active site remained neatly closed, thus avoiding the entrance of the natural substrate, because the ligands caused a dramatic reduction in the flexibility of the lid and SB domain by a series of favorable apolar interactions between the substituent and the residues in this pocket (Fig. 4A-D). It is worth highlighting that MD studies in the enzyme product complex, i.e., in the presence of ADP and shikimate-3-phosphate, revealed that the flexibility of the lid and the SB domain are key for the catalytic turnover. ${ }^{13}$ The lid is the substrate-covering loop that closes over the shikimic acid binding site for catalysis and it contains the essential residue Arg116/Arg117 (H. pylori and M. tuberculosis, respectively). NMR studies revealed that this residue might also be involved in the phosphoryl-transfer mechanism catalyzed by SK by activating and positioning the reaction intermediate for subsequent nucleophilic attack by the C3 hydroxyl group in 1. ${ }^{18}$ The aforementioned apolar interactions would be more numerous as the length of the chain increases, which would explain the enhancement in ligand affinity. In general, these interactions would involve the residues of the: (i) lid: Arg116 (essential), Pro117 (conserved) and Leu118; (ii) the SB domain: Val44 and Arg45; and (iii) the P-loop: Met10 (Fig. S7†). For the most potent inhibitor, compound $\mathbf{4 f}$, an additional interaction was identified between the oxygen atom of the substituent and the amide main chain (carbonyl) of Val44 through a water network, and this could explain the higher affinity of $\mathbf{4 f}$ for $\mathrm{Hp}$-SK than $\mathbf{4 d}$, which has a $\mathrm{CH}_{2}$ group in the same position (Fig. 4D and C, respectively).

Moreover, for ligands $\mathbf{5}$, the simulation studies revealed a different behavior of both compounds, mainly relative to the ether bridge. Thus, while for ligand $\mathbf{5} \mathbf{R}$ no significant conformational changes were observed during the dynamic simulation, this was not the case for ligand 5S. The ether bridge moiety in $\mathbf{5 S}$ underwent a conformational change to locate the 
A

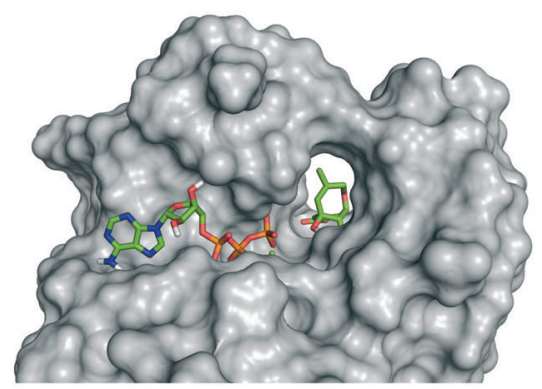

B

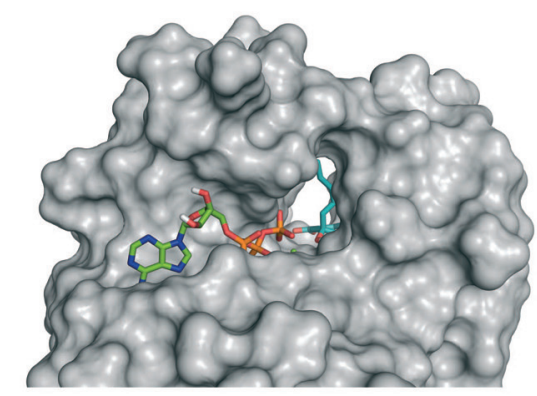

C

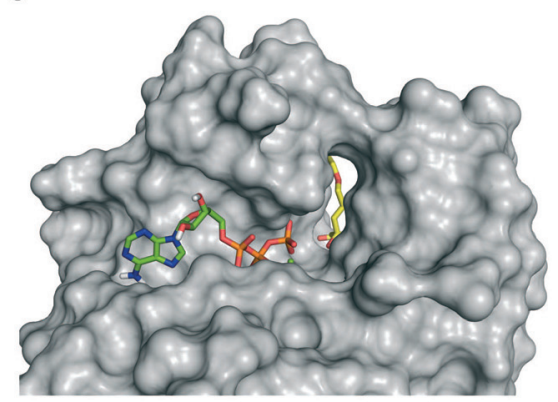

D

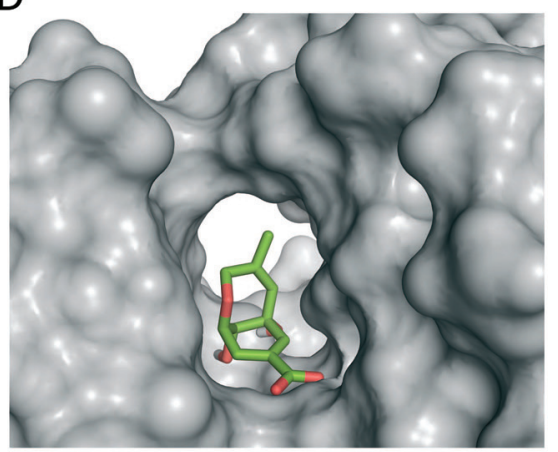

G

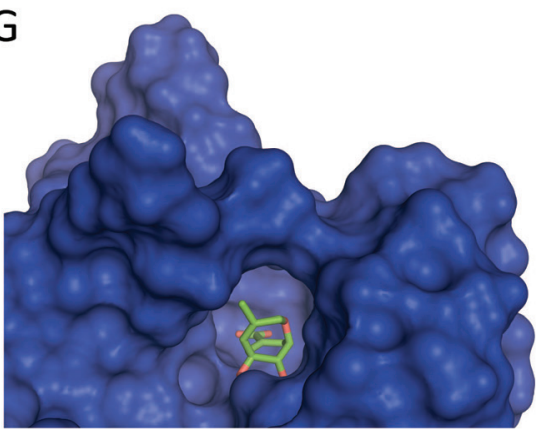

E

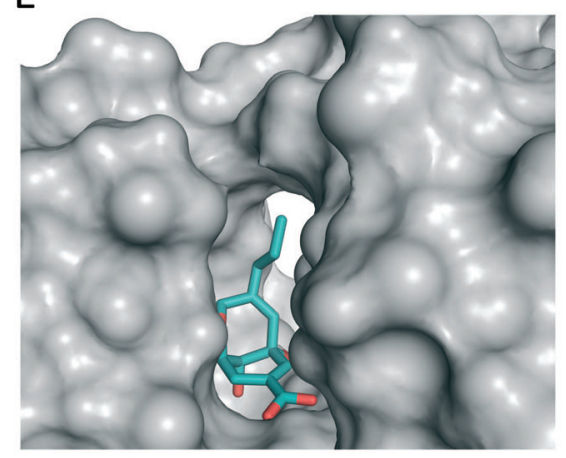

$\mathrm{H}$

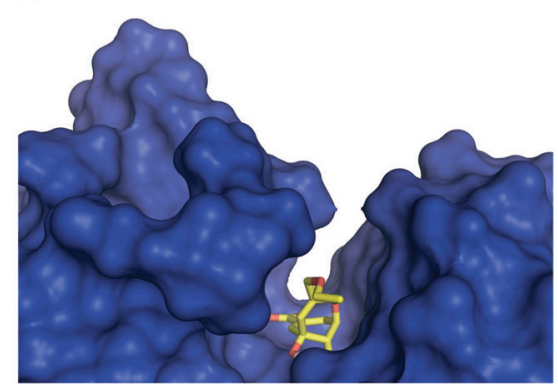

$\mathrm{F}$

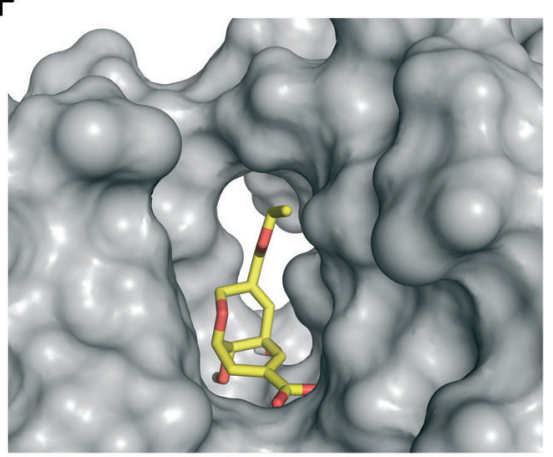

I

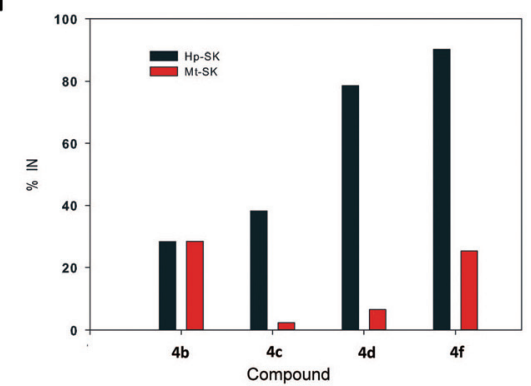

Fig. 3 Binding mode of compounds $4 \mathrm{a}$ (green), $4 \mathrm{c}$ (cyan) and $\mathbf{4 f}$ (yellow) obtained by docking and MD simulation studies in the active site of the $\mathrm{Hp}$-SK (gray) and Mt-SK (dark blue) enzymes. A-C. Overall view of the $\mathrm{Hp}$-SK/ATP/ $\mathrm{Mg}^{2+} /$ ligand complexes. Snapshots after $80 \mathrm{~ns}$ of simulation are shown. $\mathrm{Mg}^{2+}$ (sphere) and ligands (sticks) and ATP (sticks) are displayed. D-F. Close view of ligands $4 \mathrm{a}, 4 \mathrm{c}$ and $4 \mathrm{f}$ in the SB binding pocket of $H p-S K$. Note how these ligands and the substituents of the ether bridge are perfectly surrounded by the enzyme, in particular for compounds $4 \mathrm{c}$ and $\mathbf{4 f}$. $\mathrm{G}-\mathrm{H}$. Close view of ligands $4 \mathrm{a}$ and $\mathbf{4 f}$ in the $\mathrm{Mt}-\mathrm{SK} / \mathrm{ATP} / \mathrm{Mg}^{2+} /$ ligand complexes. Note how for ligand $4 \mathrm{f}$ the substituent of the ether bridge would not be embedded in the active site as for the $H$. pylori enzyme. I. Percentage of conformations of the ligands $4 \mathrm{~b}-\mathrm{d}$ and $4 \mathrm{f}$ during the $100 \mathrm{~ns}$ of simulation in which the substituent of the ether bridge ( $\mathrm{Et}, n \mathrm{Pr}, n \mathrm{Bu}, \mathrm{CH}_{2} \mathrm{OEt}$ ) would be located pointing towards the active site (inside).

methyl group in parallel to the cyclohexene ring. This conformation remained stable after $\sim 40$ ns of simulation (Fig. S8 $\dagger$ ). As a consequence, for both ligands 5, an interaction of the methyl group with the carbon chain of the essential arginine was not identified, as observed with compound $4 \mathbf{f}$ and previously reported saturated derivative 3 . This fact revealed how the rigidity of the ether bridge in the ligands would be crucial to fix the position and direction of the substituent towards the key residues of the lid.

In contrast to the above, for $M t$-SK, as the length of the substituent increases ( $\mathrm{R}=\mathrm{Et}, n \mathrm{Pr}, n \mathrm{Bu}, \mathrm{CH}_{2} \mathrm{OEt}$ ) the ligands would be located preferentially with the substituent pointing outside the active site (Fig. 3G-H). In this arrangement, the introduc- tion of this type of substituent in 2 would not contribute to an improvement in ligand affinity since additional interactions with the residues of the active site could not be established (Fig. 4E-F).

For both enzymes, the substituent of the ligand interacts with a similar region of the lid and this is quite similar in terms of amino acid sequences. However, the results of the computational studies revealed a clear and markedly distinct induced fitting of the ligands by the two enzymes, which would explain the differences found. These are due to key differences in the folding of the lid over the active site - a situation that can be easily visualized by analysis of the vibrational modes of the two enzymes (Fig. 5). ${ }^{19}$ 
A

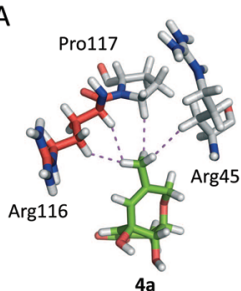

D

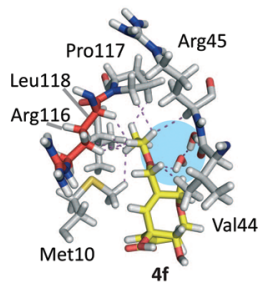

B

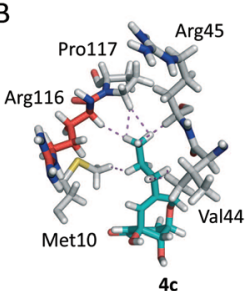

E

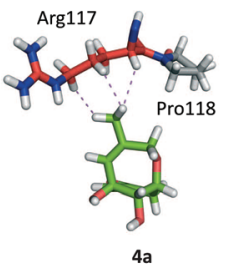

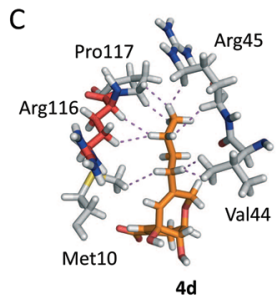

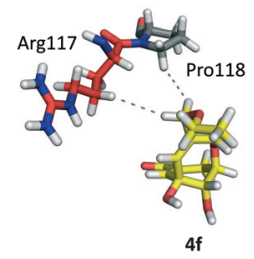

Fig. 4 Detailed view of the interactions of the ether bridge substituent in $4 a, 4 c-d$ and $4 f$ with $\mathrm{Hp}-\mathrm{SK}(\mathrm{A}-\mathrm{D})$ and in $\mathbf{4 a}$ and $4 \mathrm{f}$ with $\mathrm{Mt}-\mathrm{SK}(\mathrm{E}-\mathrm{F})$ in their respective enzyme complexes. Relevant side chain residues are shown and labeled. Apolar (magenta) and polar (blue) contacts are shown as dashed lines. The interaction of the oxygen atom of the substituent in $\mathbf{4 f}$ with the amide main chain (carbonyl) of Val44 through a water network is highlighted with blue shading.
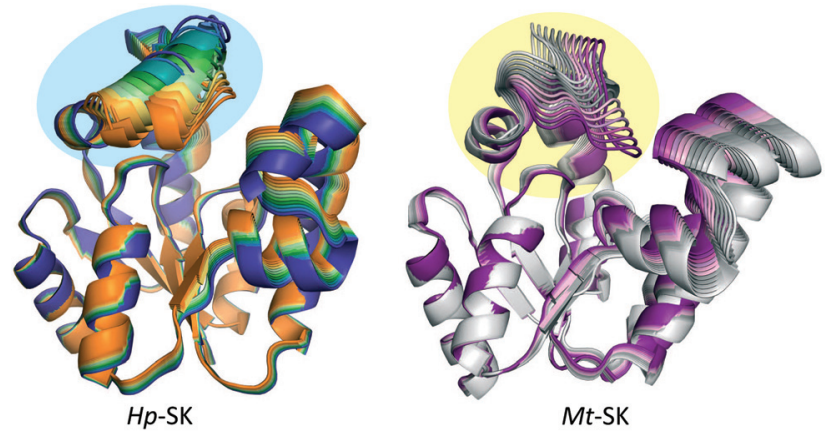

Fig. 5 Overall view of the Hp-SK and Mt-SK motion obtained by examination of the vibrational modes. The motion of the lid is highlighted with blue and yellow shading, respectively. Note how the folding of the lid and as a consequence the essential arginine that it contains is quite distinct in the two enzymes.

\section{Conclusions}

The functionalization of the double bond of previously identified scaffold 2, a stable mimetic of the high-energy conformation of shikimic acid and a competitive reversible inhibitor of the shikimate kinase enzyme, was carried out by ringclosing metathesis of allyloxy vinyl derivatives 6 as the key step. The latter compounds were prepared by Trost allylation of previously reported alcohol 7 with allyl methyl carbonates $\mathbf{8}$. The RCM approach required reaction temperatures of $90{ }^{\circ} \mathrm{C}$ and the use of second-generation Grubbs' catalyst.

The results obtained for the rigidified shikimic acid derivatives reported, namely compounds $\mathbf{4 - 5}$, with the two enzymes studied, SK from M. tuberculosis and from $H$. pylori, revealed that: (i) the rigidification of the functionalized ether bridge

between C3 and C5 of the shikimic acid is crucial for improving ligand affinity; (ii) this functionalization generally provides more potent analogs against the $H$. pylori enzyme than the M. tuberculosis enzyme. A 20-fold improvement against the H. pylori enzyme was achieved by the introduction of a $\mathrm{CH}_{2} \mathrm{OEt}$ group in the rigid ether bridge of the reported shikimic acid analogs. For the $M$. tuberculosis enzyme, the introduction of a methyl group in 2 enhanced the ligand potency by a factor of two.

Computational studies revealed that the differences in affinity found with the two homologous enzymes are due to the distinct induced-fit conformation adopted by the two enzymes upon ligand binding, which mainly involves the substrate-covering loop (lid). For $\mathrm{Hp}$-SK, the substituents ( $\mathrm{R}=\mathrm{Et}$, $n \mathrm{Pr}, n \mathrm{Bu}, \mathrm{CH}_{2} \mathrm{OEt}$ ) would be embedded in the active site, with both the lid and the SB domain completely surrounding the entire ligand. As a result, the active site would be neatly closed because the ligands cause a dramatic reduction in the flexibility of the lid and SB domain through a series of favorable apolar interactions between the substituent and the residues in this pocket. In contrast, for $M t$-SK, as the length of the substituent increases ( $\mathrm{R}=\mathrm{Et}, n \mathrm{Pr}, n \mathrm{Bu}, \mathrm{CH}_{2} \mathrm{OEt}$ ) this moiety of the ligand would be pointing away from the active site and therefore they would not contribute to an improvement in ligand affinity. The results reported here can be considered as a good example of how the rigidification of a ligand is a useful strategy to enhance ligand affinity for a target due to the pre-orientation and maximization of the interactions of its substituents.

\section{Experimental}

\section{General}

All starting materials and reagents were commercially available and were used without further purification. ${ }^{1} \mathrm{H}$ NMR spectra (250, 300 and $500 \mathrm{MHz}$ ) and ${ }^{13} \mathrm{C}$ NMR spectra (63, 75 and $125 \mathrm{MHz}$ ) were measured in deuterated solvents. $J$ values are given in hertz. NMR assignments were carried out by a combination of $1 \mathrm{D}$, COSY, and DEPT-135 experiments. FT-IR spectra were recorded in a PerkinElmer two FTIR spectrometer with attenuated total reference. $[\alpha]_{\mathrm{D}}^{20}=$ values are given in $10^{-1}$ deg $\mathrm{cm}^{2} \mathrm{~g}^{-1}$. MilliQ deionized water was used in all the buffers. Melting points were measured in a Büchi M-560 apparatus. The experimental procedures for the synthesis of carbonates $\mathbf{8}$ are described in the ESI. $\dagger$

\section{General procedure for synthesis of compounds 6}

To a stirred solution of $\mathrm{Pd}_{2}(\mathrm{dba})_{3}(0.025 \mathrm{mmol})$ and $\mathrm{dppb}$ $(0.1 \mathrm{mmol})$ in dry THF $(0.8 \mathrm{~mL})$, under argon and at room temperature, were added the alcohol $7^{13}(1 \mathrm{mmol})$, followed by a solution of the carbonates $8 \mathbf{8}-\mathbf{g}$ and $\mathbf{8 i}(1.5 \mathrm{mmol})$ in dry THF ( $3 \mathrm{~mL}, 0.5 \mathrm{M}$ ). The resulting suspension was heated at $60{ }^{\circ} \mathrm{C}$ for $24 \mathrm{~h}$ and then cooled to room temperature. The mixture was filtered over Celite ${ }^{\circledR}$ and the residue was washed with diethyl ether. The filtrate and washings were evaporated 
under reduced pressure to yield an oil which was purified by flash chromatography to afford the allyl ethers 6.

Methyl $\quad(3 R, 4 S, 5 R)$-5-(2-methyl)allyloxy-3,4-O-isopropylidenedioxy-3-vinylcyclohex-1-ene-1-carboxylate $(6 a, R=M e)$. It was prepared following the general allylation procedure using 7 (49 mg), $\mathrm{Pd}_{2}(\mathrm{dba})_{3}(4.9 \mathrm{mg})$, dppb (8.1 mg), methyl-2-methylallyl carbonate $(\mathbf{8 a})^{17}(30 \mathrm{mg})$ in dry THF $(0.28 \mathrm{~mL})$, THF $(0.8 \mathrm{~mL})$. Eluent for chromatography $=(30: 70)$ diethyl ether/ hexane. Yield $=88 \%(52 \mathrm{mg})$. Colorless oil. $[\alpha]_{\mathrm{D}}^{20}=+107.6^{\circ}$ $\left(c\right.$ 3.5, $\left.\mathrm{CHCl}_{3}\right) .{ }^{1} \mathrm{H}$ NMR $\left(300 \mathrm{MHz}, \mathrm{CDCl}_{3}\right) \delta: 6.64(\mathrm{~m}, 1 \mathrm{H}, \mathrm{H} 2)$, $5.92\left(\mathrm{dd}, J=17.3\right.$ and $\left.10.7 \mathrm{~Hz}, 1 \mathrm{H}, \mathrm{C} H=\mathrm{CH}_{2}\right), 5.44(\mathrm{dd}, J=17.3$ and $\left.1.5 \mathrm{~Hz}, 1 \mathrm{H}, \mathrm{CH}=\mathrm{CH}_{2}\right), 5.17(\mathrm{dd}, J=10.7$ and $1.5 \mathrm{~Hz}, 1 \mathrm{H}$, $\left.\mathrm{CH}=\mathrm{CH}_{2}\right), 4.89\left(\mathrm{~d}, J=18.6 \mathrm{~Hz}, 2 \mathrm{H}, \mathrm{H}_{3} \mathrm{CCH}=\mathrm{CH}_{2}\right), 4.09(\mathrm{~d}, J=$ $4.0 \mathrm{~Hz}, 1 \mathrm{H}, \mathrm{H} 4), 4.02$ (dd, $J=6.6$ and $3.9 \mathrm{~Hz}, 1 \mathrm{H}, \mathrm{H} 5), 3.91$ (d, $\left.J=5.3 \mathrm{~Hz}, 2 \mathrm{H}, \mathrm{CH}_{2}\right), 3.76\left(\mathrm{~s}, 3 \mathrm{H}, \mathrm{OCH}_{3}\right), 2.64(\mathrm{dd}, J=18.0$ and $2.6 \mathrm{~Hz}, 1 \mathrm{H}, \mathrm{C} H \mathrm{H}-6$ ), 2.44 (ddd, $J=18.0,3.9$ and $2.7 \mathrm{~Hz}, 1 \mathrm{H}$, $\mathrm{CH} H-6), 1.69\left(\mathrm{~s}, 3 \mathrm{H}, \mathrm{CH}_{3}\right), 1.41\left(\mathrm{~s}, 3 \mathrm{H}, \mathrm{CH}_{3}\right)$ and $1.34(\mathrm{~s}, 3 \mathrm{H}$, $\mathrm{CH}_{3}$ ) ppm. ${ }^{13} \mathrm{C}$ NMR (63 MHz, $\mathrm{CDCl}_{3}$ ) $\delta: 167.4$ (C), 141.9 (C), 137.8 (C), 137.6 (C), 126.2 (C), $115.0\left(\mathrm{CH}_{2}\right), 112.1\left(\mathrm{CH}_{2}\right), 109.1$ (C), $80.1(\mathrm{C}), 77.3(\mathrm{CH}), 73.3\left(\mathrm{CH}_{2}\right), 73.2(\mathrm{CH}), 51.9(\mathrm{CH}), 27.9$ $\left(\mathrm{CH}_{3}\right), 26.9\left(\mathrm{CH}_{3}\right), 24.3\left(\mathrm{CH}_{2}\right)$ and $19.4\left(\mathrm{CH}_{3}\right)$ ppm. FTIR (film) $\nu: 1719(\mathrm{CO}) \mathrm{cm}^{-1}$. MS (ESI) $\mathrm{m} / z=331\left(\mathrm{MNa}^{+}\right)$. HRMS calcd for $\mathrm{C}_{17} \mathrm{H}_{24} \mathrm{O}_{5} \mathrm{Na}\left(\mathrm{MNa}^{+}\right)$: 331.1516; found, 331.1511.

Methyl $\quad(3 R, 4 S, 5 R)$-5-(2-ethylallyloxy)-3,4-O-isopropylidenedioxy-3-vinylcyclohex-1-ene-1-carboxylate $(6 \mathbf{b}, \mathbf{R}=\mathbf{E t})$. It was prepared following the general allylation procedure using 7 (530 mg), $\mathrm{Pd}_{2}(\mathrm{dba})_{3}$ (48 mg), dppb (89 mg), methyl (2-methylenebutyl) carbonate $(\mathbf{8 b})^{17}(599 \mathrm{mg})$ in THF $(8.3 \mathrm{~mL})$, THF $(9 \mathrm{~mL})$. Eluent for chromatography $=(50: 50)$ diethyl ether/ hexane. Yield $=32 \%(213 \mathrm{mg})$. It was recovered $221 \mathrm{mg}$ of starting material. Corrected yield $=74 \%$. Colorless oil. $[\alpha]_{\mathrm{D}}^{20}=$ $+99.1^{\circ}\left(c 1.1, \mathrm{CHCl}_{3}\right) .{ }^{1} \mathrm{H}$ NMR $\left(300 \mathrm{MHz}, \mathrm{CDCl}_{3}\right) \delta: 6.64(\mathrm{t}, J=$ $1.3 \mathrm{~Hz}, 1 \mathrm{H}, \mathrm{H} 2), 5.92\left(\mathrm{dd}, J=10.7\right.$ and $17.3 \mathrm{~Hz}, 1 \mathrm{H}, \mathrm{CH}=\mathrm{CH}_{2}$ ), $5.45(\mathrm{dd}, J=1.5$ and $17.3 \mathrm{~Hz}, 1 \mathrm{H}, \mathrm{CH}=\mathrm{CHH}), 5.18(\mathrm{dd}, J=1.4$ and $10.7 \mathrm{~Hz}, 1 \mathrm{H}, \mathrm{CH}=\mathrm{CH} H), 4.95(\mathrm{~m}, 1 \mathrm{H}, \mathrm{C}=\mathrm{CHH}), 4.87(\mathrm{~m}$, $1 \mathrm{H}, \mathrm{C}=\mathrm{CH} H), 4.09(\mathrm{~m}, 1 \mathrm{H}, \mathrm{H} 5), 4.02(\mathrm{~m}, 1 \mathrm{H}, \mathrm{H} 4), 3.99(\mathrm{~d}, J=$ $12.5 \mathrm{~Hz}, 1 \mathrm{H}, \mathrm{OCH \textrm {H }}), 3.92(\mathrm{~d}, J=12.5 \mathrm{~Hz}, 1 \mathrm{H}, \mathrm{OCH} H), 3.76$ (s, $\left.3 \mathrm{H}, \mathrm{OCH}_{3}\right), 2.65(\mathrm{dd}, J=2.5$ and $17.9 \mathrm{~Hz}, 1 \mathrm{H}, \mathrm{CH}-6), 2.44$ (ddd, $J=2.8,3.8$ and $18.0 \mathrm{~Hz}, 1 \mathrm{H}, \mathrm{CH} H-6), 2.02(\mathrm{q}, J=7.4 \mathrm{~Hz}$, $\left.2 \mathrm{H}, \mathrm{CH}_{2} \mathrm{CH}_{3}\right), 1.42\left(\mathrm{~s}, 3 \mathrm{H}, \mathrm{CH}_{3}\right), 1.34\left(\mathrm{~s}, 3 \mathrm{H}, \mathrm{CH}_{3}\right)$ and $1.02(\mathrm{t}$, $\left.J=7.4 \mathrm{~Hz}, 3 \mathrm{H}, \mathrm{CH}_{2} \mathrm{CH}_{3}\right)$ ppm. ${ }^{13} \mathrm{C}$ NMR $\left(63 \mathrm{MHz}, \mathrm{CDCl}_{3}\right) \delta$ : 167.5 (C), 147.5 (C), $137.9(\mathrm{CH}), 137.7(\mathrm{CH}), 126.3(\mathrm{C}), 115.1$ $\left(\mathrm{CH}_{2}\right), 110.3\left(\mathrm{CH}_{2}\right), 109.1(\mathrm{C}), 80.2(\mathrm{C}), 77.3(\mathrm{CH}), 73.2(\mathrm{CH})$, $72.5\left(\mathrm{CH}_{2}\right), 52.0\left(\mathrm{OCH}_{3}\right), 28.0\left(\mathrm{CH}_{3}\right), 27.0\left(\mathrm{CH}_{3}\right), 25.9\left(\mathrm{CH}_{2}\right)$, $24.4\left(\mathrm{CH}_{2}\right)$ and $12.0\left(\mathrm{CH}_{3}\right)$ ppm. FTIR (film): $1710(\mathrm{CO}) \mathrm{cm}^{-1}$. MS (ESI) $m / z=345\left(\mathrm{MNa}^{+}\right)$. HRMS calcd for $\mathrm{C}_{18} \mathrm{H}_{26} \mathrm{O}_{5} \mathrm{Na}$ $\left(\mathrm{MNa}^{+}\right)$: 345.1672; found, 345.1681.

Methyl (3R,4S,5R)-3,4-O-isopropylidenedioxy-5-(2-propylallyloxy)-3-vinylcyclohex-1-ene-1-carboxylate $(6 \mathrm{c}, \mathrm{R}=n \mathrm{Pr})$. It was prepared following the general allylation procedure using 7 (198 mg), $\mathrm{Pd}_{2}(\mathrm{dba})_{3}(20 \mathrm{mg})$, dppb (33 mg), methyl (2-methylenepentyl) carbonate $(8 \mathbf{c})(320 \mathrm{mg})$ in THF $(2.3 \mathrm{~mL})$, THF $(3 \mathrm{~mL})$. Eluent for chromatography $=(20: 80)$ diethyl ether/ hexane. Yield $=47 \%(122 \mathrm{mg})$. Colorless oil. $[\alpha]_{\mathrm{D}}^{20}=+92.8^{\circ}$ (c 1.1, $\left.\mathrm{CHCl}_{3}\right) .{ }^{1} \mathrm{H}$ NMR $\left(300 \mathrm{MHz}, \mathrm{CDCl}_{3}\right) \delta: 6.62(\mathrm{t}, J=1.4 \mathrm{~Hz}$, $1 \mathrm{H}, \mathrm{H} 2), 5.89\left(\mathrm{dd}, J=10.7\right.$ and $17.4 \mathrm{~Hz}, 1 \mathrm{H}, \mathrm{CH}=\mathrm{CH}_{2}$ ), 5.42 (dd, $J=1.5$ and $17.3 \mathrm{~Hz}, 1 \mathrm{H}, \mathrm{CH}=\mathrm{CHH}), 5.14(\mathrm{dd}, J=1.5$ and $10.7 \mathrm{~Hz}, 1 \mathrm{H}, \mathrm{CH}=\mathrm{CH} H), 4.93(\mathrm{br} \mathrm{s}, 1 \mathrm{H}, \mathrm{C}=\mathrm{CHH}), 4.83$ (br s, $1 \mathrm{H}, \mathrm{C}=\mathrm{CH} H), 4.06(\mathrm{br} \mathrm{d}, J=4.0 \mathrm{~Hz}, 1 \mathrm{H}, \mathrm{H} 4), 4.00(\mathrm{td}, J=2.6$ and $3.9 \mathrm{~Hz}, 1 \mathrm{H}, \mathrm{H} 5), 3.94(\mathrm{~d}, J=12.6 \mathrm{~Hz}, 1 \mathrm{H}, \mathrm{OCH \textrm {H }}), 3.87(\mathrm{~d}$, $J=12.6 \mathrm{~Hz}, 1 \mathrm{H}, \mathrm{OCH} H), 3.73\left(\mathrm{~s}, 3 \mathrm{H}, \mathrm{OCH}_{3}\right), 2.63(\mathrm{dd}, J=2.6$ and $18.0 \mathrm{~Hz}, 1 \mathrm{H}, \mathrm{CH} H-6$ ), 2.41 (ddd, $J=2.8,3.8$ and $18.0 \mathrm{~Hz}$, $1 \mathrm{H}, \mathrm{CHH}-6), 1.95\left(\mathrm{t}, J=7.5 \mathrm{~Hz}, 2 \mathrm{H}, \mathrm{CH}_{2} \mathrm{CH}_{3}\right), 1.47-1.35(\mathrm{~m}, 5 \mathrm{H}$, $\left.\mathrm{CH}_{2}+\mathrm{CH}_{3}\right), 1.31\left(\mathrm{~s}, 3 \mathrm{H}, \mathrm{CH}_{3}\right)$ and $0.86(\mathrm{t}, J=7.3 \mathrm{~Hz}, 3 \mathrm{H}$, $\mathrm{CH}_{2} \mathrm{CH}_{3}$ ) ppm. ${ }^{13} \mathrm{C}$ NMR (63 MHz, $\left.\mathrm{CDCl}_{3}\right) \delta: 167.5$ (C), 145.8 (C), $137.9(\mathrm{CH}), 137.7(\mathrm{CH}), 126.3(\mathrm{C}), 115.0\left(\mathrm{CH}_{2}\right), 111.4\left(\mathrm{CH}_{2}\right)$, $109.1(\mathrm{C}), 80.2(\mathrm{C}), 77.4(\mathrm{CH}), 73.3(\mathrm{CH}), 72.3\left(\mathrm{CH}_{2}\right), 52.0$ $\left(\mathrm{OCH}_{3}\right), 35.2\left(\mathrm{CH}_{2}\right), 28.0\left(\mathrm{CH}_{3}\right), 27.0\left(\mathrm{CH}_{3}\right), 24.4\left(\mathrm{CH}_{2}\right), 20.8$ $\left(\mathrm{CH}_{2}\right)$ and $13.9\left(\mathrm{CH}_{3}\right)$ ppm. FTIR (film): $1711(\mathrm{CO}) \mathrm{cm}^{-1}$. MS (ESI) $m / z=359\left(\mathrm{MNa}^{+}\right)$. HRMS calcd for $\mathrm{C}_{19} \mathrm{H}_{28} \mathrm{O}_{5} \mathrm{Na}\left(\mathrm{MNa}^{+}\right)$: 359.1829; found, 359.1826.

Methyl $\quad(3 R, 4 S, 5 R)-3,4-O$-isopropylidenedioxy-5-(2-butylallyloxy)-3-vinylcyclohex-1-ene-1-carboxylate $(6 \mathrm{~d}, \mathrm{R}=n \mathrm{Bu})$. It was prepared following the general allylation procedure using 7 (373 mg), $\mathrm{Pd}_{2}(\mathrm{dba})_{3}(38 \mathrm{mg})$, dppb (63 mg), methyl (2-methylenehexyl) carbonate $(8 d)(380 \mathrm{mg})$ in THF $(4.4 \mathrm{~mL})$, THF $(6.4 \mathrm{~mL})$. Eluent for chromatography $=(10: 90)$ diethyl ether/ hexane. Yield $=49 \%(250 \mathrm{mg})$. Colorless oil. $[\alpha]_{\mathrm{D}}^{20}=105.9^{\circ}$ $\left(c 1.0, \mathrm{CHCl}_{3}\right) .{ }^{1} \mathrm{H}$ NMR $\left(300 \mathrm{MHz}, \mathrm{CDCl}_{3}\right) \delta: 6.64(\mathrm{~m}, 1 \mathrm{H}, \mathrm{H} 2)$, $5.91\left(\mathrm{dd}, J=10.7\right.$ and $\left.17.3 \mathrm{~Hz}, 1 \mathrm{H}, \mathrm{CH}=\mathrm{CH}_{2}\right), 5.44(\mathrm{dd}, J=1.5$ and $17.3 \mathrm{~Hz}, 1 \mathrm{H}, \mathrm{CH}=\mathrm{CHH}), 5.17(\mathrm{dd}, J=1.5$ and $10.7 \mathrm{~Hz}, 1 \mathrm{H}$, $\mathrm{CH}=\mathrm{CH} H), 4.94(\mathrm{~m}, 1 \mathrm{H}, \mathrm{C}=\mathrm{CHH}), 4.85(\mathrm{~m}, 1 \mathrm{H}, \mathrm{C}=\mathrm{CH} H)$, $4.08(\mathrm{td}, J=1.1$ and $4.0 \mathrm{~Hz}, 1 \mathrm{H}, \mathrm{H} 4), 4.01(\mathrm{dt}, J=2.5$ and $3.8 \mathrm{~Hz}, 1 \mathrm{H}, \mathrm{H} 5), 3.96$ (d, $J=12.8 \mathrm{~Hz}, 1 \mathrm{H}, \mathrm{OCHH}), 3.89$ (d, $J=$ $12.8 \mathrm{~Hz}, 1 \mathrm{H}, \mathrm{OCH} H), 3.75\left(\mathrm{~s}, 3 \mathrm{H}, \mathrm{OCH}_{3}\right), 2.64(\mathrm{~m}, 1 \mathrm{H}, \mathrm{CH} \mathrm{H}-6)$, 2.43 (ddd, $J=2.8,3.8$ and $18.0 \mathrm{~Hz}, 1 \mathrm{H}, \mathrm{CH} H-6), 1.99(\mathrm{t}, J=$ $\left.6.9 \mathrm{~Hz}, 2 \mathrm{H}, \mathrm{CH}_{2}\left(\mathrm{CH}_{2}\right)_{2} \mathrm{CH}_{3}\right), 1.43-1.23\left(\mathrm{~m}, 4 \mathrm{H}, \mathrm{CH}_{2}\left(\mathrm{CH}_{2}\right)_{2} \mathrm{CH}_{3}\right)$, $1.41\left(\mathrm{~s}, 3 \mathrm{H}, \mathrm{CH}_{3}\right), 1.33\left(\mathrm{~s}, 3 \mathrm{H}, \mathrm{CH}_{3}\right)$ and $0.88(\mathrm{t}, J=7.1 \mathrm{~Hz}, 3 \mathrm{H}$, $\left.\mathrm{CH}_{2}\left(\mathrm{CH}_{2}\right)_{2} \mathrm{CH}_{3}\right)$ ppm. ${ }^{13} \mathrm{C}$ NMR (63 MHz, $\left.\mathrm{CDCl}_{3}\right) \delta: 167.5$ (C), $146.1(\mathrm{C}), 137.9(\mathrm{CH}), 137.7(\mathrm{CH}), 126.3(\mathrm{C}), 115.0\left(\mathrm{CH}_{2}\right), 111.2$ $\left(\mathrm{CH}_{2}\right), 109.1(\mathrm{C}), 80.2(\mathrm{C}), 77.3(\mathrm{CH}), 73.2(\mathrm{CH}), 72.4\left(\mathrm{CH}_{2}\right), 52.0$ $\left(\mathrm{OCH}_{3}\right), 32.8\left(\mathrm{CH}_{2}\right), 29.8\left(\mathrm{CH}_{2}\right), 28.0\left(\mathrm{CH}_{3}\right), 27.0\left(\mathrm{CH}_{3}\right), 24.4$ $\left(\mathrm{CH}_{2}\right), 22.5\left(\mathrm{CH}_{2}\right)$ and $14.0\left(\mathrm{CH}_{3}\right)$ ppm. FTIR (film): 1717 (CO) $\mathrm{cm}^{-1}$. MS (ESI) $\mathrm{m} / z=373\left(\mathrm{MNa}^{+}\right)$. HRMS calcd for $\mathrm{C}_{20} \mathrm{H}_{30} \mathrm{O}_{5} \mathrm{Na}$ $\left(\mathrm{MNa}^{+}\right)$: 373.1985; found, 373.1982.

Methyl $(3 R, 4 S, 5 R)-5$-(2-cyclopropylmethylallyloxy)-3,4-O-isopropylidenedioxy-3-vinylcyclohex-1-ene-1-carboxylate $(6 e, R=$ $\mathbf{C H}_{2} \boldsymbol{c P r}$ ). It was prepared following the general allylation procedure using 7 (191 mg), $\mathrm{Pd}_{2}(\mathrm{dba})_{3}(39 \mathrm{mg})$, dppb (64 mg), 2-(cyclopropylmethyl)allyl methyl carbonate $(8 \mathrm{e})(191 \mathrm{mg})$ in THF $(2.2 \mathrm{~mL})$, THF $(3 \mathrm{~mL})$. Eluent for chromatography $=$ $(20: 80)$ diethyl ether $/$ hexane. Yield $=34 \%$ ( $89 \mathrm{mg})$. Colorless oil. $[\alpha]_{\mathrm{D}}^{20}=+93.8^{\circ}\left(c\right.$ 1.0, $\left.\mathrm{CHCl}_{3}\right) \cdot{ }^{1} \mathrm{H}$ NMR $\left(300 \mathrm{MHz}, \mathrm{CDCl}_{3}\right)$ $\delta: 6.64(\mathrm{~m}, 1 \mathrm{H}, \mathrm{H} 2), 5.91(\mathrm{dd}, J=10.7$ and $17.3 \mathrm{~Hz}, 1 \mathrm{H}$, $\left.\mathrm{C} H=\mathrm{CH}_{2}\right), 5.44(\mathrm{dd}, J=1.4$ and $17.3 \mathrm{~Hz}, 1 \mathrm{H}, \mathrm{CH}=\mathrm{CHH}), 5.18$ $(\mathrm{dd}, J=1.4$ and $10.7 \mathrm{~Hz}, 1 \mathrm{H}, \mathrm{CH}=\mathrm{CH} H), 5.01(\mathrm{br} \mathrm{s}, 1 \mathrm{H}$, $\mathrm{C}=\mathrm{CHH}), 4.97 \quad(\mathrm{br} \mathrm{s}, 1 \mathrm{H}, \mathrm{C}=\mathrm{CH} H), 4.07 \quad(\mathrm{~m}, 1 \mathrm{H}, \mathrm{H} 5)$, 4.04-4.02 (m, $2 \mathrm{H}, \mathrm{H} 4+\mathrm{OCH \textrm {H }}), 3.95(\mathrm{br} \mathrm{d}, J=12.5 \mathrm{~Hz}, 1 \mathrm{H}$, $\mathrm{OCH} H), 3.76\left(\mathrm{~s}, 3 \mathrm{H}, \mathrm{OCH}_{3}\right), 2.65(\mathrm{dd}, J=2.5$ and $18.0 \mathrm{~Hz}, 1 \mathrm{H}$, $\mathrm{CH} H-6$ ), 2.44 (ddd, $J=2.8,3.8$ and $18.0 \mathrm{~Hz}, 1 \mathrm{H}, \mathrm{C} H \mathrm{H}-6$ ), 1.90 $\left(\mathrm{d}, J=6.8 \mathrm{~Hz}, 2 \mathrm{H}, \mathrm{CH}_{2} \mathrm{CH}\left(\mathrm{CH}_{2}\right)_{2}\right), 1.42\left(\mathrm{~s}, 3 \mathrm{H}, \mathrm{CH}_{3}\right), 1.34(\mathrm{~s}$, $\left.3 \mathrm{H}, \mathrm{CH}_{3}\right), 0.84-0.70\left(\mathrm{~m}, 1 \mathrm{H}, \mathrm{CH}_{2} \mathrm{CH}\left(\mathrm{CH}_{2}\right)_{2}\right), 0.50-0.44(\mathrm{~m}, 2 \mathrm{H}$, 
$\left.\mathrm{CH}_{2} \mathrm{CHCH}_{2} \mathrm{CH}_{2}\right)$ and $0.08-0.03\left(\mathrm{~m}, 2 \mathrm{H}, \mathrm{CH}_{2} \mathrm{CHCH}_{2} \mathrm{CH}_{2}\right)$ ppm. ${ }^{13} \mathrm{C}$ NMR (75 MHz, $\mathrm{CDCl}_{3}$ ) $\delta: 167.6(\mathrm{C}), 146.1(\mathrm{C}), 138.0(\mathrm{CH})$, $137.8(\mathrm{CH}), 126.4(\mathrm{C}), 115.2\left(\mathrm{CH}_{2}\right), 111.6\left(\mathrm{CH}_{2}\right), 109.2(\mathrm{C})$, $80.3(\mathrm{C}), 77.5(\mathrm{CH}), 73.3(\mathrm{CH}), 72.6\left(\mathrm{CH}_{2}\right), 52.1\left(\mathrm{OCH}_{3}\right), 38.2$ $\left(\mathrm{CH}_{2}\right), 28.1\left(\mathrm{CH}_{3}\right), 27.1\left(\mathrm{CH}_{3}\right), 24.4\left(\mathrm{CH}_{2}\right), 9.3(\mathrm{CH}), 4.8$ $\left(\mathrm{CH}_{2}\right)$ and $4.7\left(\mathrm{CH}_{2}\right)$ ppm. FTIR (film): 1717 (CO) $\mathrm{cm}^{-1}$. MS (ESI) $m / z=371\left(\mathrm{MNa}^{+}\right)$. HRMS calcd for $\mathrm{C}_{20} \mathrm{H}_{28} \mathrm{O}_{5} \mathrm{Na}\left(\mathrm{MNa}^{+}\right)$: 371.1829; found, 371.1825.

Methyl $(3 R, 4 S, 5 R)-5$-[(2-(ethoxymethyl)allyloxy]-3,4-O-isopropilidendioxi-3-vinylcyclohex-1-ene-1-carboxylate $(6 f, \quad R=$ $\mathbf{C H}_{2} \mathbf{O E t}$ ). It was prepared following the general allylation procedure using 7 (255 mg), $\mathrm{Pd}_{2}(\mathrm{dba})_{3}(26 \mathrm{mg})$, dppb (43 mg), 2-(ethoxymethyl)allyl methyl carbonate $(\mathbf{8 f})(209 \mathrm{mg})$ in tetrahydrofuran $(2.4 \mathrm{~mL})$, tetrahydrofuran $(4.3 \mathrm{~mL})$. Eluent for chromatography $=(20: 80)$ diethyl ether/hexane. Yield $=54 \%$ (190 mg). Colorless oil. $[\alpha]_{\mathrm{D}}^{20}=+85.2^{\circ}\left(c\right.$ 1.0, $\left.\mathrm{CHCl}_{3}\right) .{ }^{1} \mathrm{H} \mathrm{NMR}$ $\left(300 \mathrm{MHz}, \mathrm{CDCl}_{3}\right) \delta: 6.63(\mathrm{t}, J=1.2 \mathrm{~Hz}, 1 \mathrm{H}, \mathrm{H} 2), 5.89(\mathrm{dd}, J=$ 10.7 and $\left.17.3 \mathrm{~Hz}, 1 \mathrm{H}, \mathrm{CH}=\mathrm{CH}_{2}\right), 5.43(\mathrm{dd}, J=1.4$ and $17.3 \mathrm{~Hz}$, $1 \mathrm{H}, \mathrm{CH}=\mathrm{CHH}), 5.16(\mathrm{dd}, J=1.4$ and $10.7 \mathrm{~Hz}, 1 \mathrm{H}, \mathrm{CH}=\mathrm{CH} H$ ), $5.12\left(\mathrm{~m}, 2 \mathrm{H}, \mathrm{C}=\mathrm{CH}_{2}\right), 4.08-3.96\left(\mathrm{~m}, 4 \mathrm{H}, \mathrm{H} 4+\mathrm{H} 5+\mathrm{OCH}_{2}\right)$, 3.91 (br s, $2 \mathrm{H}, \mathrm{CH}_{2} \mathrm{OEt}$ ), 3.74 (s, $3 \mathrm{H}, \mathrm{OCH}_{3}$ ), 3.44 (q, $J=7.0 \mathrm{~Hz}$, $2 \mathrm{H}, \mathrm{OCH}_{2} \mathrm{CH}_{3}$ ), 2.64 (dd, $J=2.5$ and $18.0 \mathrm{~Hz}, 1 \mathrm{H}, \mathrm{CHH}-6$ ), 2.43 (ddd, $J=2.8,3.7$ and $18.0 \mathrm{~Hz}, 1 \mathrm{H}, \mathrm{CH} H-6), 1.40$ (s, $3 \mathrm{H}, \mathrm{CH}_{3}$ ), $1.32\left(\mathrm{~s}, 3 \mathrm{H}, \mathrm{CH}_{3}\right)$ and $1.18\left(\mathrm{t}, J=7.0 \mathrm{~Hz}, 3 \mathrm{H}, \mathrm{OCH}_{2} \mathrm{CH}_{3}\right) \mathrm{ppm}$. ${ }^{13} \mathrm{C}$ NMR (75 MHz, $\mathrm{CDCl}_{3}$ ) $\delta: 167.5(\mathrm{C}), 142.9(\mathrm{C}), 137.9(\mathrm{CH})$, 137.7 (CH), $126.3(\mathrm{C}), 115.1\left(\mathrm{CH}_{2}\right), 113.9\left(\mathrm{CH}_{2}\right), 109.2(\mathrm{C})$, $80.2(\mathrm{C}), 77.4(\mathrm{CH}), 73.7(\mathrm{CH}), 71.4\left(\mathrm{CH}_{2}\right), 70.3\left(\mathrm{CH}_{2}\right), 65.9\left(\mathrm{CH}_{2}\right)$, $52.0\left(\mathrm{OCH}_{3}\right), 28.0\left(\mathrm{CH}_{3}\right), 27.0\left(\mathrm{CH}_{3}\right), 24.5\left(\mathrm{CH}_{2}\right)$ and $15.3\left(\mathrm{CH}_{3}\right)$ ppm. FTIR (film): 1716 (CO) $\mathrm{cm}^{-1}$. MS (ESI) $\mathrm{m} / z=375\left(\mathrm{MNa}^{+}\right)$. HRMS calcd for $\mathrm{C}_{19} \mathrm{H}_{28} \mathrm{O}_{6} \mathrm{Na}\left(\mathrm{MNa}^{+}\right)$: 375.1778; found, 375.1777.

Methyl $(3 R, 4 S, 5 R)-5$-[(2-(benzyloxymethyl)allyloxy]-3,4-O-isopropilidendioxi-3-vinylcyclohex-1-ene-1-carboxylate $(6 \mathrm{~g}, \mathrm{R}=$ $\left.\mathbf{C H}_{2} \mathbf{O B n}\right)$. It was prepared following the general allylation procedure using 7 (217 mg), $\mathrm{Pd}_{2}(\mathrm{dba})_{3}(22 \mathrm{mg})$, dppb (37 mg), 2-(benzyloxymethyl)allyl methyl carbonate $(\mathbf{8 g})(242 \mathrm{mg})$ in tetrahydrofuran $(2.1 \mathrm{~mL})$, tetrahydrofuran $(3.7 \mathrm{~mL})$. Eluent for chromatography $=(50: 50)$ diethyl ether/hexane. Yield $=63 \%$ (207 mg). Yellow oil. $[\alpha]_{\mathrm{D}}^{20}=+85.9^{\circ}\left(c \quad 0.8, \mathrm{CHCl}_{3}\right) .{ }^{1} \mathrm{H} \mathrm{NMR}$ $\left(300 \mathrm{MHz}, \mathrm{CDCl}_{3}\right) \delta: 7.38-7.28(\mathrm{~m}, 5 \mathrm{H}, 5 \times \mathrm{ArH}), 6.65(\mathrm{t}, J=$ $1.3 \mathrm{~Hz}, 1 \mathrm{H}, \mathrm{H} 2$ ), 5.89 (dd, $J=10.7$ and $17.3 \mathrm{~Hz}, 1 \mathrm{H}, \mathrm{CH}=\mathrm{CH}_{2}$ ), $5.43(\mathrm{dd}, J=1.4$ and $17.3 \mathrm{~Hz}, 1 \mathrm{H}, \mathrm{CH}=\mathrm{CHH}), 5.18-5.14(\mathrm{~m}$, $\left.3 \mathrm{H}, \mathrm{CH}=\mathrm{CH} H+\mathrm{C}=\mathrm{CH}_{2}\right), 4.49\left(\mathrm{~s}, 2 \mathrm{H}, \mathrm{OCH}_{2}\right), 4.12-4.02(\mathrm{~m}$, $\left.4 \mathrm{H}, \mathrm{H} 4+\mathrm{H} 5+\mathrm{CH}_{2} \mathrm{OBn}\right), 3.99$ (br s, $\left.2 \mathrm{H}, \mathrm{OCH}_{2} \mathrm{Ph}\right), 3.76(\mathrm{~s}, 3 \mathrm{H}$, $\mathrm{OCH}_{3}$ ), 2.65 (dd, $J=2.5$ and $18.0 \mathrm{~Hz}, 1 \mathrm{H}, \mathrm{CH} H-6$ ), 2.45 (ddd, $J=2.8,3.7$ and $18.0 \mathrm{~Hz}, 1 \mathrm{H}, \mathrm{CH}-6), 1.42\left(\mathrm{~s}, 3 \mathrm{H}, \mathrm{CH}_{3}\right)$ and $1.34\left(\mathrm{~s}, 3 \mathrm{H}, \mathrm{CH}_{3}\right)$ ppm. ${ }^{13} \mathrm{C} \mathrm{NMR}\left(75 \mathrm{MHz}, \mathrm{CDCl}_{3}\right) \delta: 167.5(\mathrm{C})$, $142.6(\mathrm{C}), 138.3(\mathrm{C}), 137.9(\mathrm{CH}), 137.7(\mathrm{CH}), 128.5(2 \times \mathrm{CH})$, $127.8(2 \times \mathrm{CH}), 127.8(\mathrm{CH}), 126.3(\mathrm{C}), 115.2\left(\mathrm{CH}_{2}\right), 114.3\left(\mathrm{CH}_{2}\right)$, $109.2(\mathrm{C}), 80.2(\mathrm{C}), 77.4(\mathrm{CH}), 73.7(\mathrm{CH}), 72.3\left(\mathrm{CH}_{2}\right), 70.9\left(\mathrm{CH}_{2}\right)$, $70.3\left(\mathrm{CH}_{2}\right), 52.0\left(\mathrm{OCH}_{3}\right), 28.0\left(\mathrm{CH}_{3}\right), 27.0\left(\mathrm{CH}_{3}\right)$ and $24.5\left(\mathrm{CH}_{2}\right)$ ppm. FTIR (film): 1709 (CO) $\mathrm{cm}^{-1}$. MS (ESI) $\mathrm{m} / z=437\left(\mathrm{MNa}^{+}\right)$. HRMS calcd for $\mathrm{C}_{24} \mathrm{H}_{30} \mathrm{O}_{6} \mathrm{Na}\left(\mathrm{MNa}^{+}\right)$: 437.1935; found, 437.1936.

Methyl $(3 R, 4 S, 5 R)-5-[(2-(($ tert-butyldimethylsilyloxy)methyl) allyloxy]-3,4-O-isopropilidendioxi-3-vinylcyclohex-1-ene-1-carboxylate $\left(\mathbf{6} \mathbf{i}, \mathbf{R}=\mathbf{C H}_{\mathbf{2}} \mathbf{O T B S}\right)$. It was prepared following the general allylation procedure using 7 (96 mg), $\mathrm{Pd}_{2}(\mathrm{dba})_{3}$ (10 mg), dppb (16 mg), 2-((tert-butyldimethylsilyloxy)methyl) allyl methyl carbonate (8i) (118 mg) in THF (1 mL), THF (1.6 mL). Eluent for chromatography $=(25: 75)$ diethyl ether/ hexane. Yield $=43 \%$ (72 mg). Colorless oil. $[\alpha]_{\mathrm{D}}^{20}=+63.2^{\circ}(c$ 1.0, $\mathrm{CHCl}_{3}$ ). ${ }^{1} \mathrm{H}$ NMR $\left(250 \mathrm{MHz}, \mathrm{CDCl}_{3}\right.$ ) $\delta: 6.63$ (br s, $1 \mathrm{H}, \mathrm{H} 2$ ), 5.89 $\left(\mathrm{dd}, J=10.7\right.$ and $17.3 \mathrm{~Hz}, 1 \mathrm{H}, H \mathrm{C}=\mathrm{CH}_{2}$ ), $5.43(\mathrm{dd}, J=1.4$ and $17.3 \mathrm{~Hz}, 1 \mathrm{H}, \mathrm{HC}=\mathrm{CHH}), 5.18-5.14(\mathrm{~m}, 2 \mathrm{H}, \mathrm{HC}=\mathrm{CH}+$ $\mathrm{C}=\mathrm{CHH}$ ), 5.04 (br s, $1 \mathrm{H}, \mathrm{C}=\mathrm{CH} H$ ), 4.10 (br s, 2H, $\mathrm{OCH}_{2}$ ), 4.07-3.94 (m, 4H, $\left.\mathrm{H} 4+\mathrm{H} 5+\mathrm{CH}_{2} \mathrm{OTBS}\right), 3.75\left(\mathrm{~s}, 3 \mathrm{H}, \mathrm{OCH}_{3}\right)$, $2.63(\mathrm{dd}, J=1.9$ and $18.0 \mathrm{~Hz}, 1 \mathrm{H}, \mathrm{CHH}-6), 2.42(\mathrm{dt}, J=3.3$ and $18.0 \mathrm{~Hz}, 1 \mathrm{H}, \mathrm{CH} H-6), 1.40$ (s, 3H, $\mathrm{CH}_{3}$ ), 1.33 (s, 3H, $\left.\mathrm{CH}_{3}\right), 0.89$ $\left(\mathrm{s}, 9 \mathrm{H}, \mathrm{C}\left(\mathrm{CH}_{3}\right)_{3}\right)$ and $0.04\left(\mathrm{~s}, 6 \mathrm{H}, 2 \times \mathrm{CH}_{3}\right) \mathrm{ppm} .{ }^{13} \mathrm{C} \mathrm{NMR}$ $\left(63 \mathrm{MHz}, \mathrm{CDCl}_{3}\right) \delta: 167.5(\mathrm{C}), 145.0(\mathrm{C}), 137.9(\mathrm{CH}), 137.7(\mathrm{CH})$, 126.3 (C), $115.2\left(\mathrm{CH}_{2}\right), 112.0\left(\mathrm{CH}_{2}\right), 109.2(\mathrm{C}), 80.2(\mathrm{C}), 77.3$ $(\mathrm{CH}), 73.3(\mathrm{CH}), 70.2\left(\mathrm{CH}_{2}\right), 63.9\left(\mathrm{CH}_{2}\right), 52.1\left(\mathrm{OCH}_{3}\right), 28.0$ $\left(\mathrm{CH}_{3}\right), 27.0\left(\mathrm{CH}_{3}\right), 26.0\left(\mathrm{C}\left(\mathrm{CH}_{3}\right)_{3}\right), 24.4\left(\mathrm{CH}_{2}\right), 18.5\left(\mathrm{C}\left(\mathrm{CH}_{3}\right)_{3}\right)$ and $-5.3\left(2 \times \mathrm{CH}_{3}\right)$ ppm. FTIR (film): 1716 (CO) $\mathrm{cm}^{-1}$. MS (ESI) $m / z=461\left(\mathrm{MNa}^{+}\right)$. HRMS calcd for $\mathrm{C}_{23} \mathrm{H}_{38} \mathrm{O}_{6} \mathrm{SiNa}\left(\mathrm{MNa}^{+}\right)$: 461.2330; found, 461.2330.

\section{General procedure for ring-closing metathesis of compounds} $6 a-g$ and $6 \mathrm{i}$

A solution of compounds $\mathbf{6 a}-\mathbf{g}$ and $\mathbf{6 i}(1 \mathrm{mmol})$ and $2^{\text {nd }}$ generation Grubbs' catalyst $(0.02 \mathrm{mmol})$ in dry toluene $(20 \mathrm{mM})$, under an inert atmosphere, was heated at $90{ }^{\circ} \mathrm{C}$ for $24-48 \mathrm{~h}$. After cooling to room temperature, the mixture was filtered over Celite ${ }^{\circledR}$ and the residue was washed with diethyl ether. The filtrate and the washings were concentrated under reduced pressure and purified by flash chromatography to yield the bicycles $24 \mathbf{a}-\mathbf{g}$ and $24 \mathbf{i}$.

Methyl (1R,6S,10S)-6,10-O-isopropylidenedioxy-4-methyl-2oxabicyclo[4.3.1] deca-4(Z),7-diene-8-carboxylate (24a, $\mathbf{R}=\mathbf{M e})$. It was prepared following the general RCM procedure using $\mathbf{6 a}$ (100 mg), $2^{\text {nd }}$ generation Grubbs' catalyst $(5.4 \mathrm{mg})$, toluene $(16 \mathrm{~mL})$. Reaction time $=24 \mathrm{~h}$. Eluent for chromatography $=$ (50:50) diethyl ether/hexane. Yield $=63 \%(57 \mathrm{mg})$. It was also recovered $18 \mathrm{mg}$ of starting material. Corrected yield $=77 \%$. Colorless oil. $[\alpha]_{\mathrm{D}}^{20}=+11.4^{\circ}\left(c\right.$ 1.1, $\left.\mathrm{CHCl}_{3}\right) \cdot{ }^{1} \mathrm{H}$ NMR $(300 \mathrm{MHz}$, $\left.\mathrm{CDCl}_{3}\right) \delta: 6.70(\mathrm{q}, J=1.7 \mathrm{~Hz}, 1 \mathrm{H}, \mathrm{H} 7), 5.68(\mathrm{t}, J=1.7 \mathrm{~Hz}, 1 \mathrm{H}$, H5), 4.50 (m, 1H, H1), 4.35 (dd, $J=5.0$ and $1.7 \mathrm{~Hz}, 1 \mathrm{H}, \mathrm{H} 10)$, 4.28 (br d, $J=16.8 \mathrm{~Hz}, 1 \mathrm{H}, \mathrm{OCHH}$ ), 3.97 (d, $J=16.8 \mathrm{~Hz}, 1 \mathrm{H}$, $\mathrm{OCH} H), 3.72\left(\mathrm{~s}, 3 \mathrm{H}, \mathrm{OCH}_{3}\right), 2.52\left(\mathrm{~m}, 2 \mathrm{H}, \mathrm{CH}_{2}-9\right), 1.66(\mathrm{~s}, 3 \mathrm{H}$, $\left.\mathrm{CH}_{3}\right), 1.39\left(\mathrm{~s}, 3 \mathrm{H}, \mathrm{CH}_{3}\right)$ and $1.31\left(\mathrm{~s}, 3 \mathrm{H}, \mathrm{CH}_{3}\right) \mathrm{ppm} .{ }^{13} \mathrm{C} \mathrm{NMR}$ $\left(75 \mathrm{MHz}, \mathrm{CDCl}_{3}\right.$ ) $\delta: 167.6(\mathrm{C}), 140.0(\mathrm{C}), 138.0(\mathrm{CH}), 125.2(\mathrm{C})$, $123.9(\mathrm{CH}), 110.1(\mathrm{C}), 79.8(\mathrm{C}), 75.0(\mathrm{CH}), 70.3(\mathrm{CH}), 68.0$ $\left(\mathrm{OCH}_{2}\right), 51.9\left(\mathrm{OCH}_{3}\right), 28.1\left(\mathrm{CH}_{3}\right), 27.3\left(\mathrm{CH}_{3}\right), 27.3\left(\mathrm{CH}_{2}\right)$ and $21.9\left(\mathrm{CH}_{3}\right)$ ppm. FTIR (film): 1798 (CO) $\mathrm{cm}^{-1}$. MS (ESI) $\mathrm{m} / z=$ $303\left(\mathrm{MNa}^{+}\right)$. HRMS calcd for $\mathrm{C}_{15} \mathrm{H}_{20} \mathrm{O}_{5} \mathrm{Na}\left(\mathrm{MNa}^{+}\right)$: 303.1203; found, 303.1202.

Methyl $(1 R, 6 S, 10 S)$-4-ethyl-6,10-O-isopropylidenedioxy-2-oxabiciclo[4.3.1]deca-4( $Z$ ),7-diene-8-carboxylate $(24 b, R=E t)$. It was prepared following the general RCM procedure using $\mathbf{6 b}$ (190 $\mathrm{mg}), 2^{\text {nd }}$ generation Grubbs' catalyst $(7 \mathrm{mg})$, toluene $(30 \mathrm{~mL})$. Eluent for chromatography $=(30: 70)$ diethyl ether/ hexane. Reaction time $=48 \mathrm{~h}$. Yield $=47 \%(82 \mathrm{mg})$. It was also 
recovered $95 \mathrm{mg}$ of starting material. Corrected yield $=97 \%$. Colorless oil. $[\alpha]_{\mathrm{D}}^{20}=+30.8^{\circ}\left(c\right.$ 1.0, $\left.\mathrm{CHCl}_{3}\right) \cdot{ }^{1} \mathrm{H}$ NMR $(300 \mathrm{MHz}$, $\left.\mathrm{CDCl}_{3}\right) \delta: 6.67$ (m, 1H, H7), 5.63 (m, 1H, H5), 4.46 (m, 1H, H1), 4.35-4.26 (m, 2H, H10 + OCHH-3), 3.99 (d, $J=16.6 \mathrm{~Hz}, 1 \mathrm{H}$, $\mathrm{OCH} H-3), 3.70\left(\mathrm{~m}, 3 \mathrm{H}, \mathrm{OCH}_{3}\right), 2.51\left(\mathrm{~m}, 2 \mathrm{H}, \mathrm{CH}_{2}-9\right), 1.93$ (q, $J=$ $\left.7.4 \mathrm{~Hz}, 2 \mathrm{H}, \mathrm{CH}_{2} \mathrm{CH}_{3}\right), 1.37\left(\mathrm{~s}, 3 \mathrm{H}, \mathrm{CH}_{3}\right), 1.30\left(\mathrm{~s}, 3 \mathrm{H}, \mathrm{CH}_{3}\right)$ and $0.98\left(\mathrm{t}, J=7.3 \mathrm{~Hz}, 3 \mathrm{H}, \mathrm{CH}_{2} \mathrm{CH}_{3}\right) \mathrm{ppm} .{ }^{13} \mathrm{C} \mathrm{NMR}(75 \mathrm{MHz}$, $\left.\mathrm{CDCl}_{3}\right) \delta: 167.5(\mathrm{C}), 145.4(\mathrm{C}), 138.0(\mathrm{CH}), 125.0(\mathrm{C}), 122.1$ $(\mathrm{CH}), 110.0(\mathrm{C}), 80.0(\mathrm{C}), 75.0(\mathrm{CH}), 70.2(\mathrm{CH}), 67.3\left(\mathrm{CH}_{2}\right), 51.9$ $\left(\mathrm{OCH}_{3}\right), 28.6\left(\mathrm{CH}_{2}\right), 28.1\left(\mathrm{CH}_{3}\right), 27.3\left(\mathrm{CH}_{3}\right), 27.2\left(\mathrm{CH}_{2}\right)$ and 12.0 $\left(\mathrm{CH}_{3}\right)$ ppm. FTIR (film): $1712(\mathrm{CO}) \mathrm{cm}^{-1}$. MS (ESI) $\mathrm{m} / z=317$ $\left(\mathrm{MNa}^{+}\right)$. HRMS calcd for $\mathrm{C}_{16} \mathrm{H}_{22} \mathrm{O}_{5} \mathrm{Na}\left(\mathrm{MNa}^{+}\right)$: 317.1359; found, 317.1359.

Methyl $\quad(1 R, 6 S, 10 S)$-6,10-O-isopropylidenedioxy-4-propyl-2oxabiciclo[4.3.1]deca-4(Z),7-diene-8-carboxylate (24c, $\mathrm{R}=n \mathrm{Pr})$. It was prepared following the general RCM procedure using $\mathbf{6 c}$ (162 $\mathrm{mg}), 2^{\text {nd }}$ generation Grubbs' catalyst $(6 \mathrm{mg})$, toluene $(24 \mathrm{~mL})$. Eluent for chromatography $=(20: 80)$ diethyl ether/ hexane. Reaction time $=48 \mathrm{~h}$. Yield $=63 \%$ (94 mg). It was also recovered $43 \mathrm{mg}$ of starting material. Corrected yield $=89 \%$. Colorless oil. $[\alpha]_{\mathrm{D}}^{20}=+32.0^{\circ}\left(c\right.$ 1.0, $\left.\mathrm{CHCl}_{3}\right) \cdot{ }^{1} \mathrm{H}$ NMR $(300 \mathrm{MHz}$, $\left.\mathrm{CDCl}_{3}\right) \delta: 6.69(\mathrm{~m}, 1 \mathrm{H}, \mathrm{H} 7), 5.67$ (m, 1H, H5), 4.48 (m, 1H, H1), $4.36(\mathrm{dd}, J=1.6$ and $6.6 \mathrm{~Hz}, 1 \mathrm{H}, \mathrm{H} 10), 4.29(\mathrm{dd}, J=1.9$ and 16.7 Hz, 1H, ОСНH-3), 4.01 (d, $J=16.7 \mathrm{~Hz}, 1 \mathrm{H}, \mathrm{OCH} H-3), 3.73$ $\left(\mathrm{m}, 3 \mathrm{H}, \mathrm{OCH}_{3}\right), 2.53\left(\mathrm{~m}, 2 \mathrm{H}, \mathrm{CH}_{2}-9\right), 1.92(\mathrm{t}, J=7.5 \mathrm{~Hz}, 2 \mathrm{H}$, $\mathrm{CH}_{2} \mathrm{CH}_{2} \mathrm{CH}_{3}$ ), 1.44-1.36 (m, 5H, $\left.\mathrm{CH}_{2} \mathrm{CH}_{2} \mathrm{CH}_{3}+\mathrm{CH}_{3}\right), 1.33$ (s, $\left.3 \mathrm{H}, \mathrm{CH}_{3}\right)$ and $0.88\left(\mathrm{t}, J=7.3 \mathrm{~Hz}, 3 \mathrm{H},\left(\mathrm{CH}_{2}\right)_{2} \mathrm{CH}_{3}\right) \mathrm{ppm}$. ${ }^{13} \mathrm{C}$ NMR (75 MHz, $\mathrm{CDCl}_{3}$ ) $\delta: 167.5(\mathrm{C}), 143.8(\mathrm{C}), 137.9(\mathrm{CH})$, $125.0(\mathrm{C}), 123.3(\mathrm{CH}), 110.0(\mathrm{C}), 79.9(\mathrm{C}), 74.9(\mathrm{CH}), 70.2(\mathrm{CH})$, $67.3\left(\mathrm{CH}_{2}\right), 51.9\left(\mathrm{OCH}_{3}\right), 38.0\left(\mathrm{CH}_{2}\right), 28.1\left(\mathrm{CH}_{3}\right), 27.2\left(\mathrm{CH}_{3}\right)$, $27.2\left(\mathrm{CH}_{2}\right), 20.8\left(\mathrm{CH}_{2}\right)$ and $13.8\left(\mathrm{CH}_{3}\right)$ ppm. FTIR (film): 1717 (CO) $\mathrm{cm}^{-1}$. MS (ESI) $\mathrm{m} / z=331\left(\mathrm{MNa}^{+}\right)$. HRMS calcd for $\mathrm{C}_{17} \mathrm{H}_{24} \mathrm{O}_{5} \mathrm{Na}\left(\mathrm{MNa}^{+}\right)$: 331.1516; found, 331.1513.

Methyl $(1 R, 6 S, 10 S)$-4-butyl-6,10-O-isopropylidenedioxy-2-oxabiciclo[4.3.1] deca-4(Z),7-diene-8-carboxylate (24d, $\mathrm{R}=n \mathrm{Bu})$. It was prepared following the general RCM procedure using $\mathbf{6 d}$ (110 $\mathrm{mg}), 2^{\text {nd }}$ generation Grubbs' catalyst $(4 \mathrm{mg})$, toluene $(16 \mathrm{~mL})$. Eluent for chromatography $=(15: 85)$ diethyl ether/ hexane. Reaction time $=24 \mathrm{~h}$. Yield $=54 \%$ (54 mg). Colorless oil. $[\alpha]_{\mathrm{D}}^{20}=37.5^{\circ}\left(c\right.$ 1.0, $\left.\mathrm{CHCl}_{3}\right) \cdot{ }^{1} \mathrm{H} \mathrm{NMR}\left(300 \mathrm{MHz}, \mathrm{CDCl}_{3}\right)$ $\delta: 6.68$ (m, 1H, H7), 5.65 (br s, 1H, H5), 4.47 (m, 1H, H1), 4.34 (dd, $J=1.7$ and $5.0 \mathrm{~Hz}, 1 \mathrm{H}, \mathrm{H} 10), 4.29(\mathrm{dd}, J=2.2$ and $16.7 \mathrm{~Hz}$, $1 \mathrm{H}, \mathrm{OCH}-3$ ), 4.00 (d, $J=16.7 \mathrm{~Hz}, 1 \mathrm{H}, \mathrm{OCH} H-3), 3.72(\mathrm{~m}, 3 \mathrm{H}$, $\left.\mathrm{OCH}_{3}\right), 2.52\left(\mathrm{~m}, 2 \mathrm{H}, \mathrm{CH}_{2}-9\right), 1.92(\mathrm{t}, J=6.9 \mathrm{~Hz}, 2 \mathrm{H}$, $\left.\mathrm{CH}_{2}\left(\mathrm{CH}_{2}\right)_{2} \mathrm{CH}_{3}\right), 1.38\left(\mathrm{~s}, 3 \mathrm{H}, \mathrm{CH}_{3}\right), \quad 1.36-1.21 \quad(\mathrm{~m}, 4 \mathrm{H}$, $\left.\mathrm{CH}_{2}\left(\mathrm{CH}_{2}\right)_{2} \mathrm{CH}_{3}\right), 1.31\left(\mathrm{~s}, 3 \mathrm{H}, \mathrm{CH}_{3}\right)$ and $0.87(\mathrm{t}, J=7.1 \mathrm{~Hz}, 3 \mathrm{H}$, $\left.\left(\mathrm{CH}_{2}\right)_{3} \mathrm{CH}_{3}\right)$ ppm. ${ }^{13} \mathrm{C} \mathrm{NMR}\left(75 \mathrm{MHz}, \mathrm{CDCl}_{3}\right) \delta: 167.6(\mathrm{C}), 144.1$ (C), 138.0 (CH), 125.0 (C), $123.1(\mathrm{CH}), 110.1$ (C), 79.9 (C), 75.0 (CH), $70.2(\mathrm{CH}), 67.4\left(\mathrm{CH}_{2}\right), 51.9\left(\mathrm{OCH}_{3}\right), 35.7\left(\mathrm{CH}_{2}\right), 29.8\left(\mathrm{CH}_{2}\right)$, $28.1\left(\mathrm{CH}_{3}\right), 27.3\left(\mathrm{CH}_{3}\right), 27.2\left(\mathrm{CH}_{2}\right), 22.5\left(\mathrm{CH}_{2}\right)$ and $14.0\left(\mathrm{CH}_{3}\right)$ ppm. FTIR (film): 1717 (CO) $\mathrm{cm}^{-1}$. MS (ESI) $\mathrm{m} / z=345\left(\mathrm{MNa}^{+}\right)$. HRMS calcd for $\mathrm{C}_{18} \mathrm{H}_{26} \mathrm{O}_{5} \mathrm{Na}\left(\mathrm{MNa}^{+}\right)$: 345.1672; found, 345.1670.

Methyl (1R,6S,10S)-4-cyclopropylmethyl-6,10-O-isopropylidenedioxy-2-oxabiciclo[4.3.1] deca-4(Z),7-diene-8-carboxylate (24e, $\mathbf{R}=\mathbf{C H}_{2} \boldsymbol{c P r}$ ). It was prepared following the general RCM procedure using $6 \mathrm{e}(105 \mathrm{mg}), 2^{\text {nd }}$ generation Grubbs' catalyst
(19 mg), toluene (15 mL). Eluent for chromatography $=(20: 80)$ diethyl ether/hexane. Reaction time $=48 \mathrm{~h}$. Yield $=45 \%$ (43 mg). It was also recovered $59 \mathrm{mg}$ of starting material. Corrected yield $=$ quant. Colorless oil. $[\alpha]_{\mathrm{D}}^{20}=+30.5^{\circ}(c$ 1.1, $\left.\mathrm{CHCl}_{3}\right) .{ }^{1} \mathrm{H}$ NMR (300 MHz, $\left.\mathrm{CDCl}_{3}\right) \delta: 6.69(\mathrm{~m}, 1 \mathrm{H}, \mathrm{H} 7), 5.82$ $(\mathrm{m}, 1 \mathrm{H}, \mathrm{H} 5), 4.48(\mathrm{~m}, 1 \mathrm{H}, \mathrm{H} 1), 4.38-4.30(\mathrm{~m}, 2 \mathrm{H}, \mathrm{H} 10+$ OCHH-3), 4.05 (d, $J=16.7 \mathrm{~Hz}, 1 \mathrm{H}, \mathrm{OCH} H-3), 3.72(\mathrm{~m}, 3 \mathrm{H}$, $\left.\mathrm{OCH}_{3}\right), 2.52\left(\mathrm{~m}, 2 \mathrm{H}, \mathrm{CH}_{2}-9\right), 1.90(\mathrm{dd}, J=6.4$ and $15.8 \mathrm{~Hz}, 1 \mathrm{H}$, $\mathrm{CHH}), 1.77(\mathrm{dd}, J=7.0$ and $15.9 \mathrm{~Hz}, 1 \mathrm{H}, \mathrm{CH}), 1.40(\mathrm{~s}, 3 \mathrm{H}$, $\mathrm{CH}_{3}$ ), 1.32 (s, 3H, $\left.\mathrm{CH}_{3}\right), 0.71\left(\mathrm{~m}, 1 \mathrm{H}, \mathrm{CH}_{2} \mathrm{CH}\left(\mathrm{CH}_{2}\right)_{2}\right), 0.50-0.45$ $\left(\mathrm{m}, 2 \mathrm{H}, \mathrm{CHCH}_{2} \mathrm{CH}_{2}\right.$ ) and 0.06-0.03 (m, 2H, $\left.\mathrm{CHCH}_{2} \mathrm{CH}_{2}\right) \mathrm{ppm}$. ${ }^{13} \mathrm{C}$ NMR (75 MHz, $\mathrm{CDCl}_{3}$ ) $\delta: 167.6(\mathrm{C}), 144.0(\mathrm{C}), 138.1(\mathrm{CH})$, $125.1(\mathrm{C}), 123.2(\mathrm{CH}), 110.1(\mathrm{C}), 80.0(\mathrm{C}), 75.0(\mathrm{CH}), 70.3(\mathrm{CH})$, $67.4\left(\mathrm{CH}_{2}\right), 52.0\left(\mathrm{OCH}_{3}\right), 40.5\left(\mathrm{CH}_{2}\right), 28.1\left(\mathrm{CH}_{3}\right), 27.3\left(\mathrm{CH}_{3}\right)$, $27.3\left(\mathrm{CH}_{3}\right), 9.0(\mathrm{CH}), 4.8\left(\mathrm{CH}_{2}\right)$ and $4.7\left(\mathrm{CH}_{2}\right)$ ppm. FTIR (film): 1718 (CO) $\mathrm{cm}^{-1}$. MS (ESI) $m / z=343\left(\mathrm{MNa}^{+}\right)$. HRMS calcd for $\mathrm{C}_{18} \mathrm{H}_{24} \mathrm{O}_{5} \mathrm{Na}\left(\mathrm{MNa}^{+}\right)$: 343.1516; found, 343.1524.

Methyl (1R,6S,10S)-4-(ethoxymethyl)-6,10-O-isopropylidenedioxy-2-oxabiciclo[4.3.1] deca-4(Z),7-diene-8-carboxylate (24f, $\mathbf{R}=\mathbf{C H}_{2} \mathbf{O E t}$ ). It was prepared following the general RCM procedure using 6 f $(251 \mathrm{mg}), 2^{\text {nd }}$ generation Grubbs' catalyst (9 $\mathrm{mg})$, toluene $(23 \mathrm{~mL})$. Reaction time $=48 \mathrm{~h}$. Eluent for chromatography $=(20: 80)$ diethyl ether $/$ hexane. Yield $=16 \%$ (36 mg). It was also recovered $156 \mathrm{mg}$ of starting material. Corrected yield $=78 \%$. Yellow oil. $[\alpha]_{\mathrm{D}}^{20}=+36.9^{\circ}\left(c\right.$ 1.0, $\left.\mathrm{CHCl}_{3}\right)$. ${ }^{1} \mathrm{H}$ NMR (300 MHz, $\left.\mathrm{CDCl}_{3}\right) \delta: 6.68(\mathrm{~m}, 1 \mathrm{H}, \mathrm{H} 7), 5.95(\mathrm{~m}, 1 \mathrm{H}$, H5), 4.51 (m, 1H, H1), 4.40 (dd, $J=1.4$ and $4.8 \mathrm{~Hz}, 1 \mathrm{H}, \mathrm{H} 10)$, $4.32(\mathrm{dd}, J=1.5$ and $16.7 \mathrm{~Hz}, 1 \mathrm{H}, \mathrm{OCH \textrm {H } - 3 ) ,} 4.16(\mathrm{~d}, J=$ $16.7 \mathrm{~Hz}, 1 \mathrm{H}, \mathrm{OCH} H-3$ ), 3.84 (sa, 2H, $\mathrm{CH}_{2} \mathrm{OEt}$ ), 3.74 (s, 3H, $\mathrm{OCH}_{3}$ ), 3.43 (q, $\left.J=7.0 \mathrm{~Hz}, 1 \mathrm{H}, \mathrm{OCH}_{2} \mathrm{CH}_{3}\right), 2.55$ (m, 2H, $\left.\mathrm{CH}_{2}-9\right)$, $1.40\left(\mathrm{~s}, 3 \mathrm{H}, \mathrm{CH}_{3}\right), 1.33\left(\mathrm{~s}, 3 \mathrm{H}, \mathrm{CH}_{3}\right)$ and $1.18(\mathrm{t}, J=7.0 \mathrm{~Hz}, 3 \mathrm{H}$, $\mathrm{CH}_{3}$ ) ppm. ${ }^{13} \mathrm{C}$ NMR (75 MHz, $\mathrm{CDCl}_{3}$ ) $\delta: 167.5$ (C), $140.6(\mathrm{C})$, $137.4(\mathrm{CH}), 125.9(\mathrm{CH}), 125.6(\mathrm{C}), 110.3(\mathrm{C}), 79.6(\mathrm{C}), 74.8(\mathrm{CH})$, $73.1\left(\mathrm{CH}_{2}\right), 70.3(\mathrm{CH}), 66.0\left(\mathrm{CH}_{2}\right), 65.0\left(\mathrm{CH}_{2}\right), 52.0\left(\mathrm{OCH}_{3}\right), 28.1$ $\left(\mathrm{CH}_{3}\right), 27.3\left(\mathrm{CH}_{3}\right), 27.2\left(\mathrm{CH}_{2}\right)$ and $15.2\left(\mathrm{CH}_{3}\right)$ ppm. FTIR (film): 1695 (CO) $\mathrm{cm}^{-1}$. MS (ESI) $m / z=347\left(\mathrm{MNa}^{+}\right)$. HRMS calcd for $\mathrm{C}_{17} \mathrm{H}_{24} \mathrm{O}_{6} \mathrm{Na}\left(\mathrm{MNa}^{+}\right)$: 347.1465; found, 347.1466.

\section{Preparation of $24 f$ from $24 i$}

A solution of the alcohol $24 \mathbf{i}(34 \mathrm{mg}, 0.10 \mathrm{mmol})$ in dry DMF $(0.2 \mathrm{~mL})$, at $0{ }^{\circ} \mathrm{C}$ and under argon, was treated with $\mathrm{NaH}$ (6.6 mg, $0.17 \mathrm{mmol}, \mathrm{ca} .60 \% \mathrm{w} / \mathrm{w}$ in mineral oil). After $30 \mathrm{~min}$ stirring, bromoethane $(20 \mu \mathrm{L}, 0.17 \mathrm{mmol})$ was added, the ice bath was removed and the reaction mixture was stirred for $3 \mathrm{~h}$ at room temperature. The reaction mixture was diluted with a mixture of $(4: 1)$ water/ethyl acetate, the organic layer was separated and the aqueous layer was extracted with ethyl acetate keeping the same proportion. The combined organic extracts were dried (anh. $\mathrm{Na}_{2} \mathrm{SO}_{4}$ ), filtered and concentrated under reduced pressure. The resulting residue was purified by flash chromatography, eluting with $(50: 50)$ ethyl acetate/hexane, to give compound $24 \mathrm{f}$ (12 $\mathrm{mg}, 31 \%$ ). It was also recovered $4 \mathrm{mg}$ of starting material. Corrected yield $=57 \%$.

Methyl $(1 R, 6 S, 10 S)$-4-(benzyloxymethyl)-6,10-O-isopropylidenedioxy-2-oxabiciclo[4.3.1] deca-4( $Z$ ),7-diene-8-carboxylate (24g, $\left.\mathbf{R}=\mathrm{CH}_{2} \mathrm{OBn}\right)$. It was prepared following the general RCM 
procedure using $6 \mathbf{g}(202 \mathrm{mg}), 2^{\text {nd }}$ generation Grubbs' catalyst (7 mg), toluene $(27 \mathrm{~mL})$. Reaction time $=48 \mathrm{~h}$. Eluent for chromatography $=(20: 80)$ diethyl ether/hexane. Yield $=26 \%$ (53 mg). It was also recovered $138 \mathrm{mg}$ of starting material. Corrected yield $=94 \%$. Yellow oil. $[\alpha]_{\mathrm{D}}^{20}=+22.3^{\circ}\left(c 1.0, \mathrm{CHCl}_{3}\right)$. ${ }^{1} \mathrm{H}$ NMR (300 MHz, $\mathrm{CDCl}_{3}$ ) $\delta: 7.37-7.26(\mathrm{~m}, 5 \mathrm{H}, 5 \times \mathrm{ArH}), 6.69$ (m, 1H, H7), 5.98 (br s, 1H, H5), 4.51 (m, 1H, H1), 4.46 (s, 2H, $\mathrm{CH}_{2} \mathrm{Ph}$ ), 4.39 (dd, $J=1.5$ and $\left.4.8 \mathrm{~Hz}, 1 \mathrm{H}, \mathrm{H} 10\right), 4.33$ (dd, $J=1.4$ and $16.8 \mathrm{~Hz}, 1 \mathrm{H}, \mathrm{OCHH}-3), 4.18$ (d, $J=16.8 \mathrm{~Hz}, 1 \mathrm{H}, \mathrm{OCH} H-3$ ), 3.89 (sa, $\left.2 \mathrm{H}, \mathrm{CH}_{2} \mathrm{OBn}\right), 3.74\left(\mathrm{~s}, 3 \mathrm{H}, \mathrm{OCH}_{3}\right), 2.55\left(\mathrm{~m}, 2 \mathrm{H}, \mathrm{CH}_{2}-\right.$ 9), $1.41\left(\mathrm{~s}, 3 \mathrm{H}, \mathrm{CH}_{3}\right)$ and $1.34\left(\mathrm{~s}, 3 \mathrm{H}, \mathrm{CH}_{3}\right) \mathrm{ppm} .{ }^{13} \mathrm{C} \mathrm{NMR}$ $\left(75 \mathrm{MHz}, \mathrm{CDCl}_{3}\right) \delta: 167.5(\mathrm{C}), 140.4(\mathrm{C}), 137.9(\mathrm{C}), 137.3(\mathrm{CH})$, $128.6(2 \times \mathrm{CH}), 127.9(3 \times \mathrm{CH}), 126.5(\mathrm{CH}), 125.7(\mathrm{C}), 110.3(\mathrm{C})$, $79.6(\mathrm{C}), 74.8(\mathrm{CH}), 72.6\left(\mathrm{CH}_{2}\right), 72.5\left(\mathrm{CH}_{2}\right), 70.3(\mathrm{CH}), 65.1$ $\left(\mathrm{CH}_{2}\right), 52.0\left(\mathrm{OCH}_{3}\right), 28.1\left(\mathrm{CH}_{3}\right), 27.3\left(\mathrm{CH}_{3}\right)$ and $27.2\left(\mathrm{CH}_{2}\right)$ ppm. FTIR (film): 1716 (CO) $\mathrm{cm}^{-1}$. MS (ESI) $\mathrm{m} / z=409\left(\mathrm{MNa}^{+}\right)$. HRMS calcd for $\mathrm{C}_{22} \mathrm{H}_{26} \mathrm{O}_{6} \mathrm{Na}\left(\mathrm{MNa}^{+}\right)$: 409.1622; found, 409.1619.

\section{Preparation of $24 \mathrm{~g}$ from $24 \mathrm{i}$}

A solution of the alcohol $24 \mathbf{i}(31 \mathrm{mg}, 0.10 \mathrm{mmol})$ in dry THF $(0.3 \mathrm{~mL})$, at $0{ }^{\circ} \mathrm{C}$ and under argon, was treated with $\mathrm{NaH}$ ( $6 \mathrm{mg}, 0.15 \mathrm{mmol}, \mathrm{ca} .60 \% \mathrm{w} / \mathrm{w}$ in mineral oil). After $30 \mathrm{~min}$ stirring, benzyl bromide $(20 \mu \mathrm{L}, 0.15 \mathrm{mmol})$ was added, the ice bath was removed and the reaction mixture was stirred for $3 \mathrm{~h}$ at room temperature. Saturated $\mathrm{NH}_{4} \mathrm{Cl}$ was added, the organic solvent was removed under reduced pressure and the aqueous solution was extracted with ethyl acetate $(\times 3)$. The combined organic extracts were dried (anh. $\mathrm{Na}_{2} \mathrm{SO}_{4}$ ), filtered and concentrated under reduced pressure. The resulting residue was purified by flash chromatography, eluting with (25:75) ethyl acetate/hexane, to give compound $\mathbf{2 4 g}$ ( $25 \mathrm{mg}, 64 \%$ ).

Methyl (1R,6S,10S)-4-((tert-butyldimethylsilyloxy)methyl)6,10-O-isopropylidenedioxy-2-oxabiciclo[4.3.1] deca-4(Z),7-diene-8carboxylate (24i, $\mathbf{R}=\mathbf{C H}_{2} \mathbf{O T B S}$ ). It was prepared following the general RCM procedure using $6 \mathbf{i}(133 \mathrm{mg}), 2^{\text {nd }}$ generation Grubbs' catalyst (9 mg), toluene $(15 \mathrm{~mL})$. Reaction time $=48 \mathrm{~h}$. Eluent for chromatography $=(20: 80)$ diethyl ether/hexane. Yield $=42 \%$ (52 mg). Colorless oil. $[\alpha]_{\mathrm{D}}^{20}=+33.9^{\circ}\left(c 1.0, \mathrm{CHCl}_{3}\right)$. ${ }^{1} \mathrm{H}$ NMR (300 MHz, $\left.\mathrm{CDCl}_{3}\right) \delta: 6.68(\mathrm{~m}, 1 \mathrm{H}, \mathrm{H} 7), 5.92(\mathrm{~m}, 1 \mathrm{H}$, H5), 4.51 (m, 1H, H1), 4.39 (dd, $J=1.6$ and $4.8 \mathrm{~Hz}, 1 \mathrm{H}, \mathrm{H} 10$ ), $4.28(\mathrm{dd}, J=1.4$ and $16.7 \mathrm{~Hz}, 1 \mathrm{H}, \mathrm{OCHH}-3), 4.08(\mathrm{~d}, J=$ $16.7 \mathrm{~Hz}, 1 \mathrm{H}, \mathrm{OCH} H-3), 4.01\left(\mathrm{dd}, J=1.3\right.$ and $4.6 \mathrm{~Hz}, 2 \mathrm{H}, \mathrm{CH}_{2}$ ), $3.73\left(\mathrm{~s}, 3 \mathrm{H}, \mathrm{OCH}_{3}\right), 2.54\left(\mathrm{~m}, 2 \mathrm{H}, \mathrm{CH}_{2}-9\right), 1.40\left(\mathrm{~s}, 3 \mathrm{H}, \mathrm{CH}_{3}\right), 1.33$ $\left(\mathrm{s}, 3 \mathrm{H}, \mathrm{CH}_{3}\right), 0.89\left(\mathrm{~s}, 9 \mathrm{H}, \mathrm{C}\left(\mathrm{CH}_{3}\right)_{3}\right), 0.05\left(\mathrm{~s}, 3 \mathrm{H}, \mathrm{CH}_{3}\right)$ and 0.05 $\left(\mathrm{s}, 3 \mathrm{H}, \mathrm{CH}_{3}\right) \mathrm{ppm} .{ }^{13} \mathrm{C} \mathrm{NMR}\left(75 \mathrm{MHz}, \mathrm{CDCl}_{3}\right) \delta: 167.5(\mathrm{C})$, 142.7 (C), $137.6(\mathrm{CH}), 125.4(\mathrm{C}), 123.3(\mathrm{CH}), 110.2$ (C), $79.8(\mathrm{C})$, $74.9(\mathrm{CH}), 70.3(\mathrm{CH}), 65.3\left(\mathrm{CH}_{2}\right), 64.7\left(\mathrm{CH}_{2}\right), 52.0\left(\mathrm{OCH}_{3}\right), 28.1$ $\left(\mathrm{CH}_{3}\right), 27.2\left(\mathrm{CH}_{3}\right), 27.2\left(\mathrm{CH}_{2}\right), 26.0\left(\mathrm{C}\left(\mathrm{CH}_{3}\right)_{3}\right), 18.5\left(\mathrm{C}\left(\mathrm{CH}_{3}\right)_{3}\right)$, $-5.2\left(\mathrm{CH}_{3}\right)$ and $-5.2\left(\mathrm{CH}_{3}\right)$ ppm. FTIR (film): $1716(\mathrm{CO}) \mathrm{cm}^{-1}$. MS (ESI) $m / z=433\left(\mathrm{MNa}^{+}\right)$. HRMS calcd for $\mathrm{C}_{21} \mathrm{H}_{34} \mathrm{O}_{6} \mathrm{SiNa}$ $\left(\mathrm{MNa}^{+}\right)$: 433.2017; found, 433.2013.

Methyl (1R,6S,10S)-4-(hydroxymethyl)-6,10-O-isopropylidenedioxy-2-oxabiciclo[4.3.1] deca-4(Z),7-diene-8-carboxylate (24h, $\left.\mathbf{R}=\mathbf{C H}_{2} \mathbf{O H}\right)$. A solution of silyl ether $24 \mathbf{i}$ (53 mg, $0.13 \mathrm{mmol})$ in dry THF $(1.3 \mathrm{~mL})$, at $0{ }^{\circ} \mathrm{C}$ and under inert atmo- sphere, was treated with TBAF $(0.5 \mathrm{~mL}, c a .1 \mathrm{M}$ in THF). The reaction mixture was stirred for $50 \mathrm{~min}$ and then diluted with ethyl acetate. The organic solution was washed with water $(\times 2)$, $\mathrm{NaHCO}_{3}$ (sat) ( $\times 2$ ), dried (anh. $\mathrm{Na}_{2} \mathrm{SO}_{4}$ ), filtered and concentrated under reduced pressure. The resulting residue was purified by flash chromatography, eluting with (50:50) diethyl ether/hexane, to give the alcohol $24 \mathbf{h}(31 \mathrm{mg}, 81 \%)$ as a colorless oil. $[\alpha]_{\mathrm{D}}^{20}=+37.1^{\circ}$ (c 1.0, $\mathrm{CHCl}_{3}$ ). ${ }^{1} \mathrm{H}$ NMR $(300 \mathrm{MHz}$, $\left.\mathrm{CDCl}_{3}\right) \delta: 6.68(\mathrm{~d}, J=1.0 \mathrm{~Hz}, 1 \mathrm{H}, \mathrm{H} 7), 5.97$ (br s, 1H, H5), 4.52 (m, 1H, H1), 4.40-4.32 (m, 2H, H10 + OCHH-3), 4.18 (d, $J=$ $16.7 \mathrm{~Hz}, 1 \mathrm{H}, \mathrm{OCH} H), 4.02\left(\mathrm{t}, J=4.3 \mathrm{~Hz}, 2 \mathrm{H}, \mathrm{CH}_{2}\right), 3.74(\mathrm{~s}, 3 \mathrm{H}$, $\left.\mathrm{OCH}_{3}\right), 2.55\left(\mathrm{~m}, 2 \mathrm{H}, \mathrm{CH}_{2}-9\right), 1.40\left(\mathrm{~s}, 3 \mathrm{H}, \mathrm{CH}_{3}\right)$ and $1.34(\mathrm{~s}, 3 \mathrm{H}$, $\mathrm{CH}_{3}$ ) ppm. ${ }^{13} \mathrm{C} \mathrm{NMR}\left(75 \mathrm{MHz}, \mathrm{CDCl}_{3}\right) \delta: 167.3$ (C), 142.9 (C), $137.2(\mathrm{CH}), 125.5(\mathrm{C}), 124.4(\mathrm{CH}), 110.2(\mathrm{C}), 79.5(\mathrm{C}), 74.6(\mathrm{CH})$, $70.2(\mathrm{CH}), 65.0\left(\mathrm{CH}_{2}\right), 64.5\left(\mathrm{CH}_{2}\right), 51.9\left(\mathrm{CH}_{3}\right), 28.0\left(\mathrm{CH}_{3}\right), 27.1$ $\left(\mathrm{CH}_{3}\right)$ and $27.0\left(\mathrm{CH}_{2}\right)$ ppm. FTIR (film): $3441(\mathrm{OH})$ and 1709 (CO) $\mathrm{cm}^{-1}$. MS (ESI) $\mathrm{m} / z=319\left(\mathrm{MNa}^{+}\right)$. HRMS calcd for $\mathrm{C}_{15} \mathrm{H}_{20} \mathrm{O}_{6} \mathrm{Na}\left(\mathrm{MNa}^{+}\right)$: 319.1152; found, 319.1152.

\section{General procedure for the acetal deprotection in $24 a-h$}

A solution of the acetals $24 \mathbf{a}-\mathbf{h}(1 \mathrm{mmol})$ in methanol $(7 \mathrm{~mL})$ and aqueous $\mathrm{HCl}(8.6 \mathrm{~mL}, 6 \mathrm{M})$ was heated at $60^{\circ} \mathrm{C}$ for $6 \mathrm{~h}$. The mixture was cooled and concentrated under reduced pressure. The residue was purified by flash chromatography to yield the diols $25 \mathbf{a}-\mathbf{h}$.

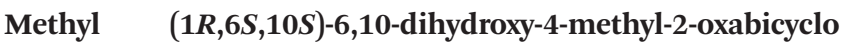
[4.3.1] deca-4 $(Z), 7$-diene-8-carboxylate $(25 \mathrm{a}, \mathrm{R}=\mathrm{Me})$. It was prepared following the general deprotection procedure using 24a (39 mg), $\mathrm{HCl}(0.2 \mathrm{~mL})$ and methanol $(1 \mathrm{~mL})$. Eluent for chromatography $=(50: 50)$ ethyl acetate $/$ hexane. Yield $=88 \%(30 \mathrm{mg})$. Colorless oil. $[\alpha]_{\mathrm{D}}^{20}=-86.6^{\circ}\left(c 3.0, \mathrm{CH}_{3} \mathrm{OH}\right) .{ }^{1} \mathrm{H}$ NMR $(300 \mathrm{MHz}$, $\left.\mathrm{CD}_{3} \mathrm{OD}\right) \delta: 6.64(\mathrm{~m}, 1 \mathrm{H}, \mathrm{H} 7), 5.46(\mathrm{~m}, 1 \mathrm{H}, \mathrm{H} 5), 4.25(\mathrm{~m}, 2 \mathrm{H}$, $\mathrm{H} 1+\mathrm{OCHH}), 4.12(\mathrm{dd}, J=4.9$ and $1.6 \mathrm{~Hz}, 1 \mathrm{H}, \mathrm{H} 10), 3.85$ (d, $J=$ $16.5 \mathrm{~Hz}, 1 \mathrm{H}, \mathrm{OCH} H$ ), 2.59 (dt, $J=17.9$ and $2.9 \mathrm{~Hz}, 1 \mathrm{H}, \mathrm{CHH}-9$ ), $2.28(\mathrm{dd}, J=17.9$ and $2.3 \mathrm{~Hz}, 1 \mathrm{H}, \mathrm{CH} H-9)$ and $1.68\left(\mathrm{~s}, 3 \mathrm{H}, \mathrm{CH}_{3}\right)$ ppm. ${ }^{13} \mathrm{C}$ NMR (75 MHz, CD 3 OD) $\delta: 168.3(\mathrm{C}), 144.0(\mathrm{CH})$, $140.2(\mathrm{C}), 139.9(\mathrm{CH}), 129.4(\mathrm{C}), 128.7(\mathrm{CH}), 75.4(\mathrm{CH}), 72.6(\mathrm{C})$, $70.6(\mathrm{CH}), 67.5\left(\mathrm{CH}_{2}\right), 28.3\left(\mathrm{CH}_{2}\right)$ and $22.2\left(\mathrm{CH}_{3}\right)$ ppm. FTIR (ATR): $3416(\mathrm{OH})$ and $1698(\mathrm{CO}) \mathrm{cm}^{-1}$. MS (ESI) $\mathrm{m} / z=263$ $\left(\mathrm{MNa}^{+}\right)$. HRMS calcd for $\mathrm{C}_{12} \mathrm{H}_{16} \mathrm{O}_{5} \mathrm{Na}\left(\mathrm{MNa}^{+}\right)$: 263.0890; found, 263.0881.

Methyl (1R,6S,10S)-4-ethyl-6,10-dihydroxy-2-oxabicyclo[4.3.1] deca-4(Z),7-diene-8-carboxylate $(25 \mathrm{~b}, \mathbf{R}=\mathbf{E t})$. It was prepared following the general deprotection procedure using $\mathbf{2 4 b}$ (128 mg), HCl $(0.7 \mathrm{~mL})$ and methanol $(2.9 \mathrm{~mL})$. Eluent for chromatography = ethyl acetate. Yield $=91 \%$ (99 mg). Colorless oil. ${ }^{1} \mathrm{H}$ NMR (300 MHz, $\mathrm{CDCl}_{3}$ ) $\delta: 6.69$ (m, 1H, H7), 5.47 (dd, $J=1.6$ and $3.5 \mathrm{~Hz}, 1 \mathrm{H}, \mathrm{H} 5$ ), 4.33 (quint, $J=2.6 \mathrm{~Hz}, 1 \mathrm{H}, \mathrm{H} 1$ ), 4.21-4.15 (m, 2H, H10 + OCHH-3), 3.92 (d, $J=16.4 \mathrm{~Hz}, 1 \mathrm{H}$, $\mathrm{OCH}-3$ ), 3.72 (s, 3H, $\mathrm{OCH}_{3}$ ), 3.00 (br s, $\left.2 \mathrm{H}, 2 \times \mathrm{OH}\right), 2.61$ (td, $J=2.9$ and $18.3 \mathrm{~Hz}, 1 \mathrm{H}, \mathrm{CH}-9), 2.40(\mathrm{dd}, J=2.0$ and $18.3 \mathrm{~Hz}$, $1 \mathrm{H}, \mathrm{CH} H-9$ ), 1.97 (qd, $J=1.2$ and $7.4 \mathrm{~Hz}, 2 \mathrm{H}, \mathrm{CH}_{2} \mathrm{CH}_{3}$ ) and $0.98\left(\mathrm{t}, J=7.4 \mathrm{~Hz}, 3 \mathrm{H}, \mathrm{CH}_{3}\right)$ ppm. ${ }^{13} \mathrm{C} \mathrm{NMR}\left(63 \mathrm{MHz}, \mathrm{CDCl}_{3}\right.$ ) $\delta: 167.8(\mathrm{C}), 145.3(\mathrm{C}), 138.8(\mathrm{CH}), 127.4(\mathrm{C}), 125.7(\mathrm{CH}), 73.3$ $(\mathrm{CH}), 72.0(\mathrm{C}), 69.8(\mathrm{CH}), 66.3\left(\mathrm{CH}_{2}\right), 52.1\left(\mathrm{OCH}_{3}\right), 29.0\left(\mathrm{CH}_{2}\right)$, $27.2\left(\mathrm{CH}_{2}\right)$ and $12.2\left(\mathrm{CH}_{3}\right)$ ppm. FTIR (film): $3395(\mathrm{OH})$ and 
1701 (CO) $\mathrm{cm}^{-1}$. MS (ESI) $m / z=277\left(\mathrm{MNa}^{+}\right)$. HRMS calcd for $\mathrm{C}_{13} \mathrm{H}_{18} \mathrm{O}_{5} \mathrm{Na}\left(\mathrm{MNa}^{+}\right): 277.1046$; found, 277.1044.

Methyl (1R,6S,10S)-6,10-dihydroxy-4-propyl-2-oxabicyclo [4.3.1] deca-4 $(Z), 7$-diene-8-carboxylate $(25 \mathrm{c}, \mathrm{R}=\boldsymbol{n P r})$. It was prepared following the general deprotection procedure using $24 \mathrm{c}$ (122 $\mathrm{mg})$, HCl $(0.7 \mathrm{~mL})$ and methanol $(2.6 \mathrm{~mL})$. Reaction time $=18 \mathrm{~h}$. Eluent for chromatography $=(80: 20)$ diethyl ether/hexane. Yield $=80 \%$ (87 mg). Colorless oil. $[\alpha]_{\mathrm{D}}^{20}=-48.1^{\circ}$ (c 1.0, $\mathrm{CHCl}_{3}$ ). ${ }^{1} \mathrm{H}$ NMR (300 $\left.\mathrm{MHz}, \mathrm{CDCl}_{3}\right) \delta: 6.69$ (br s, $1 \mathrm{H}$, H7), 5.48 (d, $J=1.4 \mathrm{~Hz}, 1 \mathrm{H}, \mathrm{H} 5), 4.32$ (m, 1H, H1), 4.20-4.14 (m, 2H, H10 + OCHH-3), 3.93 (d, $J=16.4 \mathrm{~Hz}, 1 \mathrm{H}, \mathrm{OCH} H-3)$, $3.72\left(\mathrm{~m}, 3 \mathrm{H}, \mathrm{OCH}_{3}\right), 3.07$ (br s, $\left.2 \mathrm{H}, 2 \times \mathrm{OH}\right), 2.61(\mathrm{dt}, J=2.9$ and $18.3 \mathrm{~Hz}, 1 \mathrm{H}, \mathrm{CHH}-9), 2.40$ (dd, $J=1.7$ and $18.2 \mathrm{~Hz}, 1 \mathrm{H}$, $\mathrm{CH} H-9), 1.93\left(\mathrm{t}, J=7.4 \mathrm{~Hz}, 2 \mathrm{H}, \mathrm{CH}_{2} \mathrm{CH}_{2} \mathrm{CH}_{3}\right), 1.38(\mathrm{~m}, 2 \mathrm{H}$, $\left.\mathrm{CH}_{2} \mathrm{CH}_{2} \mathrm{CH}_{3}\right)$ and $0.87\left(\mathrm{t}, J=7.3 \mathrm{~Hz}, 3 \mathrm{H},\left(\mathrm{CH}_{2}\right)_{2} \mathrm{CH}_{3}\right) \mathrm{ppm} .{ }^{13} \mathrm{C}$ NMR (75 MHz, $\mathrm{CDCl}_{3}$ ) $\delta: 167.8(\mathrm{C}), 143.6(\mathrm{C}), 138.8(\mathrm{CH}), 127.3$ (C), $127.0(\mathrm{CH}), 73.3(\mathrm{CH}), 72.0(\mathrm{C}), 69.7(\mathrm{CH}), 66.2\left(\mathrm{CH}_{2}\right), 52.0$ $\left(\mathrm{OCH}_{3}\right), 38.6\left(\mathrm{CH}_{2}\right), 27.2\left(\mathrm{CH}_{2}\right), 21.0\left(\mathrm{CH}_{2}\right)$ and $13.8\left(\mathrm{CH}_{3}\right)$ ppm. FTIR (film): $3412(\mathrm{OH})$ and $1700(\mathrm{CO}) \mathrm{cm}^{-1}$. MS (ESI) $m / z=291\left(\mathrm{MNa}^{+}\right)$. HRMS calcd for $\mathrm{C}_{14} \mathrm{H}_{20} \mathrm{O}_{5} \mathrm{Na}\left(\mathrm{MNa}^{+}\right)$: 291.1203; found, 291.1202.

Methyl $(1 R, 6 S, 10 S)-4-b u t y l-6,10-d i h y d r o x y-2-o x a b i c y c l o[4.3 .1]$ deca-4(Z),7-diene-8-carboxylate $(25 \mathrm{~d}, \mathrm{R}=\boldsymbol{n B u})$. It was prepared following the general deprotection procedure using 24d $(124 \mathrm{mg}), \mathrm{HCl}(0.7 \mathrm{~mL})$ and methanol $(3 \mathrm{~mL})$. Reaction time $=$ 6 h. Eluent for chromatography $=(90: 10)$ diethyl ether/ hexane. Yield $=89 \%$ (95 mg). Colorless oil. $[\alpha]_{\mathrm{D}}^{20}=-42.3^{\circ}$ (c 1.0, $\left.\mathrm{CH}_{3} \mathrm{OH}\right) .{ }^{1} \mathrm{H}$ NMR $\left(300 \mathrm{MHz}, \mathrm{CD}_{3} \mathrm{OD}\right) \delta: 6.68$ (br s, $1 \mathrm{H}$, H7), 5.48 (br s, 1H, H5), 4.31-4.26 (m, 2H, H1 + OCHH-3), 4.16 (br d, $J=4.8 \mathrm{~Hz}, 1 \mathrm{H}, \mathrm{H} 10$ ), 3.94 (d, $J=16.3 \mathrm{~Hz}, 1 \mathrm{H}, \mathrm{OCH} H-3$ ), $3.77\left(\mathrm{~s}, 3 \mathrm{H}, \mathrm{OCH}_{3}\right), 2.63(\mathrm{td}, J=2.8$ and $18.0 \mathrm{~Hz}, 1 \mathrm{H}, \mathrm{CH}-9)$, 2.32 (br d, $J=18.5 \mathrm{~Hz}, 1 \mathrm{H}, \mathrm{CH} H-9$ ), 2.02 (t, $J=6.5 \mathrm{~Hz}, 2 \mathrm{H}$, $\left.\mathrm{CH}_{2}\left(\mathrm{CH}_{2}\right)_{2} \mathrm{CH}_{3}\right), 1.44-1.34\left(\mathrm{~m}, 4 \mathrm{H}, \mathrm{CH}_{2}\left(\mathrm{CH}_{2}\right)_{2} \mathrm{CH}_{3}\right)$ and $0.95(\mathrm{t}$, $\left.J=6.8 \mathrm{~Hz}, 3 \mathrm{H},\left(\mathrm{CH}_{2}\right)_{3} \mathrm{CH}_{3}\right)$ ppm. ${ }^{13} \mathrm{C} \mathrm{NMR}\left(75 \mathrm{MHz}, \mathrm{CD}_{3} \mathrm{OD}\right)$ $\delta: 169.2(\mathrm{C}), 144.1(\mathrm{C}), 140.9(\mathrm{CH}), 128.9(\mathrm{CH}), 127.8(\mathrm{C}), 75.1$ $(\mathrm{CH}), 72.5(\mathrm{C}), 70.5(\mathrm{CH}), 66.8\left(\mathrm{CH}_{2}\right), 52.3\left(\mathrm{OCH}_{3}\right), 37.2\left(\mathrm{CH}_{2}\right)$, $31.1\left(\mathrm{CH}_{2}\right), 28.2\left(\mathrm{CH}_{2}\right), 23.3\left(\mathrm{CH}_{2}\right)$ and $14.3\left(\mathrm{CH}_{3}\right)$ ppm. FTIR (film): $3419(\mathrm{OH})$ and $1710(\mathrm{CO}) \mathrm{cm}^{-1}$. MS (ESI) $\mathrm{m} / z=305$ $\left(\mathrm{MNa}^{+}\right)$. HRMS calcd for $\mathrm{C}_{15} \mathrm{H}_{22} \mathrm{O}_{5} \mathrm{Na}\left(\mathrm{MNa}^{+}\right)$: 305.1359; found, 305.1357.

Methyl $(1 R, 6 S, 10 S)$-4-cyclopropylmethyl-6,10-dihydroxy-2oxabicyclo[4.3.1] deca-4 $(Z), 7$-diene-8-carboxylate $(25 \mathrm{e}, \quad \mathbf{R}=$ $\mathbf{C H}_{2} \boldsymbol{c P r}$ ). It was prepared following the general deprotection procedure using 24e (160 mg), $\mathrm{HCl}(0.8 \mathrm{~mL})$ and methanol $(3.3 \mathrm{~mL})$. Reaction time $=18 \mathrm{~h}$. Eluent for chromatography $=$ (90:10) diethyl ether/hexane. Yield $=76 \%$ (107 mg). White solid. $[\alpha]_{\mathrm{D}}^{20}=-44.4^{\circ}\left(c\right.$ 1.0, $\left.\mathrm{CHCl}_{3}\right) \cdot \mathrm{Mp}: 128.2-128.7{ }^{\circ} \mathrm{C} .{ }^{1} \mathrm{H}$ NMR (300 MHz, $\left.\mathrm{CDCl}_{3}\right) \delta: 6.74(\mathrm{~m}, 1 \mathrm{H}, \mathrm{H} 7), 5.66(\mathrm{~m}, 1 \mathrm{H}, \mathrm{H} 5)$, 4.38 (m, 1H, H1), 4.28-4.22 (m, 2H, OCHH-3 + H10), 4.01 (d, $J=16.4 \mathrm{~Hz}, 1 \mathrm{H}, \mathrm{OCH} H-3), 3.74\left(\mathrm{~s}, 3 \mathrm{H}, \mathrm{OCH}_{3}\right), 2.65(\mathrm{dt}, J=3.0$ and $18.3 \mathrm{~Hz}, 1 \mathrm{H}, \mathrm{CHH}-9), 2.45$ (dd, $J=2.1$ and $18.3 \mathrm{~Hz}, 1 \mathrm{H}$, $\mathrm{CH} H-9), 1.88\left(\mathrm{~m}, 2 \mathrm{H}, \mathrm{CH}_{2}\right), 0.78-0.65\left(\mathrm{~m}, 1 \mathrm{H}, \mathrm{CH}_{2} \mathrm{CH}\left(\mathrm{CH}_{2}\right)_{2}\right)$, 0.52-0.46 (m, 2H, $\left.\mathrm{CHCH}_{2} \mathrm{CH}_{2}\right), 0.07$ (dd, $J=1.3$ and $5.0 \mathrm{~Hz}$, $1 \mathrm{H}, \mathrm{CHCH}_{2} \mathrm{CHH}$ ) and $0.04(\mathrm{dd}, J=1.4$ and $4.7 \mathrm{~Hz}, 1 \mathrm{H}$, $\mathrm{CHCH}_{2} \mathrm{CH} H$ ) ppm. ${ }^{13} \mathrm{C} \mathrm{NMR}\left(75 \mathrm{MHz}, \mathrm{CDCl}_{3}\right.$ ) $\delta: 167.8$ (C), $143.7(\mathrm{C}), 138.8(\mathrm{CH}), 127.3(\mathrm{C}), 126.8(\mathrm{CH}), 73.3(\mathrm{CH}), 72.0(\mathrm{C})$,
$69.7(\mathrm{CH}), 66.3\left(\mathrm{CH}_{2}\right), 52.0\left(\mathrm{OCH}_{3}\right), 41.0\left(\mathrm{CH}_{2}\right), 27.2\left(\mathrm{CH}_{2}\right), 9.1$ $(\mathrm{CH}), 4.8\left(\mathrm{CH}_{2}\right)$ and $4.7\left(\mathrm{CH}_{2}\right)$ ppm. FTIR (film): $3393(\mathrm{OH})$ and 1685 (CO) $\mathrm{cm}^{-1}$. MS (ESI) $m / z=303\left(\mathrm{MNa}^{+}\right)$. HRMS calcd for $\mathrm{C}_{15} \mathrm{H}_{20} \mathrm{O}_{5} \mathrm{Na}\left(\mathrm{MNa}^{+}\right)$: 303.1203; found, 303.1200.

Methyl $(1 R, 6 S, 10 S)$-4-ethoxymethyl-6,10-dihydroxy-2-oxabicyclo[4.3.1]deca-4( $Z$ ),7-diene-8-carboxylate (25f, $\left.\mathbf{R}=\mathrm{CH}_{2} \mathrm{OEt}\right)$. It was prepared following the general deprotection procedure using 24f (49 mg), $\mathrm{HCl}(0.3 \mathrm{~mL})$ and methanol (1 mL). Reaction time $=11 \mathrm{~h}$. Eluent for chromatography $=(70: 30)$ ethyl acetate/hexane. Yield $=80 \%(34 \mathrm{mg})$. Brown oil. $[\alpha]_{\mathrm{D}}^{20}=$ $-35.1^{\circ}\left(c\right.$ 1.0, $\left.\mathrm{CHCl}_{3}\right) .{ }^{1} \mathrm{H}$ NMR $\left(300 \mathrm{MHz} \mathrm{CDCl}_{3}\right) \delta: 6.70$ (br s, 1H, H7), 5.77 (br s, 1H, H5), 4.38 (q, $J=2.3 \mathrm{~Hz}, 1 \mathrm{H}, \mathrm{H} 1$ ), 4.24-4.19 (m, 2H, H10 + OCHH-3), 4.08 (d, $J=16.5 \mathrm{~Hz}, 1 \mathrm{H}$, $\mathrm{OCH} H-3$ ), 3.85 (br s, 2H, $\mathrm{CH}_{2} \mathrm{OEt}$ ), 3.74 (s, 3H, $\mathrm{OCH}_{3}$ ), 3.44 (q, $\left.J=7.0 \mathrm{~Hz}, 2 \mathrm{H}, \mathrm{OCH}_{2} \mathrm{CH}_{3}\right), 2.65(\mathrm{dt}, J=2.9$ and $18.4 \mathrm{~Hz}, 1 \mathrm{H}$, $\mathrm{CHH}-9$ ), 2.45 (br d, $J=17.9 \mathrm{~Hz}, 1 \mathrm{H}, \mathrm{CH} H-9)$ and $1.18(\mathrm{t}, J=7.0$ $\left.\mathrm{Hz}, 3 \mathrm{H}, \mathrm{OCH}_{2} \mathrm{CH}_{3}\right)$ ppm. ${ }^{13} \mathrm{C}$ NMR (75 $\left.\mathrm{MHz}, \mathrm{CDCl}_{3}\right) \delta$ : 167.6 (C), 140.2 (C), $138.1(\mathrm{CH}), 129.7(\mathrm{CH}), 127.9(\mathrm{C}), 73.5$ $(\mathrm{CH}), 73.4\left(\mathrm{CH}_{2}\right), 71.8(\mathrm{C}), 69.6(\mathrm{CH}), 66.1\left(\mathrm{CH}_{2}\right), 64.0\left(\mathrm{CH}_{2}\right)$, $52.1\left(\mathrm{OCH}_{3}\right), 27.2\left(\mathrm{CH}_{2}\right)$ and $15.2\left(\mathrm{CH}_{3}\right)$ ppm. FTIR (film): $3406(\mathrm{OH})$ and 1709 (CO) $\mathrm{cm}^{-1}$. MS (ESI) $\mathrm{m} / z=307\left(\mathrm{MNa}^{+}\right)$. HRMS calcd for $\mathrm{C}_{14} \mathrm{H}_{20} \mathrm{O}_{6} \mathrm{Na}\left(\mathrm{MNa}^{+}\right)$: 307.1152; found, 307.1153.

Methyl $(1 R, 6 S, 10 S)$-4-benzyloxymethyl-6,10-dihydroxy-2-oxabicyclo[4.3.1] deca-4(Z),7-diene-8-carboxylate (25g, $R=O B n)$. It was prepared following the general deprotection procedure using $24 \mathrm{~g}$ (55 mg), $\mathrm{HCl}(0.2 \mathrm{~mL})$ and methanol (0.9 mL). Reaction time $=12 \mathrm{~h}$. Eluent for chromatography $=$ diethyl ether. Yield $=85 \%(41 \mathrm{mg})$. Colorless oil. $[\alpha]_{\mathrm{D}}^{20}=-24.2^{\circ}(c$ 1.0, $\mathrm{MeOH}) .{ }^{1} \mathrm{H}$ NMR (300 MHz, $\left.\mathrm{CD}_{3} \mathrm{OD}\right) \delta: 7.39-7.27$ (m, 5H, $5 \times$ ArH), 6.69 (m, 1H, H7), 5.77 (m, 1H, H5), 4.48 (br s, 2H, $\left.\mathrm{CH}_{2} \mathrm{Ph}\right), 4.33-4.27$ (m, 2H, H1 + OCHH-3), 4.20 (dd, $J=1.4$ and $4.9 \mathrm{~Hz}, 1 \mathrm{H}, \mathrm{H} 10), 4.08$ (d, $J=16.4 \mathrm{~Hz}, 1 \mathrm{H}, \mathrm{OCH} H-3), 3.94$ (s, $2 \mathrm{H}, \mathrm{CH}_{2} \mathrm{OBn}$ ), $3.76\left(\mathrm{~s}, 3 \mathrm{H}, \mathrm{OCH}_{3}\right), 2.65(\mathrm{dt}, J=2.9$ and $18.1 \mathrm{~Hz}$, $1 \mathrm{H}, \mathrm{CHH}-9)$ and $2.28(\mathrm{~m}, 1 \mathrm{H}, \mathrm{CH}-9) \mathrm{ppm} .{ }^{13} \mathrm{C}$ NMR $(75 \mathrm{MHz}$, $\left.\mathrm{CD}_{3} \mathrm{OD}\right) \delta: 169.2(\mathrm{C}), 140.6(\mathrm{C}), 140.3(\mathrm{CH}), 139.4(\mathrm{C}), 132.3$ $(\mathrm{CH}), 129.4(2 \times \mathrm{CH}), 129.0(2 \times \mathrm{CH}), 128.7(\mathrm{CH}), 128.4(\mathrm{C}), 75.3$ $(\mathrm{CH}), 73.8\left(\mathrm{CH}_{2}\right), 73.0\left(\mathrm{CH}_{2}\right), 72.4(\mathrm{C}), 70.3(\mathrm{CH}), 64.6\left(\mathrm{CH}_{2}\right)$, $52.3\left(\mathrm{OCH}_{3}\right)$ and $28.2\left(\mathrm{CH}_{2}\right)$ ppm. FTIR (film): $3406(\mathrm{OH})$ and 1709 (CO) $\mathrm{cm}^{-1}$. MS (ESI) $\mathrm{m} / z=369\left(\mathrm{MNa}^{+}\right)$. HRMS calcd for $\mathrm{C}_{19} \mathrm{H}_{22} \mathrm{O}_{6} \mathrm{Na}\left(\mathrm{MNa}^{+}\right)$: 369.1309; found, 369.1307.

Methyl $(1 R, 6 S, 10 S)$-4-hydroxymethyl-6,10-dihydroxy-2-oxabicyclo[4.3.1]deca-4(Z),7-diene-8-carboxylate $\left(25 \mathrm{i}, \mathrm{R}=\mathrm{CH}_{2} \mathrm{OH}\right)$. It was prepared following the general deprotection procedure using $24 \mathbf{i}(81 \mathrm{mg}), \mathrm{HCl}(0.3 \mathrm{~mL})$ and methanol $(1.8 \mathrm{~mL})$. Reaction time $=8 \mathrm{~h}$. Eluent for chromatography $=$ ethyl acetate. Yield $=95 \%(66 \mathrm{mg})$. Colorless oil. $[\alpha]_{\mathrm{D}}^{20}=-147.5^{\circ}$ (c $0.8, \mathrm{MeOH}) .{ }^{1} \mathrm{H}$ NMR (300 MHz, $\left.\mathrm{CD}_{3} \mathrm{OD}\right) \delta: 6.65$ (br s, $1 \mathrm{H}$, H7), 5.69 (br s, 1H, H5), 4.29-4.24 (m, 2H, H1 + OCHH-3), 4.16 (m, 1H, H10), 4.01 (d, $J=16.4 \mathrm{~Hz}, 1 \mathrm{H}, \mathrm{OCH} H-3), 3.95$ (d, $J=$ $13.5 \mathrm{~Hz}, 1 \mathrm{H}, \mathrm{CH}-\mathrm{OH}$ ), 3.89 (d, $J=13.5 \mathrm{~Hz}, 1 \mathrm{H}, \mathrm{CH} H-\mathrm{OH}$ ), $3.72\left(\mathrm{~s}, 3 \mathrm{H}, \mathrm{OCH}_{3}\right), 2.60$ (dt, $J=2.8$ and $18.0 \mathrm{~Hz}, 1 \mathrm{H}, \mathrm{CH}-9$ ) and 2.29 (d, $J=18.0 \mathrm{~Hz}, 1 \mathrm{H}, \mathrm{CH} H-9) \mathrm{ppm} .{ }^{13} \mathrm{C} \mathrm{NMR}(75 \mathrm{MHz}$, $\left.\mathrm{CD}_{3} \mathrm{OD}\right) \delta$ : $169.2(\mathrm{C}), 143.4(\mathrm{C}), 140.5(\mathrm{CH}), 129.6(\mathrm{CH}), 128.2$ (C), $75.2(\mathrm{CH}), 72.4(\mathrm{C}), 70.3(\mathrm{CH}), 65.5\left(\mathrm{CH}_{2}\right), 64.4\left(\mathrm{CH}_{2}\right), 52.3$ $\left(\mathrm{OCH}_{3}\right)$ and $28.2\left(\mathrm{CH}_{2}\right)$ ppm. FTIR (film): $3372(\mathrm{OH})$ and 1697 
(CO) $\mathrm{cm}^{-1}$. MS (ESI) $\mathrm{m} / z=279\left(\mathrm{MNa}^{+}\right)$. HRMS calcd for $\mathrm{C}_{12} \mathrm{H}_{16} \mathrm{O}_{6} \mathrm{Na}\left(\mathrm{MNa}^{+}\right)$: 279.0839; found, 279.0838.

\section{General procedure for the ester hydrolysis in $25 a-h$}

A solution of the esters $25 \mathbf{a}-\mathbf{h}(1 \mathrm{mmol})$ in THF $(10 \mathrm{~mL})$ was treated at room temperature with an aqueous solution of LiOH $(1.2 \mathrm{~mL}, 2.5 \mathrm{M})$. After stirring for $1 \mathrm{~h}$, water was added and THF was removed under reduced pressure. The aqueous layer was washed with ethyl acetate $(\times 3)$ and then treated with Amberlite IR-120 $\left(\mathrm{H}^{+}\right)$until $\mathrm{pH}$ 6. The resin was filtered off and washed with MilliQ water. The filtrate and the washings were lyophilized to give acids 4 .

$(1 R, 6 S, 10 S)$-6,10-Dihydroxy-4-methyl-2-oxabicyclo[4.3.1] deca4(Z),7-diene-8-carboxylic acid ( $4 a, R=M e)$. It was prepared following the general basic hydrolysis procedure using 25a $(230 \mathrm{mg}), \mathrm{LiOH}(0.14 \mathrm{~mL})$ and THF $(1.2 \mathrm{~mL})$. Yield $=86 \%$ (25 mg). White solid. Mp: $216{ }^{\circ} \mathrm{C}$ (dec.). $[\alpha]_{\mathrm{D}}^{20}=-52^{\circ}(c$ 2.5, $\left.\mathrm{CH}_{3} \mathrm{OH}\right) .{ }^{1} \mathrm{H}$ NMR $\left(300 \mathrm{MHz}, \mathrm{CD}_{3} \mathrm{OD}\right) \delta: 6.63$ (br s, $\left.1 \mathrm{H}, \mathrm{H} 7\right)$, $5.47(\mathrm{~m}, 1 \mathrm{H}, \mathrm{H} 5), 4.27-4.22(\mathrm{~m}, 2 \mathrm{H}, \mathrm{H} 1+\mathrm{OCH}), 4.12(\mathrm{dd}, J=$ 4.9 and $1.5 \mathrm{~Hz}, \mathrm{H} 10), 3.85$ (d, $J=16.4 \mathrm{~Hz}, 1 \mathrm{H}, \mathrm{OCH} H), 2.28(\mathrm{dt}$, $J=18.0$ and $2.8 \mathrm{~Hz}, 1 \mathrm{H}, \mathrm{CHH}-9), 2.28(\mathrm{dd}, J=18.0$ and $2.0 \mathrm{~Hz}$, $1 \mathrm{H}, \mathrm{CH} H-9)$ and $1.68\left(\mathrm{~s}, 3 \mathrm{H}, \mathrm{CH}_{3}\right) \mathrm{ppm} .{ }^{13} \mathrm{C}$ NMR $(75 \mathrm{MHz}$, $\left.\mathrm{CD}_{3} \mathrm{OD}\right) \delta: 171.2(\mathrm{C}), 140.2(\mathrm{CH}), 139.9(\mathrm{C}), 129.4(\mathrm{CH}), 128.7$ (C), $75.3(\mathrm{CH}), 72.6(\mathrm{C}), 70.6(\mathrm{CH}), 67.5\left(\mathrm{CH}_{2}\right), 28.3\left(\mathrm{CH}_{2}\right)$ and $22.2\left(\mathrm{CH}_{3}\right) \mathrm{ppm}$. FTIR (ATR): $3325(\mathrm{OH})$ and $1637(\mathrm{CO}) \mathrm{cm}^{-1}$. MS (ESI) $m / z=225(\mathrm{M}-\mathrm{H})$. HRMS calcd for $\mathrm{C}_{11} \mathrm{H}_{13} \mathrm{O}_{5}$ (M - H): 225.0768; found, 225.0764.

$(1 R, 6 S, 10 S)$-4-Ethyl-6,10-dihydroxy-2-oxabicyclo[4.3.1]deca-4 (Z),7-diene-8-carboxylic acid ( $4 \mathbf{b}, \mathbf{R}=\mathbf{E t})$. It was prepared following the general basic hydrolysis procedure using 25b $(39 \mathrm{mg}), \mathrm{LiOH}(0.18 \mathrm{~mL})$ and $\mathrm{THF}(1.5 \mathrm{~mL})$. Yield $=99 \%$ (35 mg). White solid. Mp: $216{ }^{\circ} \mathrm{C}$ (dec.). $[\alpha]_{\mathrm{D}}^{20}=-24.7^{\circ}(c$ 1.0, $\mathrm{MeOH}) .{ }^{1} \mathrm{H}$ NMR $\left(300 \mathrm{MHz}, \mathrm{D}_{2} \mathrm{O}\right) \delta: 6.57(\mathrm{~s}, 1 \mathrm{H}, \mathrm{H} 7), 5.36(\mathrm{~m}$, $1 \mathrm{H}, \mathrm{H} 5), 4.23-4.17(\mathrm{~m}, 2 \mathrm{H}, \mathrm{H} 1+\mathrm{OC} H \mathrm{H}), 4.07(\mathrm{dd}, J=1.2$ and $4.8 \mathrm{~Hz}, 1 \mathrm{H}, \mathrm{H} 10), 3.81$ (d, $J=16.4 \mathrm{~Hz}, 1 \mathrm{H}, \mathrm{OCH} H), 2.49(\mathrm{dt}, J=$ 2.8 and $18.1 \mathrm{~Hz}, 1 \mathrm{H}, \mathrm{CH} H-9$ ), 2.18 (dd, $J=1.3$ and $18.0 \mathrm{~Hz}, 1 \mathrm{H}$, $\mathrm{C} H \mathrm{H}-9), 1.89\left(\mathrm{q}, J=7.4 \mathrm{~Hz}, 2 \mathrm{H}, \mathrm{CH}_{2}\right)$ and $0.91(\mathrm{t}, J=7.4 \mathrm{~Hz}$, $\left.3 \mathrm{H}, \mathrm{CH}_{3}\right) \mathrm{ppm} .{ }^{13} \mathrm{C}$ NMR $\left(75 \mathrm{MHz}, \mathrm{D}_{2} \mathrm{O}\right) \delta: 170.8(\mathrm{C}), 145.5(\mathrm{C})$, $140.8(\mathrm{CH}), 128.1(\mathrm{C}), 127.8(\mathrm{CH}), 75.2(\mathrm{CH}), 72.6(\mathrm{C}), 70.4$ (CH), $66.8\left(\mathrm{CH}_{2}\right), 29.9\left(\mathrm{CH}_{2}\right), 28.2\left(\mathrm{CH}_{2}\right)$ and $12.7\left(\mathrm{CH}_{3}\right) \mathrm{ppm}$. FTIR (film): $3365(\mathrm{OH})$ and $1688(\mathrm{CO}) \mathrm{cm}^{-1}$. MS (ESI) $\mathrm{m} / \mathrm{z}=240$ $(\mathrm{M}-\mathrm{H})$. HRMS calcd for $\mathrm{C}_{12} \mathrm{H}_{15} \mathrm{O}_{5}(\mathrm{M}-\mathrm{H}): 239.0925$; found, 239.0921 .

$(1 R, 6 S, 10 S)$-6,10-Dihydroxy-4-propyl-2-oxabicyclo[4.3.1]deca4(Z),7-diene-8-carboxylic acid ( $4 \mathrm{c}, \mathrm{R}=\boldsymbol{n P r}$ ). It was prepared following the general basic hydrolysis procedure using 25c $(58 \mathrm{mg})$, LiOH $(0.9 \mathrm{~mL})$ and $\mathrm{THF}(2.2 \mathrm{~mL})$. Yield $=99 \%$ (55 mg). White foam. $[\alpha]_{\mathrm{D}}^{20}=-38.1^{\circ}\left(c 1.0, \mathrm{H}_{2} \mathrm{O}\right) .{ }^{1} \mathrm{H}$ NMR $\left(300 \mathrm{MHz}, \mathrm{D}_{2} \mathrm{O}\right) \delta: 6.72(\mathrm{br} \mathrm{s}, 1 \mathrm{H}, \mathrm{H} 7), 5.47(\mathrm{br} \mathrm{s}, 1 \mathrm{H}, \mathrm{H} 5)$, 4.38-4.27 (m, 3H, H1 + H10 + OCHH-3), 3.93 (d, $J=16.6 \mathrm{~Hz}$, $1 \mathrm{H}, \mathrm{OCH} H-3$ ), 2.56 (br d, $J=18.6 \mathrm{~Hz}, 1 \mathrm{H}, \mathrm{C} H \mathrm{H}-9), 2.29$ (d, $J=$ $18.5 \mathrm{~Hz}, 1 \mathrm{H}, \mathrm{CH} H-9), 1.95\left(\mathrm{t}, J=7.2 \mathrm{~Hz}, 2 \mathrm{H}, \mathrm{CH}_{2} \mathrm{CH}_{2} \mathrm{CH}_{3}\right), 1.35$ $\left(\mathrm{m}, 2 \mathrm{H}, \mathrm{CH}_{2} \mathrm{CH}_{2} \mathrm{CH}_{3}\right)$ and $0.82\left(\mathrm{t}, J=7.3 \mathrm{~Hz}, 3 \mathrm{H},\left(\mathrm{CH}_{2}\right)_{2} \mathrm{CH}_{3}\right)$ ppm. ${ }^{13} \mathrm{C}$ NMR (75 MHz, $\left.\mathrm{D}_{2} \mathrm{O}\right) \delta: 173.2$ (C), 146.4 (C), 141.9 $(\mathrm{CH}), 129.6(\mathrm{C}), 129.1(\mathrm{CH}), 75.8(\mathrm{CH}), 74.3(\mathrm{C}), 71.1(\mathrm{CH}), 68.0$ $\left(\mathrm{CH}_{2}\right), 40.4\left(\mathrm{CH}_{2}\right), 29.2\left(\mathrm{CH}_{2}\right), 22.9\left(\mathrm{CH}_{2}\right)$ and $15.4\left(\mathrm{CH}_{3}\right)$ ppm.
FTIR (film): $3392(\mathrm{OH})$ and $1688(\mathrm{CO}) \mathrm{cm}^{-1}$. MS (ESI) $\mathrm{m} / z=253$ $(M-H)$. HRMS calcd for $\mathrm{C}_{13} \mathrm{H}_{17} \mathrm{O}_{5}(\mathrm{M}-\mathrm{H}): 253.1081$; found, 253.1081.

$(1 R, 6 S, 10 S)$-4-Butyl-6,10-dihydroxy-2-oxabicyclo[4.3.1] deca-4 (Z),7-diene-8-carboxylic acid ( $4 \mathrm{~d}, \mathbf{R}=\boldsymbol{n B u}$ ). It was prepared following the general basic hydrolysis procedure using 25d $(87 \mathrm{mg}), \mathrm{LiOH}(1.2 \mathrm{~mL})$ and THF $(3 \mathrm{~mL})$. Yield $=98 \%(82 \mathrm{mg})$. White solid. Mp: $129.1-131.0^{\circ} \mathrm{C} .[\alpha]_{\mathrm{D}}^{20}=-20.3^{\circ}\left(c 1.0, \mathrm{H}_{2} \mathrm{O}\right) .{ }^{1} \mathrm{H}$ NMR (300 MHz, $\left.\mathrm{D}_{2} \mathrm{O}\right) \delta: 6.52$ (br s, 1H, H7), 5.47 (br s, 1H, H5), 4.39-4.32 (m, $2 \mathrm{H}, \mathrm{H} 1+\mathrm{OCHH}-3), 4.25(\mathrm{dd}, J=1.8$ and $5.0 \mathrm{~Hz}$, $1 \mathrm{H}, \mathrm{H} 10), 3.93$ (br d, $J=16.5 \mathrm{~Hz}, 1 \mathrm{H}, \mathrm{OCH} H-3$ ), 2.57 (td, $J=3.0$ and $18.6 \mathrm{~Hz}, 1 \mathrm{H}, \mathrm{CHH}-9$ ), 2.26 (br d, $J=18.8 \mathrm{~Hz}, 1 \mathrm{H}, \mathrm{CH} H-9$ ), $1.98\left(\mathrm{t}, J=6.8 \mathrm{~Hz}, 2 \mathrm{H}, \mathrm{CH}_{2}\left(\mathrm{CH}_{2}\right)_{2} \mathrm{CH}_{3}\right), 1.36-1.18(\mathrm{~m}, 4 \mathrm{H}$, $\left.\mathrm{CH}_{2}\left(\mathrm{CH}_{2}\right)_{2} \mathrm{CH}_{3}\right)$ and $0.83\left(\mathrm{t}, J=7.1 \mathrm{~Hz}, 3 \mathrm{H},\left(\mathrm{CH}_{2}\right)_{3} \mathrm{CH}_{3}\right)$ ppm. ${ }^{13} \mathrm{C}$ NMR (75 MHz, $\mathrm{D}_{2} \mathrm{O}$ ) $\delta: 172.7$ (C), 143.1 (C), 136.6 (CH), $129.5(\mathrm{C}), 127.0(\mathrm{CH}), 73.3(\mathrm{CH}), 71.8(\mathrm{C}), 68.7(\mathrm{CH}), 65.3$ $\left(\mathrm{CH}_{2}\right), 35.6\left(\mathrm{CH}_{2}\right), 29.3\left(\mathrm{CH}_{2}\right), 27.2\left(\mathrm{CH}_{2}\right), 21.7\left(\mathrm{CH}_{2}\right)$ and 13.2 $\left(\mathrm{CH}_{3}\right)$ ppm. FTIR (film): $3367(\mathrm{OH})$ and $1691(\mathrm{CO}) \mathrm{cm}^{-1}$. MS (ESI) $m / z=267(\mathrm{M}-\mathrm{H})$. HRMS calcd for $\mathrm{C}_{14} \mathrm{H}_{19} \mathrm{O}_{5}(\mathrm{M}-\mathrm{H})$ : 267.1238; found, 267.1235.

(1R,6S,10S)-4-Cyclopropylmethyl-6,10-dihydroxy-2-oxabicyclo [4.3.1] deca-4(Z),7-diene-8-carboxylic acid $\left(4 \mathrm{e}, \mathbf{R}=\mathrm{CH}_{2} \mathrm{CPr}\right)$. It was prepared following the general basic hydrolysis procedure using $25 \mathrm{e}(44 \mathrm{mg})$, LiOH $(0.5 \mathrm{~mL})$ and THF $(1.4 \mathrm{~mL})$. Yield $=$ 99\% (37 mg). White foam. $[\alpha]_{\mathrm{D}}^{20}=-14.8^{\circ}\left(c 1.0, \mathrm{H}_{2} \mathrm{O}\right) .{ }^{1} \mathrm{H}$ NMR $\left(300 \mathrm{MHz}, \mathrm{D}_{2} \mathrm{O}\right) \delta: 6.43(\mathrm{~m}, 1 \mathrm{H}, \mathrm{H} 7), 5.62(\mathrm{~m}, 1 \mathrm{H}, \mathrm{H} 5)$, $4.42-4.36(\mathrm{~m}, 2 \mathrm{H}, \mathrm{H} 1+\mathrm{OC} H \mathrm{H}-3), 4.26(\mathrm{dd}, J=1.6$ and $4.9 \mathrm{~Hz}$, 1H, H10), 3.98 (d, $J=16.5 \mathrm{~Hz}, 1 \mathrm{H}, \mathrm{OCH} H-3), 2.57$ (td, $J=2.9$ and $18.7 \mathrm{~Hz}, 1 \mathrm{H}, \mathrm{CH} H-9$ ), 2.27 (d, $J=18.5 \mathrm{~Hz}, 1 \mathrm{H}, \mathrm{C} H \mathrm{H}-9$ ), $1.87\left(\mathrm{~d}, J=6.8 \mathrm{~Hz}, 2 \mathrm{H}, \mathrm{CH}_{2}\right), 0.73\left(\mathrm{~m}, 1 \mathrm{H}, \mathrm{CH}_{2} \mathrm{CH}\left(\mathrm{CH}_{2}\right)_{2}\right)$, 0.48-0.42 (m, 2H, $\left.\mathrm{CHCH}_{2} \mathrm{CH}_{2}\right)$ and $0.04\left(\mathrm{~m}, 2 \mathrm{H}, \mathrm{CH}_{2}\right) \mathrm{ppm} .{ }^{13} \mathrm{C}$ NMR (75 MHz, $\left.\mathrm{D}_{2} \mathrm{O}\right) \delta: 174.3$ (C), $143.1(\mathrm{C}), 134.7(\mathrm{CH}), 131.3$ (C), $126.9(\mathrm{CH}), 73.5(\mathrm{CH}), 72.0(\mathrm{C}), 68.7(\mathrm{CH}), 65.5\left(\mathrm{CH}_{2}\right), 40.1$ $\left(\mathrm{CH}_{2}\right), 27.6\left(\mathrm{CH}_{2}\right), 8.5(\mathrm{CH}), 3.8\left(\mathrm{CH}_{2}\right)$ and $3.7\left(\mathrm{CH}_{2}\right) \mathrm{ppm}$. FTIR (film): 3286 (OH) and 1680 (CO) $\mathrm{cm}^{-1}$. MS (ESI) $\mathrm{m} / \mathrm{z}=265$ (M H). HRMS calcd for $\mathrm{C}_{14} \mathrm{H}_{17} \mathrm{O}_{5}(\mathrm{M}-\mathrm{H})$ : 265.1081; found, 265.1079.

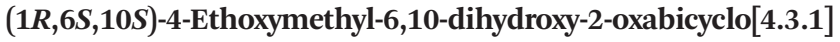
deca-4(Z),7-diene-8-carboxylic acid (4f, $\mathbf{R}=\mathbf{C H}_{2} \mathrm{OEt}$ ). It was prepared following the general basic hydrolysis procedure using $25 f(39 \mathrm{mg})$, LiOH $(0.6 \mathrm{~mL})$ and THF $(1.4 \mathrm{~mL})$. Reaction time $=$ $30 \mathrm{~min}$. Yield $=45 \%(17 \mathrm{mg})$. White foam. $[\alpha]_{\mathrm{D}}^{20}=-18.0^{\circ}(c 1.0$, $\left.\mathrm{H}_{2} \mathrm{O}\right) .{ }^{1} \mathrm{H}$ NMR $\left(300 \mathrm{MHz}, \mathrm{D}_{2} \mathrm{O}\right) \delta: 6.71(\mathrm{br} \mathrm{s}, 1 \mathrm{H}, \mathrm{H} 7), 5.82(\mathrm{br}$ $\mathrm{s}, 1 \mathrm{H}, \mathrm{H} 5), 4.45(\mathrm{~m}, 1 \mathrm{H}, \mathrm{H} 1), 4.35(\mathrm{~m}, 2 \mathrm{H}, \mathrm{H} 10+\mathrm{OCHH}-3)$, 4.07 (d, $J=16.5 \mathrm{~Hz}, 1 \mathrm{H}, \mathrm{OCH} H-3), 3.96$ (s, $2 \mathrm{H}, \mathrm{CH}_{2} \mathrm{OEt}$ ), 3.53 (q, $\left.J=7.0 \mathrm{~Hz}, 2 \mathrm{H}, \mathrm{OCH}_{2} \mathrm{CH}_{3}\right), 2.65(\mathrm{dt}, J=2.6$ and $18.8 \mathrm{~Hz}, 1 \mathrm{H}$, $\mathrm{C} H \mathrm{H}-9), 2.36$ (br d, $J=18.5 \mathrm{~Hz}, 1 \mathrm{H}, \mathrm{CH} H-9)$ and $1.18(\mathrm{t}, J=$ $\left.7.0 \mathrm{~Hz}, 3 \mathrm{H}, \mathrm{OCH}_{2} \mathrm{CH}_{3}\right) \mathrm{ppm} .{ }^{13} \mathrm{C} \mathrm{NMR}\left(75 \mathrm{MHz}, \mathrm{D}_{2} \mathrm{O}\right) \delta: 171.0$ (C), 139.0 (C), $137.7(\mathrm{CH}), 130.7(\mathrm{CH}), 128.4(\mathrm{C}), 73.4(\mathrm{CH}), 72.4$ $\left(\mathrm{CH}_{2}\right), 71.5(\mathrm{C}), 68.2(\mathrm{CH}), 65.5\left(\mathrm{CH}_{2}\right), 63.3\left(\mathrm{CH}_{2}\right), 26.6\left(\mathrm{CH}_{2}\right)$ and $14.0\left(\mathrm{CH}_{3}\right)$ ppm. FTIR (film): $3361(\mathrm{OH})$ and $1689(\mathrm{CO})$ $\mathrm{cm}^{-1}$. MS (ESI) $\mathrm{m} / z=269(\mathrm{M}-\mathrm{H})$. HRMS calcd for $\mathrm{C}_{13} \mathrm{H}_{17} \mathrm{O}_{6}$ (M - H): 269.1031; found, 269.1030.

(1R,6S,10S)-4-Benzyloxymethyl-6,10-dihydroxy-2-oxabicyclo [4.3.1] deca-4(Z),7-diene-8-carboxylic acid ( $\left.4 \mathrm{~g}, \mathrm{R}=\mathrm{CH}_{2} \mathrm{OBn}\right)$. It was prepared following the general basic hydrolysis procedure using $25 \mathrm{~g}(58 \mathrm{mg})$, LiOH $(0.7 \mathrm{~mL})$ and THF $(1.7 \mathrm{~mL})$. Reaction 
time $=4 \mathrm{~h}$. Yield $=99 \%(56 \mathrm{mg})$. White solid. $\mathrm{Mp}: 186{ }^{\circ} \mathrm{C}$ (dec.). $[\alpha]_{\mathrm{D}}^{20}=-5.5^{\circ}\left(c\right.$ 1.0, $\left.\mathrm{H}_{2} \mathrm{O}\right) .{ }^{1} \mathrm{H}$ NMR $\left(300 \mathrm{MHz}, \mathrm{D}_{2} \mathrm{O}\right) \delta$ : 7.38 (m, 5H, $5 \times \mathrm{ArH}$ ), 6.35 (br s, 1H, H7), 5.80 (br s, 1H, H5), 4.48 (br s, $2 \mathrm{H}, \mathrm{CH}_{2} \mathrm{Ph}$ ), 4.37 (m, $\left.1 \mathrm{H}, \mathrm{H} 1\right), 4.29$ (d, $J=16.5 \mathrm{~Hz}$, $1 \mathrm{H}, \mathrm{OCHH}-3$ ), 4.23 (d, $J=4.3 \mathrm{~Hz}, 1 \mathrm{H}, \mathrm{H} 10), 4.02$ (d, $J=16.5 \mathrm{~Hz}$, $1 \mathrm{H}, \mathrm{OCH} H-3$ ), 3.97 (br s, 2H, $\mathrm{CH}_{2} \mathrm{OBn}$ ), 2.59 (dt, $J=2.7$ and 18.7 Hz, 1H, CHH-9) and 2.28 (d, $J=18.5 \mathrm{~Hz}, 1 \mathrm{H}, \mathrm{CH} H-9) \mathrm{ppm}$. ${ }^{13} \mathrm{C}$ NMR (75 MHz, D ${ }_{2} \mathrm{O}$ ) $\delta: 175.0$ (C), 137.8 (C), 137.1 (C), 133.1 (C), $132.7(\mathrm{CH}), 132.2(\mathrm{CH}), 128.6(2 \times \mathrm{CH}), 128.5(2 \times \mathrm{CH})$, $128.2(\mathrm{CH}), 73.7(\mathrm{CH}), 72.5\left(\mathrm{CH}_{2}\right), 71.8(\mathrm{C}), 71.6\left(\mathrm{CH}_{2}\right), 68.4$ $(\mathrm{CH}), 63.1\left(\mathrm{CH}_{2}\right)$ and $27.7\left(\mathrm{CH}_{2}\right)$ ppm. FTIR (film): $3286(\mathrm{OH})$ and 1681 (CO) $\mathrm{cm}^{-1}$. MS (ESI) $\mathrm{m} / z=331(\mathrm{M}-\mathrm{H})$. HRMS calcd for $\mathrm{C}_{18} \mathrm{H}_{19} \mathrm{O}_{6}(\mathrm{M}-\mathrm{H})$ : 331.1187; found, 331.1185.

$\mathrm{C}_{14} \mathrm{H}_{17} \mathrm{O}_{5}(\mathrm{M}-\mathrm{H})$ : 265.1081; found, 265.1079.

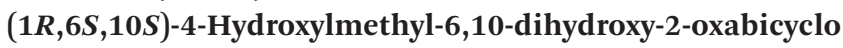
[4.3.1]deca-4(Z),7-diene-8-carboxylic acid (4h, $\left.\mathrm{R}=\mathrm{CH}_{2} \mathrm{OH}\right)$. It was prepared following the general basic hydrolysis procedure using $25 \mathbf{h}(58 \mathrm{mg})$, LiOH $(0.9 \mathrm{~mL})$ and THF $(2.3 \mathrm{~mL})$. Reaction time $=8 \mathrm{~h}$. Yield $=99 \%(55 \mathrm{mg})$. White solid. Mp: 117.3-119.2 ${ }^{\circ} \mathrm{C} .[\alpha]_{\mathrm{D}}^{20}=-28.1^{\circ}\left(c 1.0, \mathrm{H}_{2} \mathrm{O}\right) .{ }^{1} \mathrm{H}$ NMR $(300 \mathrm{MHz}$, $\left.\mathrm{D}_{2} \mathrm{O}\right) \delta: 6.36$ (br s, $\left.1 \mathrm{H}, \mathrm{H} 7\right), 5.59$ (br s, 1H, H5), 4.26-4.19 (m, $2 \mathrm{H}, \mathrm{H} 1+\mathrm{OCH}-3), 4.14(\mathrm{~m}, 1 \mathrm{H}, \mathrm{H} 10), 3.89-3.77(\mathrm{~m}, 3 \mathrm{H}$, $\left.\mathrm{OCH}-3+\mathrm{CH}_{2} \mathrm{OH}\right), 2.45(\mathrm{dt}, J=2.8$ and $18.8 \mathrm{~Hz}, 1 \mathrm{H}, \mathrm{CH}-9)$ and 2.15 (br d, $J=18.6 \mathrm{~Hz}, 1 \mathrm{H}, \mathrm{CH} H-9$ ) ppm. ${ }^{13} \mathrm{C} \mathrm{NMR}$ (75 MHz, $\left.\mathrm{D}_{2} \mathrm{O}\right) \delta$ : $175.4(\mathrm{C}), 143.8(\mathrm{C}), 138.2(\mathrm{CH}), 132.8(\mathrm{C})$, $131.0(\mathrm{CH}), 76.1(\mathrm{CH}), 74.2(\mathrm{C}), 70.9(\mathrm{CH}), 66.4\left(\mathrm{CH}_{2}\right), 65.6$ $\left(\mathrm{CH}_{2}\right)$ and $29.7\left(\mathrm{CH}_{2}\right)$ ppm. FTIR (film): $3349(\mathrm{OH})$ and 1688 (CO) $\mathrm{cm}^{-1}$. MS (ESI) $\mathrm{m} / z=241(\mathrm{M}-\mathrm{H})$. HRMS calcd for $\mathrm{C}_{11} \mathrm{H}_{13} \mathrm{O}_{6}(\mathrm{M}-\mathrm{H})$ : 241.0718; found, 241.0719.

$(1 R, 4 S, 6 S, 10 S)-(5 S)$ and $(1 R, 4 R, 6 S, 10 S)-6,10$-dihydroxy-4methyl-2-oxabicyclo[4.3.1] dec-7-ene-8-carboxylic acid (5R). A suspension of the alkene $25 \mathrm{a}$ (57 $\mathrm{mg}, 0.20 \mathrm{mmol}$ ), Rosenmund catalyst (10 mg, $5 \mathrm{wt} \%$ loading) and a few drops of pyridine in methanol $(5 \mathrm{~mL})$ was shaken under a hydrogen atmosphere at room temperature for $7 \mathrm{~h}$. The mixture was filtered over Celite ${ }^{\circledR}$ and the residue was washed with methanol. The filtrate and washings were evaporated under reduced pressure. A solution of the resulting oil (63 $\mathrm{mg})$ in ethanol $(1.5 \mathrm{~mL})$ and aqueous $\mathrm{HCl}(0.4 \mathrm{~mL}, 6 \mathrm{M})$ was heated at $60{ }^{\circ} \mathrm{C}$ for $6 \mathrm{~h}$. The mixture was cooled and concentrated under reduced pressure. A solution of the resulting oil $(50 \mathrm{mg})$ in THF $(2 \mathrm{~mL})$ was treated at room temperature with an aqueous solution of $\mathrm{LiOH}$ (1.3 mL, $0.63 \mathrm{mmol}, 0.5 \mathrm{M}$ ). After stirring for $4 \mathrm{~h}$, water was added and THF was removed under reduced pressure. The aqueous layer was washed with ethyl acetate $(\times 3)$ and it was then treated with Amberlite IR-120 $\left(\mathrm{H}^{+}\right)$until $\mathrm{pH}$ 6. The resin was filtered off and washed with milliQ water. The filtrate and the washings were lyophilized to give acids $\mathbf{5} \boldsymbol{S}$ and $\mathbf{5} \boldsymbol{R}(48 \mathrm{mg}$, $99 \%$ ) as a mixture of epimers in C4. Both compounds were separated by HPLC using semipreparative column (Phenomenex Luna5u, $250 \times 10 \mathrm{~mm}$, C18), eluting with a gradient of acetonitrile-water $[(1)$ 0-5 min $(5: 95 \rightarrow 10: 90)$ $\mathrm{CH}_{3} \mathrm{CN} / \mathrm{H}_{2} \mathrm{O}$; (2) 5-20 $\left.\min (10: 90 \rightarrow 20: 80) \mathrm{CH}_{3} \mathrm{CN} / \mathrm{H}_{2} \mathrm{O}\right]$, at a flow rate of $3.5 \mathrm{~mL} \mathrm{~min}^{-1}$.

Data for $5 \boldsymbol{R}$. Yield $=45 \%$. Retention time: $16.2 \mathrm{~min}$. Mp: 192.1-193.2 ${ }^{\circ} \mathrm{C}$. $[\alpha]_{\mathrm{D}}^{20}=+7^{\circ}\left(c 0.5, \mathrm{H}_{2} \mathrm{O}\right) .{ }^{1} \mathrm{H}$ NMR $(500 \mathrm{MHz}$,
$\left.\mathrm{D}_{2} \mathrm{O}\right) \delta: 6.70(\mathrm{br} \mathrm{s}, 1 \mathrm{H}, \mathrm{H} 7), 4.42(\mathrm{~m}, 1 \mathrm{H}, \mathrm{H} 1), 4.24(\mathrm{~m}, 1 \mathrm{H}$, H10), 3.56 (dd, $J=12.9$ and $10.1 \mathrm{~Hz}, 1 \mathrm{H}, \mathrm{OCHH}), 3.47(\mathrm{~m}, 1 \mathrm{H}$, $\mathrm{OCH} H), 2.56(\mathrm{dt}, J=18.3$ and $3.0 \mathrm{~Hz}, 1 \mathrm{H}, \mathrm{CHH}-9), 2.26(\mathrm{dd}, J=$ 18.1 and $2.0 \mathrm{~Hz}, 1 \mathrm{H}, \mathrm{CH} H-9$ ), 2.02 (ddd, $J=12.9,4.3$ and $1.6 \mathrm{~Hz}, 1 \mathrm{H}, \mathrm{CHH}-5), 1.66-1.58$ (m, 1H, H4), 1.43 (t, $J=12.9 \mathrm{~Hz}$, $1 \mathrm{H}, \mathrm{CHH}-5)$ and $0.83\left(\mathrm{~d}, J=6.9 \mathrm{~Hz}, 3 \mathrm{H}, \mathrm{CH}_{3}\right) \mathrm{ppm} .{ }^{13} \mathrm{C} \mathrm{NMR}$ (100 MHz, D $2 \mathrm{O}) \delta: 170.5(\mathrm{C}), 140.5(\mathrm{CH}), 129.2(\mathrm{C}), 73.4(\mathrm{CH})$, $71.4(\mathrm{C}), 69.3\left(\mathrm{OCH}_{2}\right), 68.7(\mathrm{CH}), 45.3\left(\mathrm{CH}_{2}\right), 31.4(\mathrm{CH}), 27.2$ $\left(\mathrm{CH}_{2}\right)$ and $16.8\left(\mathrm{CH}_{3}\right)$ ppm. FTIR (ATR): $3376(\mathrm{OH})$ and 1686 (CO) $\mathrm{cm}^{-1}$. MS (ESI) $\mathrm{m} / z=227(\mathrm{M}-\mathrm{H})$. HRMS calcd for $\mathrm{C}_{11} \mathrm{H}_{15} \mathrm{O}_{5}(\mathrm{M}-\mathrm{H}): 227.0925$; found, 227.0922.

Data for $5 \mathrm{~S}$. Yield $=45 \%$. Retention time: $16.6 \mathrm{~min}$. Mp: 179.4-180.9 ${ }^{\circ} \mathrm{C}$. $[\alpha]_{\mathrm{D}}^{20}=-22^{\circ}\left(c 0.6, \mathrm{H}_{2} \mathrm{O}\right) .{ }^{1} \mathrm{H}$ NMR $(500 \mathrm{MHz}$, $\left.\mathrm{D}_{2} \mathrm{O}\right) \delta: 6.77$ (br s, $\left.1 \mathrm{H}, \mathrm{H} 7\right), 4.36(\mathrm{dt}, J=4.0$ and $1.9 \mathrm{~Hz}, 1 \mathrm{H}$, H1), 4.23 (dd, $J=4.6$ and $1.7 \mathrm{~Hz}, 1 \mathrm{H}, \mathrm{H} 10), 3.82$ (dd, $J=13.0$ and $3.0 \mathrm{~Hz}, 1 \mathrm{H}, \mathrm{CH} H-3), 3.42(\mathrm{dd}, J=13.0$ and $5.5 \mathrm{~Hz}, 1 \mathrm{H}$, $\mathrm{CHH}-3$ ), 2.62 (ddd, $J=18.9,4.0$ and $2.8 \mathrm{~Hz}, 1 \mathrm{H}, \mathrm{CH} H-9$ ), 2.32 (d, $J=18.9 \mathrm{~Hz}, 1 \mathrm{H}, \mathrm{CHH}-9), 2.10-2.04$ (m, 1H, H4), 1.96 (dd, $J=14.3$ and $6.4 \mathrm{~Hz}, 1 \mathrm{H}, \mathrm{CHH}-5), 1.81$ (dd, $J=14.3$ and $5.9 \mathrm{~Hz}, 1 \mathrm{H}, \mathrm{CHH}-5)$ and $0.91\left(\mathrm{~d}, J=7.2 \mathrm{~Hz}, 3 \mathrm{H}, \mathrm{CH}_{3}\right) \mathrm{ppm}$. ${ }^{13} \mathrm{C}$ NMR (100 MHz, D $\left.{ }_{2} \mathrm{O}\right) \delta: 170.5(\mathrm{C}), 142.8(\mathrm{CH}), 127.9(\mathrm{C})$, $73.1(\mathrm{CH}), 71.5(\mathrm{C}), 69.3(\mathrm{CH}), 67.6\left(\mathrm{OCH}_{2}\right), 42.8\left(\mathrm{CH}_{2}\right), 30.9$ $(\mathrm{CH}), 26.7\left(\mathrm{CH}_{2}\right)$ and $18.5\left(\mathrm{CH}_{3}\right)$ ppm. FTIR (ATR): 3396 $(\mathrm{OH})$ and $1690(\mathrm{CO}) \mathrm{cm}^{-1}$. MS (ESI) $\mathrm{m} / z=227(\mathrm{M}-\mathrm{H})$. HRMS calcd for $\mathrm{C}_{11} \mathrm{H}_{15} \mathrm{O}_{5}(\mathrm{M}-\mathrm{H})$ : 227.0925; found, 227.0928 .

\section{Docking studies}

They were carried out using the GOLD 5.2.2 program and the enzyme coordinates found in the crystal structures of $\mathrm{Hp}$-SK in complex with shikimate-3-phosphate and ADP (PDB entry 3MUF, ${ }^{15} 2.3 \AA$ ) and of $M t$-SK in complex with 2 and ADP (PDB entry 4BQS, ${ }^{13} 2.15 \AA$ ). Ligand geometries were minimized using the AM1 Hamiltonian as implemented in the program Gaussian $09^{20}$ and used as MOL2 files. Each ligand was docked in 25 independent genetic algorithm (GA) runs, and for each of these a maximum number of $100000 \mathrm{GA}$ operations were performed on a single population of 50 individuals. Operator weights for crossover, mutation and migration in the entry box were used as default parameters (95, 95, and 10, respectively), as well as the hydrogen bonding (4.0 ̊) and van der Waals (2.5 $⿱$ ) parameters. The position of shikimate-3phosphate and compound 2 present in the aforementioned PDB files were used to define the active-site and the radius was set to $8 \AA$ A. All crystallographic water molecules and the aforementioned ligands were removed for docking. The "flip ring corners" flag was switched on, while all the other flags were off. The GOLD scoring function was used to rank the ligands in order to fitness. The molecular graphics program PyMOL was employed for visualization and depicting ligand/protein structures. $^{21}$

\section{Molecular dynamics simulation studies}

Ligand minimization. Ligand geometries were minimized using a restricted Hartree-Fock (RHF) method and a 6-31G(d) basis set, as implemented in the $a b$ initio program Gaussian 
09. The resulting wavefunctions were used to calculate electrostatic potential-derived (ESP) charges employing the restrained electrostatic potential (RESP) ${ }^{22}$ methodology, as implemented in the assisted model building with energy refinement $(A M B E R)^{23}$ suite of programs. The missing bonded and nonbonded parameters were assigned, by analogy or through interpolation, from those already present in the AMBER database (GAFF)..$^{20,24}$

Generation and minimization of ternary complexes. Simulations of SK/ATP $/ \mathrm{Mg}^{2+} /$ ligand complexes were carried out using the highest score solution obtained by docking and the enzyme geometries used in those docking studies, as described above. Computation of the protonation state of titratable groups at $\mathrm{pH} 7.0$ was carried out using the $\mathrm{H}^{++}$Web server. ${ }^{25}$ Addition of hydrogen and molecular mechanics parameters from the ff14SB and GAFF force fields, respectively, were assigned to the protein and the ligands using the LEaP module of AMBER Tools 17. ${ }^{26,27}$ ATP and $\mathrm{Mg}^{2+}$ parameters used with the AMBER force field were included. ${ }^{28,29}$ All systems were minimized in four stages: (a) initial minimization of the ligand and the closest residues of the SB domain (500 steps, first half using steepest descent and the rest using conjugate gradient); (b) minimization of the solvent and ions (5000 steps, first half using steepest descent and the rest using conjugate gradient); (c) minimization of the side chains, waters and ions (5000 steps, first half using steepest descent and the rest using conjugate gradient); (d) final minimization of the whole system (5000 steps, first half using steepest descent and the rest using conjugate gradient). A positional restraint force of $50 \mathrm{kcal} \mathrm{mol}^{-1} \AA^{-2}$ was applied to those unminimized atoms during the first three stages $(\mathrm{a}-\mathrm{c})$. The complex was immersed in a truncated octahedron of $\sim 5200$ TIP3P water molecules and neutralized by addition of chloride (Mt-SK) or sodium (Hp-SK) ions. ${ }^{30,31}$

Simulations. MD simulations were performed using the pmemd.cuda_SPFP ${ }^{32}$ module from the AMBER 16 suite of programs. Periodic boundary conditions were applied and electrostatic interactions were treated using the smooth particle mesh Ewald method $(\mathrm{PME})^{33}$ with a grid spacing of $1 \AA$ A. The cutoff distance for the non-bonded interactions was $9 \AA$ A. The SHAKE algorithm $^{34}$ was applied to all bonds containing hydrogen, using a tolerance of $10^{-5} \AA$ and an integration step of 2.0 fs. The minimized system was then heated at $300 \mathrm{~K}$ at 1 atm by increasing the temperature from $0 \mathrm{~K}$ to $300 \mathrm{~K}$ over $100 \mathrm{ps}$ and by keeping the system at $300 \mathrm{~K}$ another $100 \mathrm{ps}$. A positional restraint force of $50 \mathrm{kcal} \mathrm{mol} \mathrm{m}^{-1} \AA^{-2}$ was applied to all $\alpha$ carbons during the heating stage. An equilibration of the system at constant volume (100 ps with positional restraints of 5 kcal $\mathrm{mol}^{-1} \AA^{-2}$ to $\alpha$ alpha carbons) and constant pressure (another $100 \mathrm{ps}$ with positional restraints of $5 \mathrm{kcal} \mathrm{mol}^{-1} \AA^{-2}$ to $\alpha$ alpha carbons) were performed. The positional restraints were gradually reduced from 5 to $1 \mathrm{~mol}^{-1} \AA^{-2}$ (5 steps, $100 \mathrm{ps}$ each), and the resulting systems were allowed to equilibrate further (100 ps). Unrestrained MD simulations were carried out for $100 \mathrm{~ns}$. System coordinates were collected every 10 ps for further analysis.

\section{Abbreviations}

SK Shikimate kinase

Hp-SK Shikimate kinase from Helicobacter pylori

Mt-SK Shikimate kinase from Mycobacterium tuberculosis

MD Molecular dynamics

PDB Protein data bank

\section{Conflicts of interest}

There are no conflicts to declare.

\section{Acknowledgements}

Financial support from the Spanish Ministry of Economy and Competiveness (SAF2016-75638-R), the Xunta de Galicia [Centro singular de investigación de Galicia accreditation 2016-2019 (ED431G/09) and ED431B 2018/04], and the European Union (European Regional Development Fund ERDF) is gratefully acknowledged. MP and EL thank the Xunta de Galicia for their respective predoctoral and postdoctoral fellowships. We are grateful to the Centro de Supercomputación de Galicia (CESGA) for use of computational facilities.

\section{Notes and references}

1 C. E. Chang, W. Chen and M. K. Gilson, Proc. Natl. Acad. Sci. U. S. A., 2007, 104, 1534-1539.

2 M. H. Hao, O. Haq and I. Muegge, J. Chem. Inf. Model., 2007, 47, 2242-2252.

3 M. Sitzmann, I. E. Weidlich, I. V. Filippov, C. Liao, M. L. Peach, W.-D. Ihlenfeldt, R. G. Karki, Y. V. Borodina, R. E. Cachau and M. C. Nicklaus, J. Chem. Inf. Model., 2012, 52, 739-756.

4 J. Tirado-Rives and W. L. Jorgensen, J. Med. Chem., 2006, 49, 5880-5884.

5 Z. Fang, Y. Song, P. Zhan, Q. Zhang and X. Liu, Future Med. Chem., 2014, 6, 885-901.

6 R. E. Babine and S. L. Bender, Chem. Rev., 1997, 97, 13591472.

7 E. Perola and P. S. Charifson, J. Med. Chem., 2004, 47, 2499-2510.

8 G. Klebe, F. Dullweber and H.-J. Böhm, Thermodynamic models of drug-receptor interactions: a general introduction, in Drug-Receptor Thermodynamics: Introduction and Applications, John Wiley \& Sons, Chichester, U.K., 2001, pp. 83-104.

9 J. Boström and A. Grant, Molecular drug properties: measurement and prediction, in Exploiting Ligand Conformations in Drug Design, Wiley-VCH, Weinheim, Germany, 2007, vol. 37, pp. 183-205.

10 R. K. Tiwari and K. Parang, Curr. Pharm. Des., 2012, 18, 2852-2866. 
11 Y. Wang, A. Kirschner, A.-K. Fabian, R. Gopalakrishnan, C. Kress, B. Hoogeland, U. Koch, C. Kozany, A. Bracher and F. Hausch, J. Med. Chem., 2013, 56, 3922-3935.

12 (a) A. T. Namanja, X. J. Wang, B. Xu, A. Y. MercedesCamacho, B. D. Wilson, K. A. Wilson, F. A. Etzkorn and J. W. Peng, J. Am. Chem. Soc., 2010, 132, 5607-5609; (b) D. Quaglio, G. Zappia, E. De Paolis, S. Balducci, B. Botta and F. Ghirga, Org. Chem. Front., 2018, 5, 3022-3055.

13 B. Blanco, V. Prado, E. Lence, J. M. Otero, C. García-Doval, M. J. van Raaij, A. L. Llamas-Saiz, H. Lamb, A. R. Hawkins and C. González-Bello, J. Am. Chem. Soc., 2013, 135, 1236612376.

14 http://www.ccdc.cam.ac.uk/solutions/csd-discovery/components/gold/.

15 W. C. Cheng, Y. F. Chen, H. J. Wang, K. C. Hsu, S. C. Lin, T. J. Chen, J. M. Yang and W. C. Wang, PLoS One, 2012, 7, e33481.

16 D. A. Case, J. T. Berryman, R. M. Betz, D. S. Cerutti, T. E. Cheatham III, T. A. Darden, R. E. Duke, T. J. Giese, H. Gohlke, A. W. Goetz, N. Homeyer, S. Izadi, P. Janowski, J. Kaus, A. Kovalenko, T. S. Lee, S. LeGrand, P. Li, T. Luchko, R. Luo, B. Madej, K. M. Merz, G. Monard, P. Needham, H. Nguyen, H. T. Nguyen, I. Omelyan, A. Onufriev, D. R. Roe, A. Roitberg, R. Salomon-Ferrer, C. L. Simmerling, W. Smith, J. Swails, R. C. Walker, J. Wang, R. M. Wolf, X. Wu, D. M. York and P. A. Kollman, AMBER 2015, University of California, San Francisco, 2015.

17 Y. Dai, F. Wu, Z. Zang, H. You and H. Gong, Chem. - Eur. J., 2012, 18, 808-812.

18 V. Prado, E. Lence, J. A. Vallejo, A. Beceiro, P. Thompson, A. R. Hawkins and C. González-Bello, Chem. - Eur. J., 2016, 22, 2758-2768.

19 V. Prado, E. Lence, P. Thompson, A. R. Hawkins and C. González-Bello, Chem. - Eur. J., 2016, 22, 17988-18000.

20 M. J. Frisch, et al., Revision D.01, Gaussian, Inc., Wallingford CT, 2009.

21 W. L. DeLano, The PyMOL Molecular Graphics System, DeLano Scientific LLC, Palo Alto, CA, USA, 2008, http:// www.pymol.org/.

22 (a) W. D. Cornell, P. Cieplak, C. I. Bayly, I. R. Gould, K. M. Merz, D. M. Ferguson, D. C. Spellmeyer, T. Fox, J. W. Caldwell and P. A. Kollman, J. Am. Chem. Soc., 1995,
117, 5179-5197; (b) http://upjv.q4md-forcefieldtools.org/ RED/(accessed March 1, 2019).

23 D. A. Case, T. E. Cheatham, T. Darden, H. Gohlke, R. Luo, K. M. Merz, O. Onufriev, C. Simmerling, B. Wang and R. J. Woods, J. Comput. Chem., 2005, 26, 1668-1688.

24 (a) J. Wang, R. M. Wolf, J. W. Caldwell, P. A. Kollman and D. A. Case, J. Comput. Chem., 2004, 25, 1157-1174; (b) J. Wang, W. Wang, P. A. Kollman and D. A. Case, J. Mol. Graphics Modell., 2006, 25, 247-260.

25 (a) J. C. Gordon, J. B. Myers, T. Folta, V. Shoja, L. S. Heath and A. Onufriev, Nucleic Acids Res., 2005, 33(Web Server issue), W368-W371; (b) http://biophysics.cs.vt.edu/H++ (accessed March 1, 2019).

26 (a) J. Wang, R. M. Wolf, J. W. Caldwell, P. A. Kollman and D. A. Case, J. Comput. Chem., 2004, 25, 1157-1174; (b) J. Wang, W. Wang, P. A. Kollman and D. A. Case, J. Mol. Graphics Modell., 2006, 25, 247-260.

27 D. A. Case, et al., AMBER 2015, University of California, San Francisco, 2015.

$28 \mathrm{Mg}^{2+}$ parameters used with the AMBER force field were downloaded from http:/www.pharmacy.manchester.ac.uk/ bryce/amber/(accessed March 1, 2019). O. Allnér, L. Nilsson and A. Villa, J. Chem. Theory Comput., 2012, 8, 1493-1502.

29 ATP parameters used with the AMBER force field were downloaded from http://www.pharmacy.manchester.ac.uk/ bryce/amber/ (accessed March 1, 2019). K. L. Meagher, L. T. Redman and H. A. Carlson, J. Comput. Chem., 2003, 24, 1016-1025.

30 J. Aqvist, J. Phys. Chem., 1990, 94, 8021-8024.

31 W. L. Jorgensen, J. Chandrasekhar and J. D. Madura, J. Chem. Phys., 1983, 79, 926-935.

32 (a) A. W. Goetz, M. J. Williamson, D. Xu, D. Poole, S. Le Grand and R. C. Walker, J. Chem. Theory Comput., 2012, 8, 1542-1555; (b) R. Salomon-Ferrer, A. W. Goetz, D. Poole, S. Le Grand and R. C. Walker, J. Chem. Theory Comput., 2013, 9, 3878-3888; (c) S. Le Grand, A. W. Goetz and R. C. Walker, Comput. Phys. Commun., 2013, 184, 374380.

33 T. A. Darden, D. York and L. G. Pedersen, J. Chem. Phys., 1993, 98, 10089-10092.

34 J.-P. Ryckaert, G. Ciccotti and H. J. C. Berendsen, J. Comput. Phys., 1977, 23, 327-341. 